UNIVERSIDADE DE SÃO PAULO

INSTITUTO DE QUÍMICA DE SÃO CARLOS

\title{
DEGRADAÇÃO DE POLIESTIRENOSSULFONATO DE SÓDIO FOTOSSENSIBILIZADA PELO CORANTE QTX
}

\author{
JOSY ANTEVELI OSAJIMA
}

Tese apresentada ao Instituto de Química de São Carlos, da Universidade de São Paulo para obtenção do título de Doutor em Ciências Área de concentração: Físico-Química

ORIENTAÇÃO: PROF. DR. MIGUEL G. NEUMANN

SÃO CARLOS 
Dedicatória Aos meus pais, Isao e Regina, por serem exemplos de vida e perseverança As minhas queridas irmãs, Alyne e Lívia Aos meus irmãos de coração, Marcelo e Daniel Ao meu amor, Thiago. 


\section{AGRADECIMENTOS}

Ao Prof. Dr. Miguel G. Neumann pela orientação e oportunidade de trabalho no Grupo de Fotoquímica que tanto contribuíram para minha formação profissional.

À Dra. Carla C. Schmitt Cavalheiro por estar sempre presente.

Ao Prof. Dr. José Carlos Netto Ferreira pelas valiosas sugestões e discussões sobre o trabalho.

Ao Prof. Dr. Roberto G. S. Berlinck pela caracterização dos fotoprodutos da fotólise de QTX em água por HPLC-MS.

Ao Prof. Dr. Pedro Berci Filho pelas sugestões sobre o mecanismo de fragmentação de QTX.

Ao Prof. Dr. Malcolm D. E. Forbes pela oportunidade do estágio na Universidade da Carolina do Norte em Chapel Hill.

Aos amigos do grupo de Fotoquímica pela convivência diária, principalmente a Tatiana Batista por auxiliar em alguns experimentos e pela amizade e a Alessandra Poli pelo auxílio na correção da tese.

Aos funcionários do IQSC, em especial a Márcia, Celinha, Silvia e a Andréa pela amizade.

À Prof. Dra. Keiko Takashima pela amizade e por conselhos valiosos que tanto me ajudaram na minha vida profissional e a afetiva.

Aos meus amigos que fiz durante o doutorado em São Carlos.

A todos que me ajudaram direta ou indiretamente na realização deste trabalho.

Ao CNPq e CAPES pelo auxílio financeiro. 


\section{Resumo}

O mecanismo de degradação da solução de poliestirenossulfonato de sódio (PSS) fotossensibilizada por cloreto de 2-hidroxi-3-(3,4-dimetil-9-oxo-9H-tioxanton-2-iloxi)N,N,N-trimetil-1-propano (QTX) foi investigado. Inicialmente, foi estudada a fotodegradação de QTX em solução aquosa. Os fotoprodutos gerados pela fotólise foram caracterizados em sulfonas e sulfóxidos, que foram identificados por CLAEEM. A fotodegradação de QTX em solução aquosa foi também acompanhada pelos espectros de absorção UV-Vis, sugerindo a formação de sulfóxidos. As reações elementares de QTX em solução aquosa foram investigadas através da fotólise por pulso de laser. O valor das constantes de supressão do estado triplete de QTX na presença de sorbato de potássio e hidroquinona foram próximas ao valor de constante difusional. A combinação dos resultados obtidos pelas diferentes técnicas possibilitou a proposição do mecanismo para degradação da QTX. A fotodegradação de PSS em solução aquosa na presença e na ausência de QTX foi monitorada por cromatografia de exclusão de tamanho e viscosidade. A fotodegradação de PSS foi observada somente na presença de QTX. Nesta condição uma diminuição de $\overline{M w}$ foi observada, que significa quebra de cadeia aleatória. A degradação PSS/QTX também foi investigada na presença do sorbato de potássio, um supressor de triplete. Neste caso, ocorreu um aumento na porcentagem de degradação. Estes resultados sugeriram que o mecanismo de degradação de PSS fotossensibilizada por QTX ocorre principalmente pela QTX excitada no singlete abstrair um hidrogênio do polímero e na presença de oxigênio leva a formação de radicais, que contribuem para o processo de degradação.

Palavras-chave: fotodegradação, poliestirenossulfonato de sódio, QTX, fotossensibilizador. 


\begin{abstract}
The poly(styrenesulfonate) (PSS) photosensitised by 2-hydroxy-3-(3,4-dimethyl-9oxo-9H-thioxanthen-2-yloxy)-N,N,N-trimethyl-1-propanium chloride (QTX) solution degradation mechanism was investigated. Initially, the photodegradation of QTX in aqueous solution was studied. The photoproducts generated photolysis were characterized as being sulfones and sulfoxides, which were identified by HPLC-MS. The photodegradation of QTX in aqueous solution was also followed by UV-Vis absorption spectra, suggesting the formation of sulfoxides. The elementary reactions of QTX in aqueous solution were investigated by laser flash photolysis. The quenching rate constant values of the triplet state QTX in the presence of potassium sorbate and hydroquinone were close to the value of diffusion constant. It was possible to propose the mechanism of QTX degradation combining the results from the different techniques. The photodegradation PSS in aqueous solution in the presence and absence of QTX was monitored by size exclusion chromatography and viscosity. The photodegradation of PSS was observed only in the presence of QTX. In this condition a decrease of $\overline{M w}$ was observed, which means the random chain scission. The PSS/QTX degradation was also investigated in the presence of potassium sorbate, a triplet quencher. In this case, an increase of degradation percentage occurred. These results suggested that the degradation mechanism of PSS degradation photosensitised by QTX occurs mainly by the singlet excited QTX abstracts a hydrogen from the polymer and in the presence of oxygen leads to radicals formation which contributed to the degradation process.
\end{abstract}

Keywords: photodegradation, poly(styrenesulfonate), QTX, photosensitiser 


\section{SUMÁRIO}

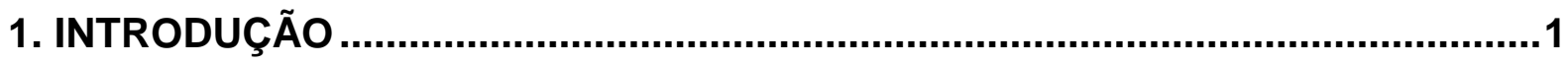

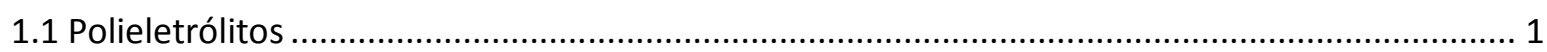

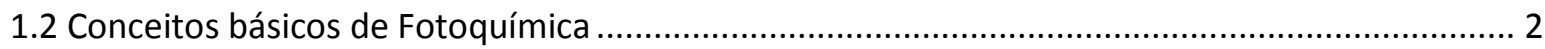

1.2.1 Cinética de processos fotofísicos bimoleculares.................................................................. 5

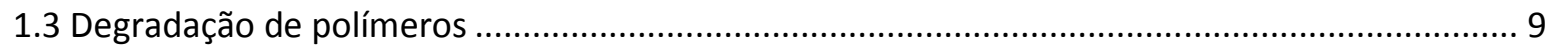

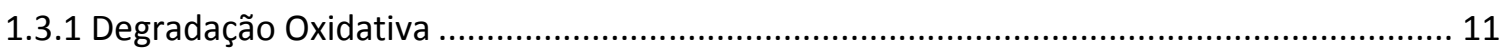

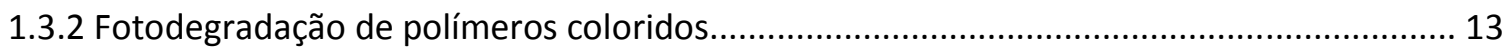

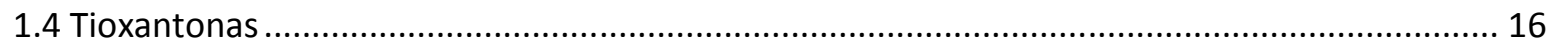

2. OBJETIVOS

3. PARTE EXPERIMENTAL .........................................................................20

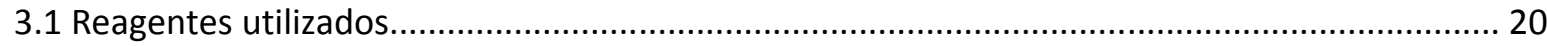

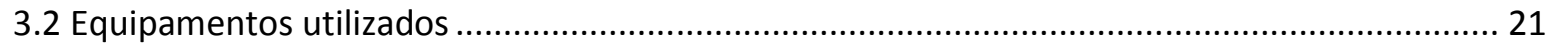

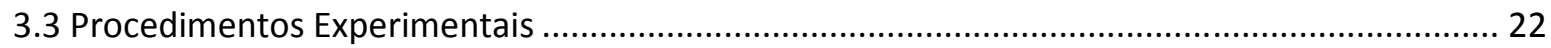

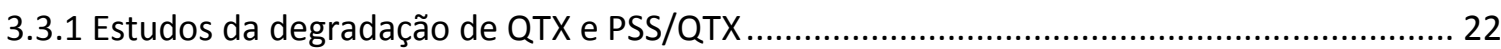

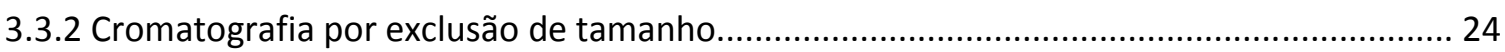

4. RESULTADOS E DISCUSSÃO .......................................................................26

4.1 Estudos da fotodegradação de QTX em solução aquosa ......................................................... 26

4.1.1 Estudo do efeito da concentração de QTX no processo de fotólise .................................... 26

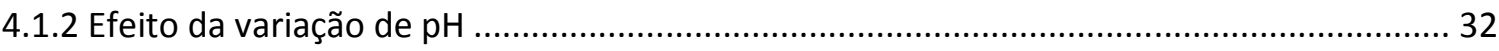

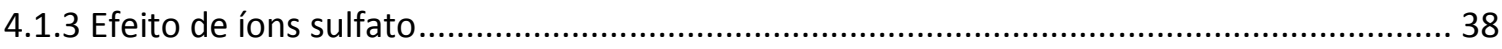

4.1.4 Efeito da adição de sorbato de potássio ............................................................................... 41

4.1.5 Determinação dos fotoprodutos gerados na fotólise de QTX em solução aquosa.............. 43

4.1.6 Estudo das reações elementares de QTX em água ........................................................... 51

4.1.6.1 Estudo dos transientes da QTX em água................................................................... 51

4.1.6.2 Estudo dos transientes da QTX em diferentes solventes............................................. 53

4.1.6.3 Determinação das constantes de supressão de QTX em água ...................................... 58

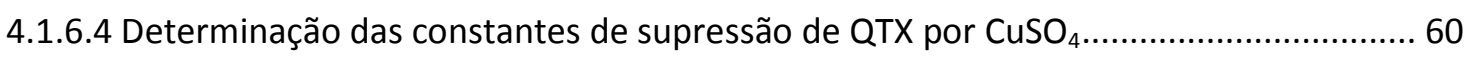

4.1.7 Mecanismo proposto de fotodegradação de QTX em água .............................................. 61

4.2 Fotodegradação de poliestirenossulfonato de sódio em água ................................................... 65

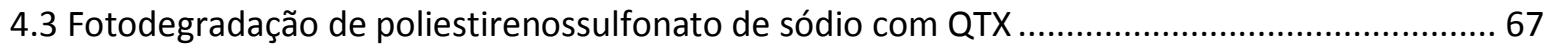

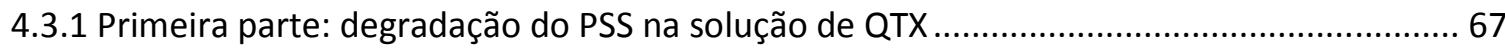

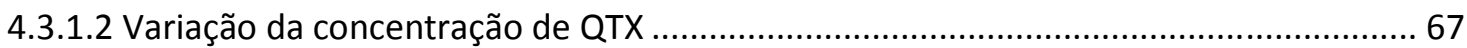




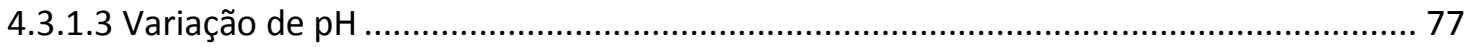

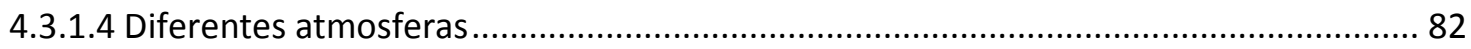

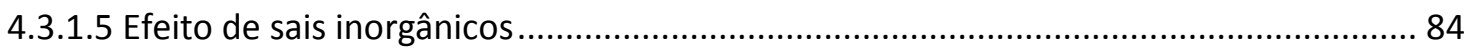

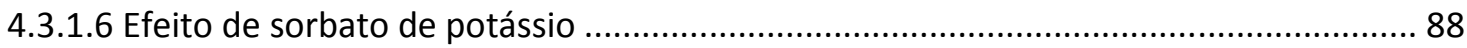

4.3.2 Segunda parte: Fotodegradação de QTX na presença de PSS .............................................. 89

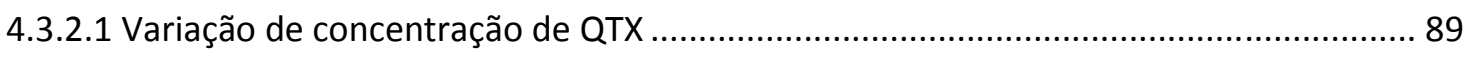

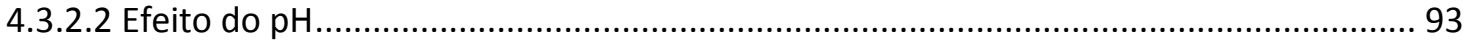

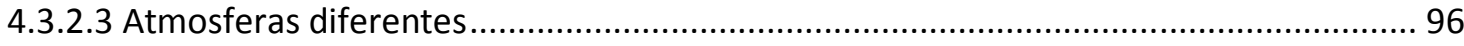

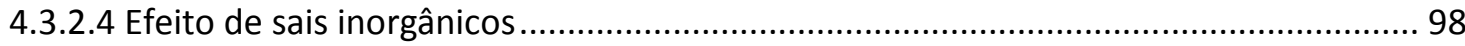

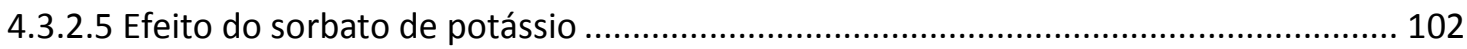

4.3.3 Terceira parte: Reações elementares .............................................................................. 103

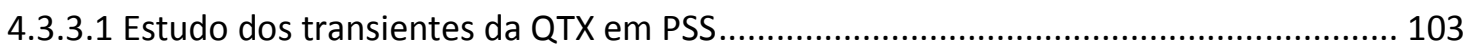

4.3.3.2 Determinação das constantes de supressão de QTX em molécula modelo ................ 106

4.3.4 Mecanismo proposto para fotodegradação de PSS sensibilizado por QTX ........................ 107

5. CONCLUSÕES ..........................................................................................112

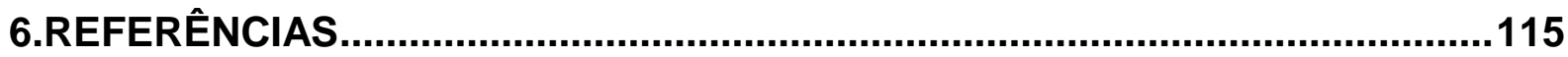




\section{INTRODUÇÃO}

\subsection{Polieletrólitos}

Sabe-se que polímeros são compostos químicos de alta massa molar, formados a partir de monômeros ligados covalentemente. ${ }^{1}$ Quando um polímero é formado por repetições de um eletrólito, ou apresenta grupos ionizáveis no meio onde se encontra é chamado de polieletrólito, pois conserva as características de macromolécula e de eletrólito. A presença de cargas na cadeia polimérica promove interações intra- e intermoleculares, influenciando as propriedades termodinâmicas e dinâmicas das soluções de polieletrólitos.

Os polieletrólitos podem ser classificados como forte e fraco dependendo do intervalo de $\mathrm{pH}$ em que o macro-íon se dissocia em solução. Um exemplo de polieletrólito forte é o poliestirenossulfonato de sódio (PSS), que está dissociado em todo o intervalo de $\mathrm{pH}(0-14)$.

Como os polieletrólitos possuem grupos ionizáveis, esta alteração estrutural é responsável por sua solubilidade em meio aquoso, inclusive nos casos em que a cadeia principal é hidrofóbica, como no caso do poliestireno.

As propriedades dos polieletrólitos, tais como a viscosidade, apresentam dependência com a força iônica do meio aquoso. Mudanças de viscosidades com o aumento da força iônica são atribuídas principalmente à blindagem das cargas elétricas do macro-íon, tornando o comportamento deste similar ao de uma macromolécula não carregada. 
Outra característica importante dos polieletrólitos é sua tendência de formar agregados com espécies carregadas. Este processo de agregação freqüentemente resulta em estruturas coloidais altamente organizadas, que são base de um grande número de aplicações.

Algumas das espécies que podem formar agregados com os polieletrólitos são os contra-íons inorgânicos de baixa massa molar, corantes orgânicos com grupos iônicos, surfactantes iônicos, partículas coloidais e superfícies sólidas.

A interação entre polieletrólitos e moléculas de corantes com cargas opostas ocorre tanto através de forças intermoleculares como de forças coulombicas. Os fenômenos de agregação são geralmente acompanhados por mudanças no máximo de absorção na região do UV-Vis., ${ }^{2,3}$

Em vista das propriedades dos polieletrólitos, em especial a interação de corantes de cargas opostas, e considerando o número restrito de trabalhos ${ }^{4,5,6,7}$ abordando o mecanismo de fotodegradação dos mesmos, foi investigada a degradação de poliestirenossulfonato de sódio na presença de um corante catiônico derivado da tioxantona.

\subsection{Conceitos básicos de Fotoquímica}

A fotoquímica envolve o estudo da absorção da radiação, assim como o comportamento de átomos e moléculas eletronicamente excitados, produzido pela absorção da luz. Após a absorção da luz, seguidos por mudanças na distribuição eletrônica, as moléculas excitadas podem sofrer vários tipos de processos fotofísicos e fotoquímicos. 
A maioria das moléculas existe no estado fundamental eletrônico singlete $\left(\mathrm{S}_{0}\right)$, um estado no qual os orbitais possuem dois elétrons emparelhados. Após a absorção do fóton são formados os estados singlete excitados $\left(S_{1}, S_{2}, S_{3}, \ldots ., S_{i}\right)$. Neste processo, um dos elétrons é deslocado a um orbital de maior energia, sendo que os spins continuam emparelhados. ${ }^{8}$

Moléculas nos estados singletes superiores podem sofrer desexcitação por conversão interna $(\mathrm{Cl})$ para o estado $\mathrm{S}_{1}$. Deste que neste estado a molécula pode ser desativada por conversão interna, fluorescer, ou através do cruzamento intersistemas (CIS) ir para o estado triplete. ${ }^{9}$

Os estados excitados da molécula $\left(S_{1}, S_{2}\right)$ promovem mudanças na configuração do spin através do cruzamento intersistemas levando ao estado triplete. Este é um processo muito importante, principalmente para os compostos carbonílicos que geralmente apresentam alto rendimento quântico de cruzamento intersistemas.

Nos estados triplete os spins dos elétrons estão desemparelhados. O estado triplete excitado de menor energia é o $T_{1}$. A formação de um triplete através da absorção direta de um fóton por uma molécula é proibida por spin. Os estados de triplete de maior energia $\left(T_{2}, T_{3}, \ldots . . T_{i}\right)$ podem ser formados quando uma molécula em seu estado triplete de menor energia absorve um novo fóton (absorção tripletetriplete). ${ }^{8}$ Esta absorção T-T pode ser medida sob condições experimentais apropriadas através da técnica de fotólise por pulso de laser.

A emissão radiativa originária do estado $T_{1}$ é denominada fosforescência, que ocorre como uma emissão proibida com tempo de vida em torno de $10^{-3} \mathrm{~s}$. A fosfosrescência pode ser observada quase sempre em comprimentos de onda maiores que a fluorescência. 
A Figura 1 mostra o diagrama de Jablonski, que ilustra todas as possibilidades de transição que podem ocorrer entre os níveis de energia de uma molécula. Todos os processos envolvidos neste diagrama são fortemente influenciados pela polaridade e viscosidade do meio. A Tabela 1 apresenta os tempos de vida de cada dos processos fotofísicos envolvidos nos estados excitados eletronicamente. $^{8}$

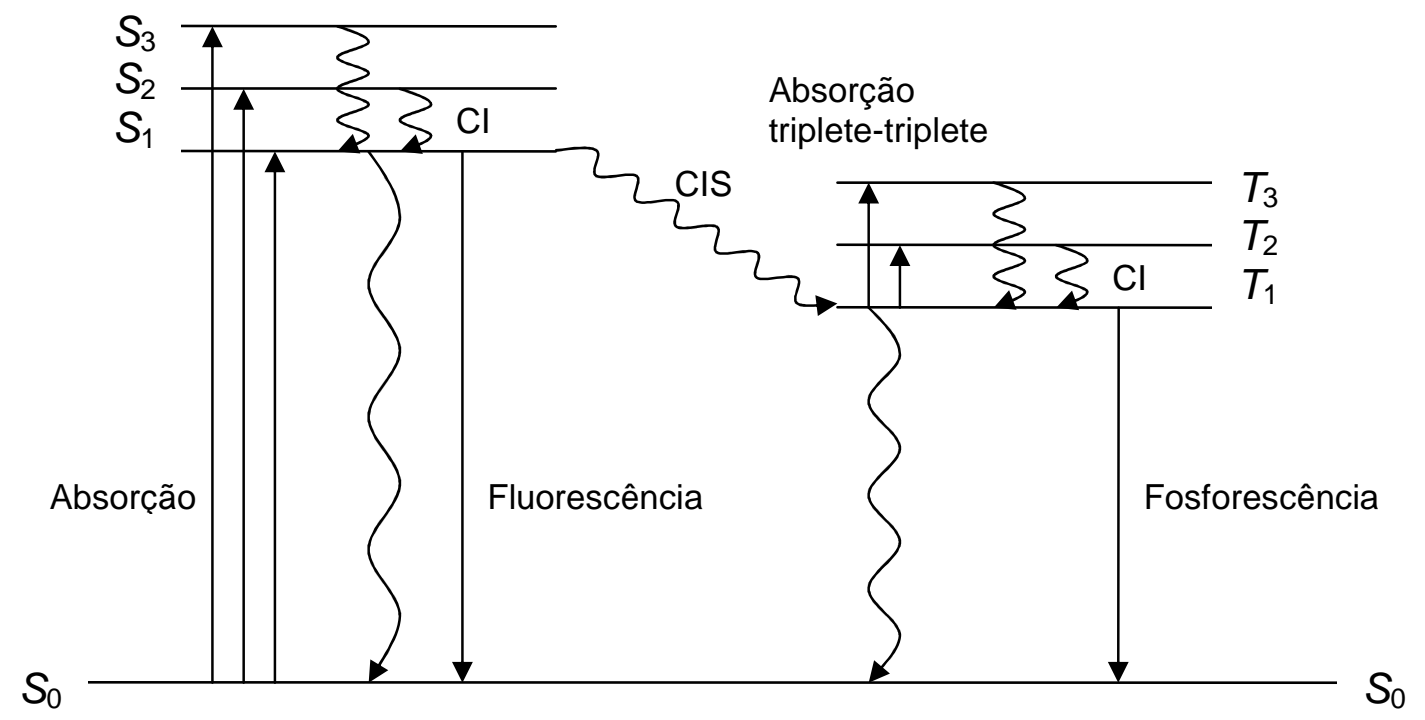

Figura 1. Diagrama de Jablonski representando os processos fotofísicos mais importantes. As transições radiativas e não radiativas são indicadas pelas setas retas e curvas, respectivamente. ${ }^{8}$ 
Tabela 1- Tempos de vida de vida dos processos fotofísicos envolvidos nos estados excitados eletronicamente. ${ }^{8}$

\begin{tabular}{|ccc|}
\hline Etapa & Processo & Tempo de vida/s \\
\hline Excitação & $S_{0}+h v \rightarrow S_{1}$ & $10^{-15}$ \\
Conversão interna (CI) & $S_{1} \rightarrow S_{1}+\Delta$ & $10^{-11}-10^{-14}$ \\
Emissão de Fluorescência & $T_{1} \rightarrow T_{1}+\Delta$ & $10^{-6}-10^{-11}$ \\
Cruzamento intersistema (CIS) & $S_{1} \rightarrow S_{0}+h v_{F}$ & $10^{-8}-10^{-11}$ \\
Emissão de fosforescência & $S_{1} \rightarrow S_{0}+h v_{F}$ & $10^{-2}-10^{-3}$ \\
\hline
\end{tabular}

\subsubsection{Cinética de processos fotofísicos bimoleculares}

Algumas substâncias quando adicionadas a uma solução fluorescentes são capazes de reduzir a intensidade de fluorescência drasticamente por um processo conhecido como Supressão de Fluorescência. O tempo de fluorescência é na ordem de $10^{-6}$ a $10^{-11} \mathrm{~s}$. Reações rápidas deste tipo podem ser investigadas facilmente medindo a diminuição da intensidade de fluorescência em função da concentração de supressor. O Esquema 1 mostra as reações que descrevem o processo de supressão, onde $M$ representa a molécula excitada que fluoresce e $Q$ é o supressor. ${ }^{10}$ 


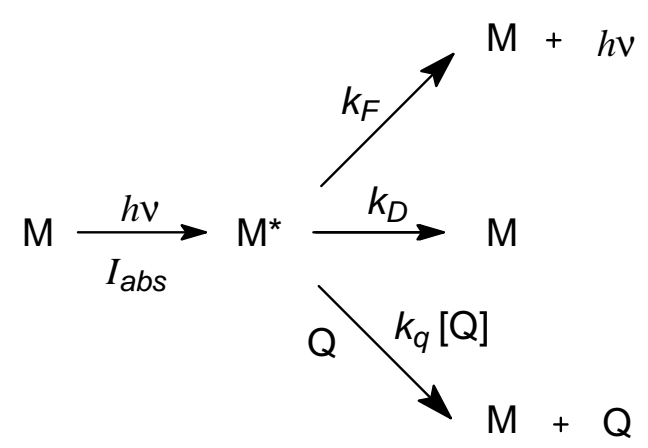

Esquema 1. Processos de uma molécula excitada no estado singlete. ${ }^{10}$

A eficiência de uma reação fotoquímica é expressa por meio do rendimento quântico de uma reação, que é definido como:

$$
\phi_{\text {reaşão }}=\frac{n^{\circ} \text { de moléculas decompostas ou formadas }}{n^{\circ} \text { de quanta de radiação absorvida }}
$$

A natureza dos fotoprodutos e os valores de rendimentos quânticos são dependentes da intensidade de luz incidente.

O rendimento quântico de fluorescência na ausência e na presença de supressor é expresso pelas Equações 2 e 3, respectivamente:

$$
\begin{gathered}
\phi_{F}^{0}=\frac{k_{F}}{k_{F}+k_{D}} \\
\phi_{F}=\frac{k_{F}}{k_{F}+k_{D}+k_{q}[Q]}
\end{gathered}
$$

Equação 2

Equação 3 
Rearranjando as Equações acima, tem-se que a relação entre os rendimentos quânticos de fluorescência, $\phi_{F}^{0} / \phi_{F}$, na ausência e na presença de supressor é:

$$
\frac{\phi_{F}^{0}}{\phi_{F}}=\frac{k_{F}+k_{D}+k_{q}[Q]}{k_{F}+k_{D}}=1+\frac{k_{q}[Q]}{k_{F}+k_{D}}=1+\tau_{F} k_{q}[Q] \quad \text { Equação } 4
$$

Onde $\tau_{\mathrm{F}}$ é o tempo de vida do estado excitado na ausência de supressor.

Se $\phi_{F}^{0} / \phi_{F}$ é plotado em função da concentração de supressor [Q] a inclinação da reta corresponderá a $k_{q} \tau$.

A Equação 5 é conhecida como a Equação Stern-Volmer, onde o $\mathrm{K}_{\mathrm{sv}}$ é a constante de Stern-Volmer.

$$
\frac{\phi_{F}^{0}}{\phi_{F}}=1+\tau_{F} k_{q}[Q]=1+K_{s v}[Q]
$$

Equação 5

Para muitos sistemas $k_{q}$ é da ordem de $10^{10} \mathrm{M}^{-1} \mathrm{~s}^{-1}$, próximo da constante de velocidade de reações controladas por difusão $\left(k_{\text {dif }}\right)$. Em alguns casos, isto sugere que a supressão é tão rápida que a etapa determinante da velocidade seja a difusão das moléculas para formar o complexo:

$$
\mathrm{M}^{*}+\mathrm{Q} \underset{k_{-1}}{\stackrel{k_{\text {dif }}}{\rightleftharpoons}}\left(\mathrm{M}^{*} \ldots \ldots \mathrm{Q}\right) \stackrel{k_{\mathrm{q}}}{\longrightarrow} \mathrm{M}+\mathrm{Q}
$$

Equação 6

A constante de supressão do complexo é $\mathrm{k}_{\mathrm{q}}$. Em condições do estado estacionário: 


$$
\begin{array}{cc}
k_{d i f}\left[M^{*}\right][Q]=\left[\left(M^{*} \ldots Q\right)\right]\left(k_{q}+k_{-1}\right) & \text { Equação } 7 \\
k q\left[\left(M^{*} \ldots Q\right]=\frac{k_{q} k_{d i f}}{k_{q}+k_{-1}}\left[M^{*}\right][Q]=k_{q(o b s)}[M][Q]\right. & \text { Equação 8 }
\end{array}
$$

A constante de supressão observada é:

$$
k_{\text {obs }}=\frac{k_{q} k_{d i f}}{k_{q}+k_{-1}}
$$

Equação 9

Se $k_{q}>k_{-1}$, então $k_{q}(o b s) \approx k_{\text {dif }}$ e a velocidade de supressão dependerá da viscosidade do solvente. Quando $k_{q}<<k_{-1}$, então $k_{q}(o b s) \approx k_{\text {dif }} / k_{-1}=k_{q} \mathrm{~K}$, onde $\mathrm{K}$ é a constante de equilíbrio para a formação do complexo e $k_{q}$ (obs) será independente da viscosidade do solvente. Finalmente, se $k_{q}$ e $k_{-1}$ forem da mesma ordem, então $k_{o b s}$ será menor que $k_{\text {dif. }}{ }^{11}$

Medidas dos tempos de vida, estudos da variação das constantes de supressão com a temperatura e viscosidade, e a dependência com o coeficiente de difusão do meio podem diferenciar entre supressão estática e dinâmica.

$\mathrm{Na}$ supressão estática o tempo de vida das substâncias fluorescentes se mantém constante em todo intervalo de concentração, uma vez que o complexo é formado no estado fundamental. Por outro lado, na supressão dinâmica, o processo de supressão ocorre via difusão das moléculas, o aumento da temperatura aumentará o coeficiente de difusão e a constante de supressão de fluorescência, $k_{q}$, proporcional a $T / \eta$ aumentará, onde $\eta$ é a viscosidade do meio. Da mesma forma, se 
um dado solvente é muito viscoso, a difusão das moléculas é dificultada e o processo de supressão é diminuído.

\subsection{Degradação de polímeros}

O termo degradação pode ser definido como qualquer mudança nas propriedades físicas de um sistema polimérico ou como uma série de reações químicas que envolvem rupturas de ligações da cadeia principal da macromolécula (normalmente seguida da redução de massa molar) e formação de outras ligações durante este processo. ${ }^{12,13}$ A degradação pode causar modificações irreversíveis nas propriedades dos materiais poliméricos, que podem ser evidenciadas até pelo

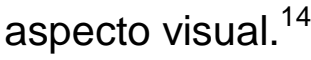

Os polímeros podem ser degradados por diversas influências ambientais como temperatura, umidade, luz, etc. A maioria dos polímeros é estável por longos períodos à temperatura ambiente na ausência de luz. A luz acelera a velocidade de degradação, e este efeito pode ser maior na presença de poluentes atmosféricos capazes de gerar espécies reativas. ${ }^{15}$

As energias de ligação C-C e C-H são aproximadamente 420 e $340 \mathrm{~kJ} \mathrm{~mol}^{-1}$, respectivamente, e podem ser menores quando adjacentes a estruturas aromáticas ou insaturadas. Dependendo do comprimento de onda incidente, a energia da radiação pode ser suficiente para quebrar ligações químicas e gerar radicais que iniciem o processo de degradação. Estes processos podem ser mais efetivo a comprimentos de onda menores. ${ }^{15}$ A Tabela 2 mostra as energias do fóton de diferentes comprimentos de onda. ${ }^{16}$ 
Tabela2. Relação entre o comprimento de onda e a energia do fóton em $\mathrm{kJ} \mathrm{mol}^{-1}{ }^{16}$

\begin{tabular}{|ccc|}
\hline $\begin{array}{c}\text { Faixa do espectro } \\
\text { eletromagnético }\end{array}$ & $\begin{array}{c}\text { Comprimento de onda } \\
(\mathbf{n m})\end{array}$ & $\begin{array}{c}\text { Energia de fóton }\left(\mathrm{kJmol}^{-1}\right) \\
\text { UV }\end{array}$ \\
\hline & 300 & 400 \\
& 400 & 300 \\
\hline & 400 & 300 \\
\hline & 500 & 240 \\
& 600 & 200 \\
& 700 & 170 \\
\hline
\end{tabular}

A presença de grupos carbonílicos ou impurezas (traços de metais, corantes, hidroperóxidos, etc), que podem ser introduzidos durante os processos de síntese dos polímeros, promovem a absorção da luz para iniciar reações de fotodegradação. ${ }^{15}$

As mudanças que ocorrem durante a degradação dependem do tipo do processo de degradação envolvido, que podem ser físicas como a diminuição da massa molar, ou químicas como a mudança de estrutura química do polímero. ${ }^{17}$

Existem muitas maneiras de estudar a degradação. Uma delas seria pelo tipo de reações químicas que ocorrem no início e durante a degradação (quebra de ligações na cadeia principal ou em grupos laterais, reticularão, eliminação ou substituição de cadeias laterais, reações intramoleculares, auto-oxidação e depolimerização) e pelo processo de iniciação destas reações (térmica, fotoquímica, mecânica, radiação de alta energia e química). ${ }^{16}$ 
Apesar desta classificação a degradação quase sempre ocorre por mais de um processo simultaneamente. Os macrorradicais que são muitos reativos dão origem a reações que podem levar à formação, por exemplo, de cadeias laterais, redução na massa molar ou despolimerização. O conhecimento da degradação sofrida pelo material torna-se essencial uma vez que as propriedades dos polímeros são determinadas pelo os arranjos físicos e massas molares "finais". ${ }^{12}$ Dentre os processos de degradação existentes, será abordada apenas a degradação oxidativa e a fotodegradação de polímeros coloridos.

\subsubsection{Degradação Oxidativa}

A oxidação de polímeros é um processo autocatalítico e ocorre em três etapas: iniciação, propagação e terminação. Muitos fatores como calor, luz, impurezas contribuem para a etapa de iniciação levando a formação dos primeiros macrorradicais alquila, (Equação 10).

A propagação ocorre a partir da reação do macrorradical alquila com o oxigênio, formando o radical alquilperoxila (Equação 11). Este radical pode reagir com outra cadeia polimérica e pela abstração de hidrogênio forma o hidroperóxido e um novo macrorradical alquila (Equação 12). Como a energia da ligação O-O do hidroperóxido é muito baixa esta pode sofrer quebra homolítica pelo efeito da luz ou calor, gerando dois radicais, uma alcoxila (PO') e uma hidroxila (HO*) (Equação 13). O radical hidroxila pode atacar a cadeia polimérica e formar um novo macrorradical alquila e uma molécula de água (Equação 14). O radical alcoxila é responsável pelos processos de quebra de cadeia gerando novos radicais (Equação 15). 
A etapa de terminação ocorre através de reações de combinação ou desproporcionamento como a reação de dois macrorradicais alquila, formando polímeros de maior massa molar. Esta etapa também pode ocorrer pela recombinação de dois radicais livres, ou pela reação de dois radicais peroxilas (Equação 16)..$^{18} \mathrm{O}$ mecanismo das etapas da fotooxidação é mostrado no Esquema 2.

$\underline{\text { Iniciação }}$

$$
P H \stackrel{h v}{\longrightarrow} P^{\bullet}+H^{\bullet}
$$

Equação 10

\section{Propagação}

$$
\begin{array}{cc}
P^{\bullet}+\mathrm{O}_{2} \rightarrow \mathrm{POO}^{\bullet} & \text { Equação 11 } \\
\mathrm{POO}^{\bullet}+\mathrm{PH} \rightarrow \mathrm{POOH}+P^{\bullet} & \text { Equação 12 } \\
\mathrm{POOH} \rightarrow \mathrm{PO}^{\bullet}+{ }^{\bullet} \mathrm{OH} & \text { Equação 13 } \\
\mathrm{PH}+{ }^{\bullet} \mathrm{OH} \rightarrow P^{\bullet}+\mathrm{H}_{2} \mathrm{O} & \text { Equação 14 } \\
\mathrm{PO}^{\bullet} \rightarrow \text { produtos de quebra de cadeia } & \text { Equação 15 }
\end{array}
$$

\section{Terminação:}

Recombinação de radicais, formando produtos inativos

$$
\begin{aligned}
& \mathrm{P}^{\bullet}+\mathrm{P}^{\bullet} \rightarrow \\
& \mathrm{PO}^{\bullet}+P^{\bullet} \rightarrow \\
& P^{\bullet}+\mathrm{POO}^{\bullet} \rightarrow \\
& \mathrm{POO}^{\bullet}+\mathrm{POO}^{\bullet} \rightarrow
\end{aligned}
$$




\subsubsection{Fotodegradação de polímeros coloridos}

O conhecimento dos mecanismos de fotodegradação de polímeros coloridos é de grande interesse, devido à possibilidade de prolongar a vida útil desses materiais e também acelerar sua degradação quando desejado. Isso envolve a presença de corantes, ou de outros cromóforos, no material polimérico, que podem estar ligados covalentemente as cadeias poliméricas ou adicionadas e dissolvidas posteriormente.

Corantes e pigmentos são aditivos que conferem cor ao material polimérico. A diferença básica entre eles está no tamanho da partícula e na solubilidade no meio. Geralmente, os corantes possuem tamanho menor que os pigmentos e são solúveis em matrizes poliméricas. Possuem vantagem de não serem abrasivos, alta capacidade de absorção luminosa e permitem que polímeros transparentes não percam esta propriedade. Por outro lado, a mesma solubilidade confere aos corantes a capacidade de migrar para a superfície do material, podendo sublimar e manifestar toxicidade. ${ }^{19}$

Os corantes são freqüentemente utilizados em processos de coloração de polímeros e podem atuar como estabilizantes ou sensibilizadores. ${ }^{19,20}$ A perda da cor de corantes ocasionada pela exposição à luz e na presença de ar, geralmente envolve reações de oxidação, que é um processo irreversível. O corante degradado pode ainda gerar fotoprodutos incolores durante este processo. ${ }^{21}$

A fotoestabilidade de corantes depende de muitos fatores, tais como a estrutura química do corante (que determina a reatividade dos seus estados excitados), a natureza física e química do polímero, a distribuição e concentração do corante no polímero (uma vez que a taxa de fotodegradação está diretamente 
associada à concentração), ambiente do polímero colorido (temperatura, umidade, poluentes atmosféricos) e distribuição espectral da radiação incidente (alguns comprimentos de onda são mais efetivos no processo de fotodegradação). ${ }^{21}$

As reações fotoquímicas de corantes podem ser induzidas e promovidas por diferentes compostos orgânicos que agem por vias distintas:

I. Fotoiniciadores: são moléculas (geralmente orgânicas) que absorvem luz e conduzem à formação de espécies reativas através de reações a partir de seus estados excitados. Dividem-se em dois grandes grupos, dependendo do tipo de reação fotoquímica responsável pela formação de radicais. O primeiro grupo correspondente aos fotoiniciadores de fragmentação, que são compostos que quando excitados por absorção de luz sofrem quebra homolítica, formando radicais livres que podem iniciar reações secundárias. ${ }^{22}$

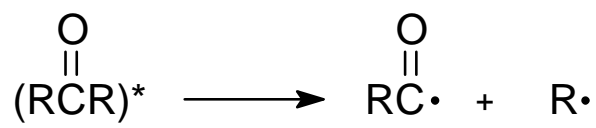

O outro grupo é dos fotoiniciadores de mecanismo bimolecular, que envolvem sistemas nos quais o iniciador é excitado eletronicamente, reagindo, posteriormente, com um co-iniciador (aminas alifáticas) levando à formação de radicais livres que desencadeiam a polimerização. ${ }^{23}$

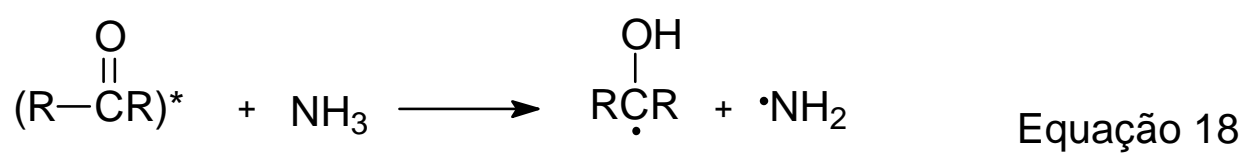


II. Fotossensibilizadores: são compostos que são excitados pela luz e transferem sua energia de excitação para outras moléculas, como, por exemplo, a formação de oxigênio singlete gerado por transferência de energia. ${ }^{23} \mathrm{O}$ Esquema 3 mostra a formação do oxigênio singlete $\left({ }^{1} \mathrm{O}_{2}\right)$ através de uma reação de fotossensibilização. ${ }^{24,11}$

$$
\begin{aligned}
& { }^{0} \text { Sens }+h v \rightarrow{ }^{1} \text { Sens } \\
& * \\
& { }^{1} \text { Sens }{ }^{*} \rightarrow{ }^{3} \text { Sens }{ }^{*} \\
& { }^{3} \text { Sens } s^{*}+{ }^{3} \mathrm{O}_{2}{ }^{*} \rightarrow{ }^{0} \text { Sens }+{ }^{1} \mathrm{O}_{2}
\end{aligned}
$$

Esquema 3. Reação de fotossensibilização do oxigênio. ${ }^{24}$

As cetonas, quinonas e peróxidos são iniciadores de diferentes reações, tais como: polimerização e degradação. Alguns destes compostos absorvem luz acima de $380 \mathrm{~nm}$, e podem formar radicais livres por clivagem, ou outras reações. Estas espécies podem iniciar a degradação dos polímeros por abstração de um hidrogênio do polímero $(\mathrm{PH})$ formando um macrorradical alquila $\left(\mathrm{P}^{\bullet}\right)$. A eficiência da ação desses fotoiniciadores depende da atmosfera, temperatura e solvente.

Existem dois mecanismos propostos para a fotodegradação de polímeros induzidos por corantes. No primeiro, o corante (D) é excitado ao estado singlete ( $\left.{ }^{1} D\right)$, que produz o estado triplete $\left({ }^{3} \mathrm{D}\right)$, que reage com uma molécula de oxigênio, produzindo oxigênio singlete $\left({ }^{1} \mathrm{O}_{2}\right)$. Na presença de água, o ${ }^{1} \mathrm{O}_{2}$ forma peróxido de hidrogênio $\left(\mathrm{H}_{2} \mathrm{O}_{2}\right)$, induz a oxidação (Esquema 4). ${ }^{10,21}$ 


$$
\begin{aligned}
& \mathrm{D} \stackrel{h v}{\longrightarrow}{ }^{1} \mathrm{D} \rightarrow{ }^{3} \mathrm{D} \\
& { }^{3} \mathrm{D}+{ }^{3} \mathrm{O}_{2} \rightarrow \mathrm{D}+\mathrm{O}_{2} \\
& { }^{1} \mathrm{O}_{2}+2 \mathrm{H}_{2} \mathrm{O} \rightarrow 2 \mathrm{H}_{2} \mathrm{O}_{2} \\
& 2 \mathrm{H}_{2} \mathrm{O}_{2}+\mathrm{P}-\mathrm{H} \rightarrow \text { produtos de oxidação }
\end{aligned}
$$

Esquema 4. Primeiro mecanismo de fotodegradação de polímeros induzido por corantes. ${ }^{10,21}$

O segundo mecanismo propõe uma interação inicial entre o corante fotoativo e o polímero através da abstração de um átomo de hidrogênio, criando um centro radicalar no polímero, que é atacado pelo oxigênio, formando a espécie $\mathrm{PO}_{2}{ }^{\circ}$, como mostra o Esquema 5. ${ }^{10,21}$

$$
\begin{aligned}
& D \stackrel{h v}{\longrightarrow} D^{*} \\
& { }^{*} D+P-H \rightarrow D H^{\bullet}+P^{\bullet} \\
& P^{\bullet}+\mathrm{O}_{2} \rightarrow \mathrm{PO}_{2}^{\bullet} \\
& \mathrm{PO}_{2}{ }^{\bullet}+\mathrm{DH}^{\bullet} \rightarrow \mathrm{PO}_{2} \mathrm{H}+\mathrm{D}
\end{aligned}
$$

Esquema 5. Segundo mecanismo de fotodegradação de polímeros induzido por corantes. ${ }^{10,21}$

\subsection{Tioxantonas}

As cetonas aromáticas possuem estados eletrônicos excitados singlete e triplete $\left(n \pi^{*}\right)$ e $\left({ }^{*} \pi-\pi^{*}\right)$ de baixa energia devido a conjugação do grupo carbonila com a parte aromática. Por isso, absorvem luz a comprimentos de onda mais longos que os cromóforos isolados. O rendimento quântico de cruzamento intersistemas é aumentado pela conjugação e pode chegar a valores próximos da unidade. As reações podem ocorrer tanto desde o estado singlete quanto desde o estado triplete, 
mas no caso de cetonas aromáticas ocorrem quase sempre do estado triplete devido ao alto rendimento quântico de cruzamento intersistemas. Os estados eletrônicos das cetonas aromáticas apresentam uma dependência com a polaridade do solvente. Por exemplo, o primeiro estado triplete de xantonas em solventes não polares possui caráter $n \pi^{*}$, e em solventes polares hidroxílicos tem caráter $\pi \pi^{*}$, levando a uma diminuição na reatividade fotoquímica quanto à abstração de hidrogênio. ${ }^{25}$

Outro exemplo de cetonas aromáticas são as tioxantonas (TX) que adquiriram importância como fonte de radicais quando irradiadas no visível em presença de aminas terciárias. ${ }^{26}$ É bem conhecido que a atividade destes compostos como fotoiniciadores na polimerização é baseada na produção de radicais a partir da interação do estado excitado triplete da TX com aminas terciárias que ocorre por meio da formação de um intermediário de transferência de carga (normalmente um exciplexo triplete), que acaba dando lugar a radicais amino e cetila. O Esquema 6 mostra o mecanismo de formação de radicais da tioxantona. ${ }^{27}$

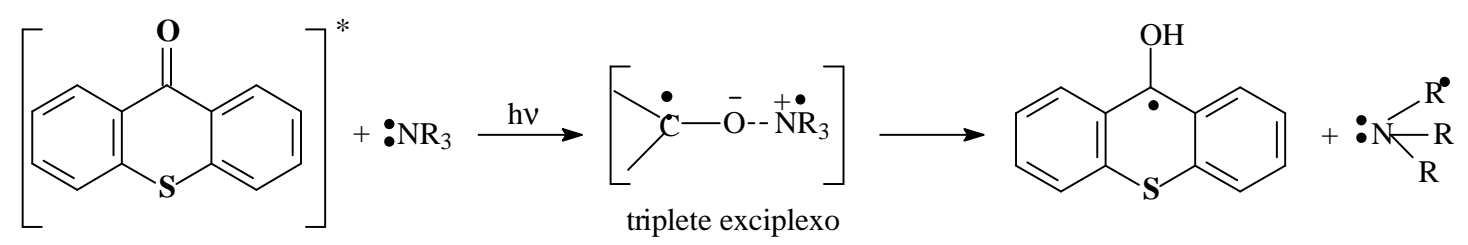

Esquema 6. Mecanismo de formação de radicais da tioxantona. ${ }^{27}$

Na fotodegradação, o estado triplete da tioxantona $T_{1}\left({ }^{*} \pi-\pi^{*}\right)$ pode abstrair 0 hidrogênio a partir de uma espécie doadora de hidrogênio $(P-H)$, que pode ser 0 polímero, formando o radical cetila, como mostrado no Esquema 7: 
<smiles>Cc1cc2sc3ccccc3c(=O)c2cc1CC(C)C(C)C(C)C</smiles><smiles>Cc1cc2sc3ccccc3c(=O)c2cc1CP(C)[PH2+][PH3+]</smiles>

Esquema 7. Formação do radical cetila da tioxantona a partir da abstração de hidrogênio do polímero $(\mathrm{PH}){ }^{8}$ 


\section{OBJETIVOS}

O trabalho da tese possui como objetivo principal investigar a degradação do poliestirenossulfonato de sódio (PSS) fotossensibilizada por cloreto de 2-hidroxi-3(3,4-dimetil-9-oxo-9H-tioxanton-2-iloxi)-N,N,N-trimetil-1-propano (QTX).

Para interpretar apropriadamente os resultados foram estudadas inicialmente as fotodegradações da QTX em água e do polímero PSS sozinho em água. Os fotoprodutos gerados pela fotólise de QTX em água foram determinados por cromatografia líquida de alta eficiência acoplado a detector de massa (CLAE-EM).

A degradação da cadeia de PSS em água e na presença de QTX foi monitorada por cromatografia de exclusão de tamanho e viscosidade.

A fotodegradação de QTX em água e do PSS fotossensibilizado por QTX envolveu:

$\checkmark$ Investigar o efeito da variação da concentração de corante, $\mathrm{pH}$ da solução, presença de sais e sorbato de potássio nas soluções irradiadas por espectroscopia de absorção na região do UV-Vis.

$\checkmark$ Investigar as reações elementares através da técnica de fótolise por pulso de laser e por fluorescência.

$\checkmark$ Propor os mecanismos de fotodegradação de QTX em água e do PSS sensibilizado por QTX. 


\section{PARTE EXPERIMENTAL}

\subsection{Reagentes utilizados}

Os reagentes foram utilizados como recebidos. Todas as soluções foram preparadas em água ultra pura. Os solventes orgânicos utilizados para as análises foram todos de grau HPLC. A Tabela 3 apresenta os principais reagentes utilizados neste trabalho.

Tabela 3- Principais reagentes utilizados.

\begin{tabular}{|c|c|c|c|}
\hline Reagentes & Estrutura & $\begin{array}{c}\mathrm{MM} \\
\left(\mathrm{g} \cdot \mathrm{mol}^{-1}\right)\end{array}$ & Procedência \\
\hline $\begin{array}{l}\text { Poliestirenossulfonato de } \\
\text { Sódio (PSS) }\end{array}$ & & 70.000 & Aldrich \\
\hline QTX & & 407,50 & * \\
\hline Sulfato de sódio & $\mathrm{Na}_{2} \mathrm{SO}_{4}$ & 142,04 & Aldrich \\
\hline Sulfato de cobre & $\mathrm{CuSO}_{4} .5 \mathrm{H}_{2} \mathrm{O}$ & 249,68 & Synth \\
\hline Cloreto de sódio & $\mathrm{NaCl}$ & 58,44 & Qhemis \\
\hline Sorbato de potássio & & 150,22 & Aldrich \\
\hline hidroquinona & $\mathrm{C}_{6} \mathrm{H}_{6} \mathrm{O}_{2}$ & 110,11 & Vetec \\
\hline
\end{tabular}




\subsection{Equipamentos utilizados}

Os principais equipamentos utilizados neste trabalho foram:

- $\quad$ Espectrofotômetro UV-2550, Shimadzu

- Cromatógrafo Líquido de Alta Eficiência, Waters 2695 (separation module) HPLC-PDA/MS, acoplado a detector de arranjo de diodos (Waters PDA 2996) e detector de massas (Waters Micromass ZT), usando uma coluna analítica C18 Symmetry ${ }^{\circledR} 4,6 \times 75 \mathrm{~mm}$ e tamanho de partícula de $3,5 \mu \mathrm{m}$.

- Cromatógrafo Líquido de Alta Eficiência, Shimadzu com detector de Ultravioleta (UV), acoplado a pré- coluna de polidivinilbenzeno (Shodex) Ohpak KBG e 3 colunas (Shodex) Ohpak KB-806M em série e bomba LC-10 AD.

- $\quad$ Viscosímetro Ubbelohde Lauda Viscoboy 2.

- Sistema de Flash Photolysis Luzchem. Laser de Nd-YAG (Brilliant B, Quantel; 5,2 ns e $165 \mathrm{~mJ} /$ pulso).

- $\quad$ Sistema de medidas de tempo de vida de fluorescência Easylife V, usando LEDs entre 280-670 nm como fontes de excitação.

- $\quad$ Espectrofluorímetro F-4500 Hitachi.

- $\quad$ Câmara de irradiação contínua TECNAL TE-383.

- $\quad$ HHmetro digital Denver Instruments UB-10 acoplado a um eletrodo de $\mathrm{Ag} / \mathrm{AgCl}$, previamente calibrado usando tampões de $\mathrm{pH}$ 4,0 e 7,0 a temperatura ambiente. 


\subsection{Procedimentos Experimentais}

\subsubsection{Estudos da degradação de QTX e PSS/QTX}

As irradiações foram realizadas em uma câmara de irradiação provida de controle de temperatura, carrossel giratório para dezesseis tubos. Foram utilizadas como fonte de radiação dezesseis lâmpadas fluorescentes tubulares (comprimento $22,5 \mathrm{~cm}$, diâmetro $1,6 \mathrm{~cm}$ ) de $6 \mathrm{~W}$ cada da marca Xelux. O espectro de luz emitida por lâmpadas fluorescentes comerciais (Philips, General Eletric, Sylvania) está apresentado na Figura $2 .^{16}$

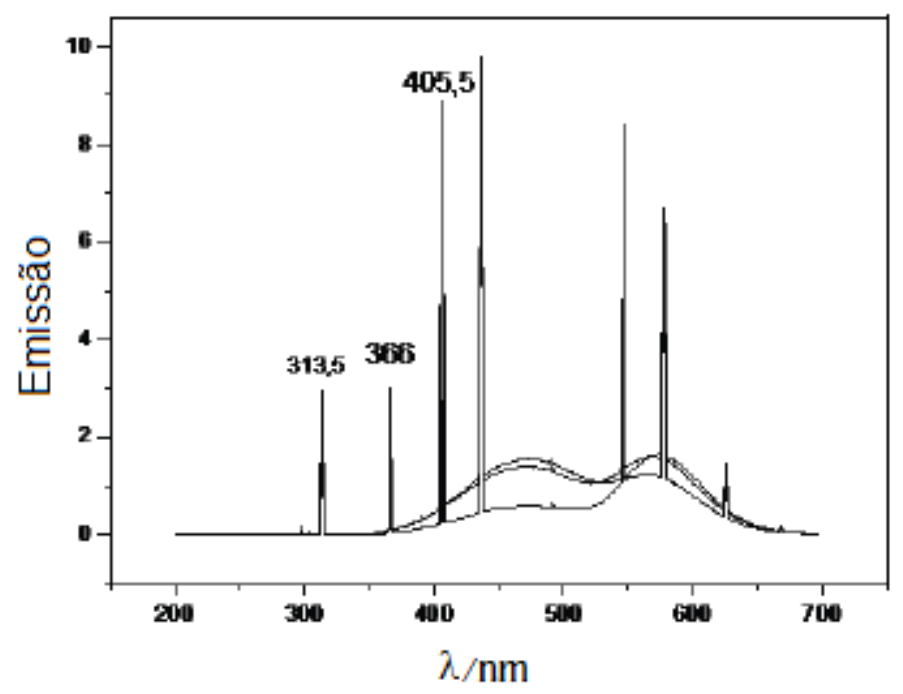

Figura 2. Espectro da luz emitida por lâmpadas fluorescentes comerciais de fabricantes diferentes, Sylvania, General Electric, Phillips. ${ }^{16}$

As amostras foram irradiadas em tubos de vidro de borossilicato (altura 19,5 $\mathrm{cm}$, diâmetro 1,0 cm), contendo em cada tubo $15 \mathrm{~mL}$ de amostra, colocadas a 13,0 
$\mathrm{cm}$ da parte superior e $7,0 \mathrm{~cm}$ da lateral. Os tubos foram fechados com septo de borracha. Para estudos em atmosfera inerte ou saturada de oxigênio foi borbulhado nitrogênio ou oxigênio por 30 minutos, respectivamente. As amostras foram coletadas através de pipeta Pasteur ou, no caso de sistemas fechados, por meio de uma seringa plástica de $5 \mathrm{~mL}$ acoplada a uma agulha de metal em tempos prédeterminados e posteriormente analisadas por diferentes técnicas. $\mathrm{O}$ volume das amostras coletadas foi $3 \mathrm{~mL}$, com exceção das análises de viscosimetria. Todas as soluções foram preparadas a temperatura ambiente no máximo 15 dias antes dos experimentos para eliminar a possibilidade de degradação tanto do polímero quanto do corante. As soluções estoque foram armazenadas em local seco e envoltas com papel alumínio.

A Figura 3 ilustra a câmara de irradiação. As soluções foram irradiadas no máximo por $160 \mathrm{~h}$ a $25 \pm 1^{\circ} \mathrm{C}$.

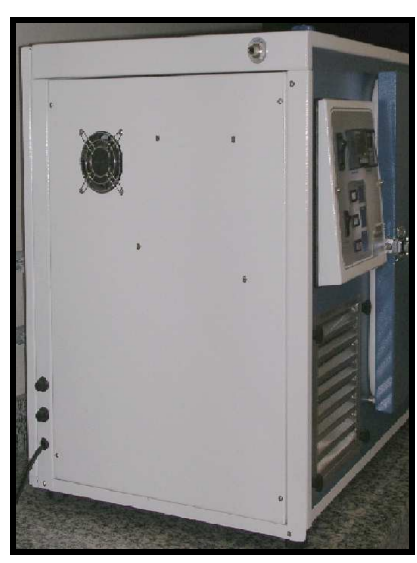

(A)

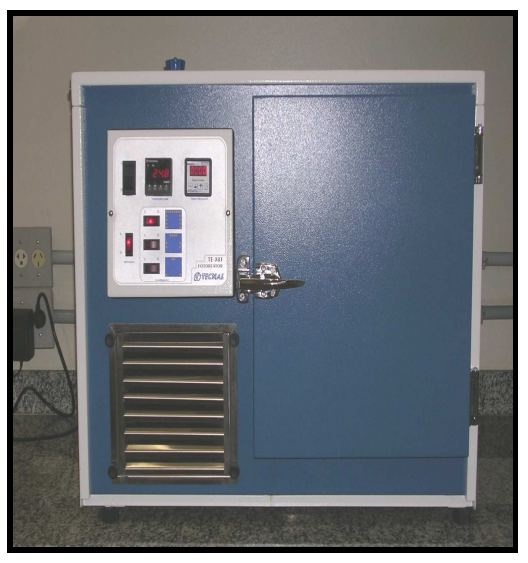

(B)

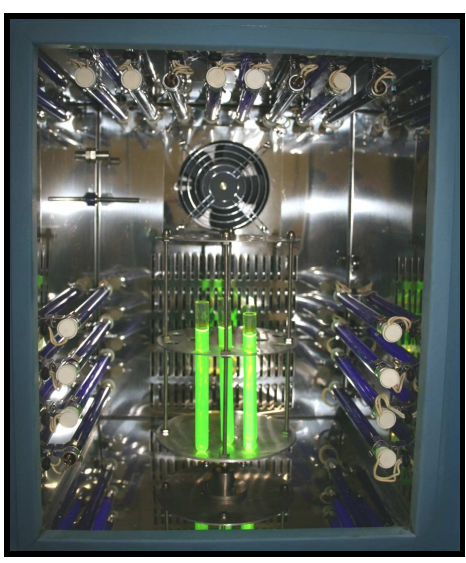

(C)

Figura 3. Câmara de irradiação: (A) lateral, (B) frontal e (C) interior da câmara. 


\subsubsection{Cromatografia por exclusão de tamanho}

Cromatografia por Exclusão de Tamanho (SEC) é uma técnica de fracionamento das cadeias poliméricas, a qual pode analisar a separação em um número muito grande de frações com diferentes massas molares de polímero. Determina-se, então, simultaneamente a massa molar numérica média, a massa molar ponderal média e a polidispersividade. A massa molar numérica média depende do número de moléculas de polímero presentes na solução, qualquer que seja a estrutura ou tamanho e está representado pela Equação 19. ${ }^{13,28}$

$$
\overline{M n}=\frac{\sum n_{i} M_{i}}{\sum n_{i}}
$$

em que:

$\bar{M} n$ é a massa molar numérica média;

Mi é a massa molar de moléculas de classe i;

$\mathrm{n}_{\mathrm{i}}$ é o número de moléculas de classe i.

A massa molar ponderal média, $\overline{M w}$, representada pela Equação 20 , depende do número e da massa de cada molécula presente na solução:

$$
\overline{\bar{w}}=\frac{\sum n_{i} M_{i}^{2}}{\sum n_{i} M_{i}}
$$


Polidispersividade da amostra polimérica é definida pela relação entre $\overline{M w}$ e $\bar{M} n,(\overline{M w} / \bar{M} n)$, e é tanto maior quanto mais heterogêneas forem às massas molares dos polímeros obtidos. A curva de calibração para a determinação de todos os sistemas deste trabalho foi obtida através das injeções de padrões conhecidos de poliestirenossulfonato de sódio com $M w$ de 1430 até 2.850.000, e de etilenoglicol com massa molar de $90 \mathrm{~g} / \mathrm{mol}$. A fase móvel utilizada foi uma mistura na proporção 80:20 (v/v) de uma solução aquosa de nitrato de sódio $0,1 \mathrm{M}$ e metanol, a vazão foi de $1 \mathrm{~mL} \mathrm{~min}^{-1}$ e a temperatura de $35^{\circ} \mathrm{C}$. 


\section{RESULTADOS E DISCUSSÃO}

\subsection{Estudos da fotodegradação de QTX em solução aquosa}

A fotodegradação de QTX em solução aquosa foi estudada com o objetivo de investigar seu comportamento fotoquímico na ausência do polímero para posteriormente usá-la como sensibilizador na fotodegradação do poliestirenossulfonato de sódio. Foi estudado o efeito de sua concentração, a influência de $\mathrm{pH}$ e o efeito de íons sulfato e sorbato de potássio. Todos os sistemas foram analisados por espectroscopia UV-Vis e todas as irradiações foram realizadas na câmara de irradiação. A combinação dos estudos de fotodegradação estacionários, caracterização de seus fotoprodutos e as reações elementares de QTX em água foram essenciais para propor o mecanismo de degradação de QTX em solução aquosa.

\subsubsection{Estudo do efeito da concentração de QTX no processo de fotólise}

A concentração do fotossensibilizador é um parâmetro importante em um sistema de fotodegradação. Desta maneira, o efeito da variação de concentração de QTX em solução aquosa foi investigado no intervalo de $3,0 \times 10^{-5}$ a $1,0 \times 10^{-4} \mathrm{M}$. Esse intervalo foi escolhido, pois não foi observado nenhum efeito de agregação nos espectro de absorção na região de $400 \mathrm{~nm}$, ou seja, a relação entre concentração e absorbância apresentou um comportamento linear, sendo possível aplicar a lei de 
Lambert-Beer (Equação 21) ${ }^{29}$ e determinar o valor do coeficiente de extinção molar do corante em água. $O$ valor obtido de $\varepsilon$ foi de $4,77 \times 10^{3} \mathrm{M}^{-1} \mathrm{~cm}^{-1}$.

$$
\varepsilon=\log \left(I_{0} / I\right) / l c=A / l c
$$

Equação 21

Onde, I $I_{0}$ é a intensidade de luz incidente; I é a intensidade de luz transmitida; $A$ é absorbância; $c$ é a concentração em moles por litro e $l$ é o comprimento do caminho óptico.

Soluções de QTX foram irradiadas nas condições descritas em 3.3.1, as Figuras 4a a 4d apresentam os espectros de QTX em diferentes concentrações, em função do tempo de irradiação, no intervalo de 0 a 160 horas.

- $[Q T X]=3 \times 10^{-5} \mathrm{M}$

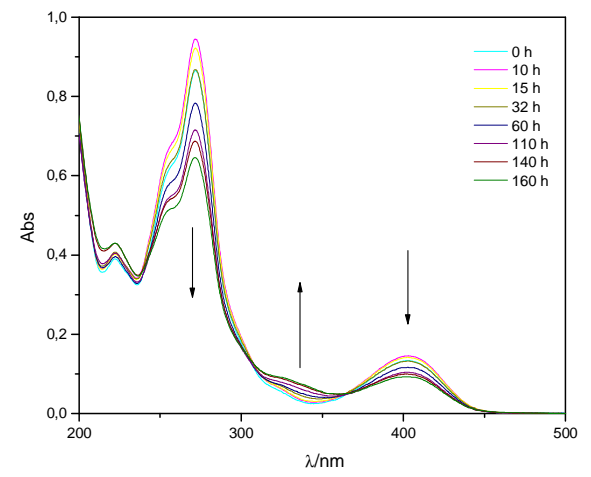

(A)

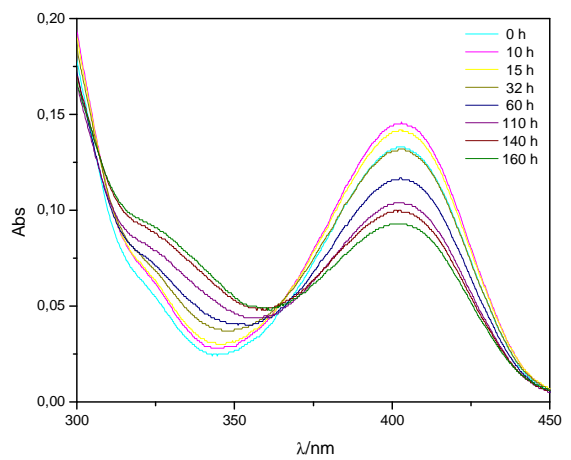

(B)

Figura 4a. Espectros de absorção de QTX $3 \times 10^{-5} \mathrm{M}$ em solução aquosa, de 200 a $500 \mathrm{~nm}$ (A) e 300 a $450 \mathrm{~nm}(\mathrm{~B})$, após irradiação por até 160 horas. 
- $[\mathrm{QTX}]=5 \times 10^{-5} \mathrm{M}$

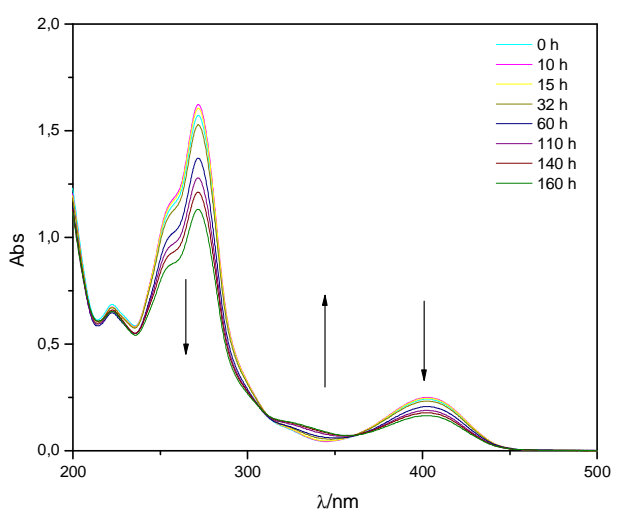

(A)

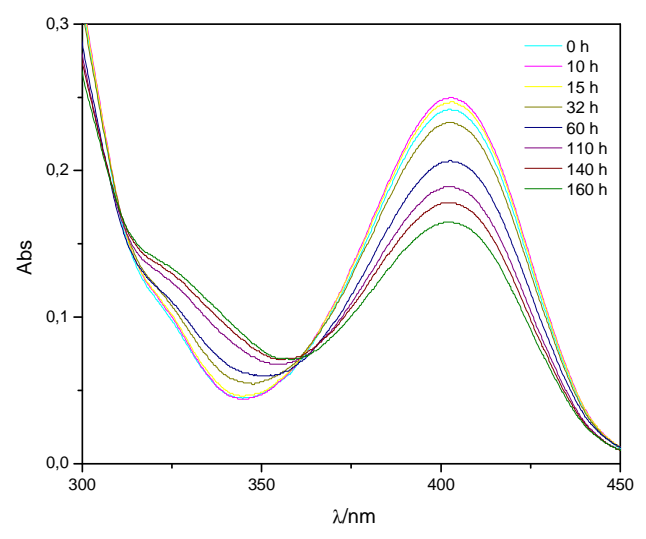

(B)

Figura 4b. Espectros de absorção de QTX $5 \times 10^{-5} \mathrm{M}$ em solução aquosa, de 200 a $500 \mathrm{~nm}$ (A) e 300 a 450 nm (B), após irradiação por até 160 horas.

- $[\mathrm{QTX}]=7 \times 10^{-5} \mathrm{M}$

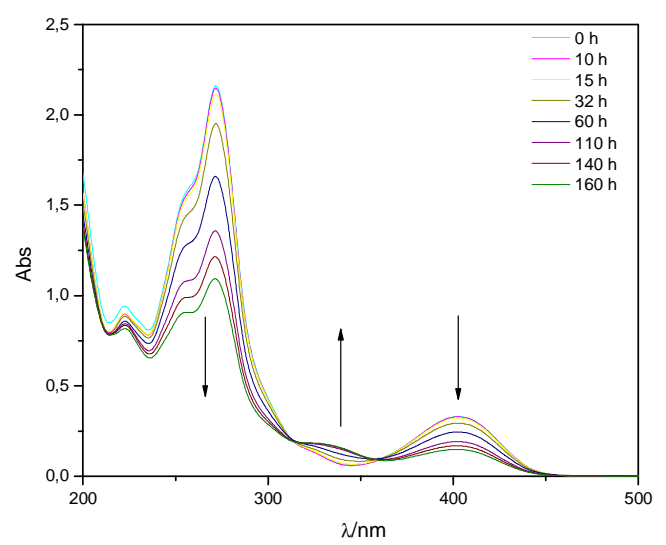

(A)

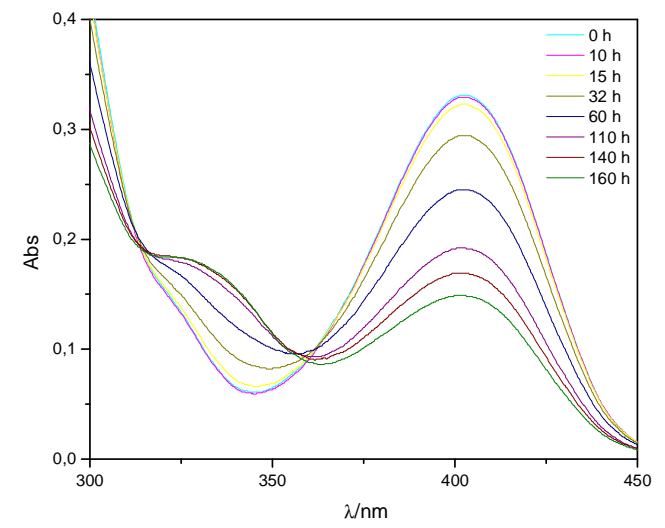

(B)

Figura 4c. Espectros de absorção de QTX $7 \times 10^{-5} \mathrm{M}$ em solução aquosa, de 200 a $500 \mathrm{~nm}$ (A) e 300 a $450 \mathrm{~nm}(\mathrm{~B})$, após irradiação por até 160 horas. 
- $[Q T X]=1 \times 10^{-4} \mathrm{M}$

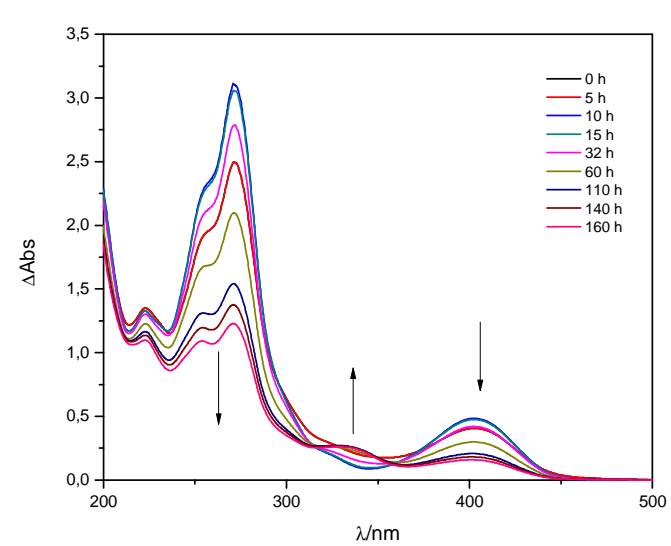

(A)

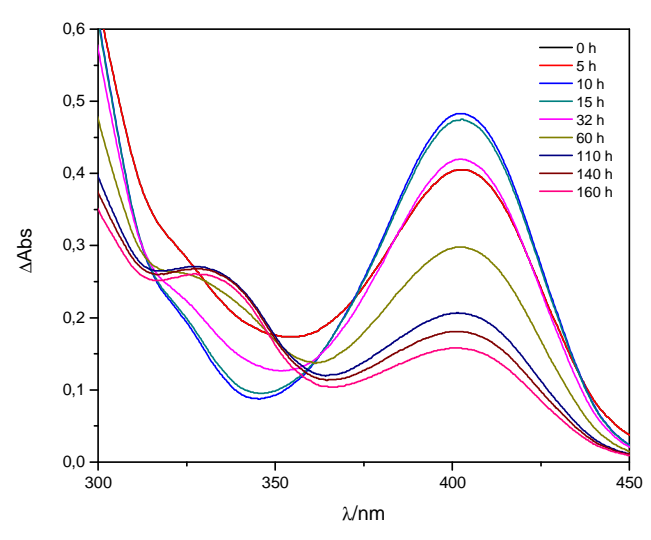

(B)

Figura 4d. Espectros de absorção de QTX $1 \times 10^{-4} \mathrm{M}$ em solução aquosa, de 200 a $500 \mathrm{~nm}$ (A) e 300 a $450 \mathrm{~nm}(\mathrm{~B})$, após irradiação por até 160 horas.

Das Figuras 4a a 4d é possível notar que, em geral, ocorre uma diminuição das bandas de absorção em 402 e 273 nm após 15 horas de irradiação. Por outro lado, aparece uma banda nova entre 310 a $350 \mathrm{~nm}$, que pode ser atribuída à oxidação da QTX.

Kinart e colaboradores investigaram a eletro-oxidação e a eletro-redução da QTX em solução aquosa e encontraram que quando o corante é oxidado surge uma nova banda em $310 \mathrm{~nm}$, ocorrendo simultaneamente à diminuição nas absorções em 404 e $270 \mathrm{~nm}$. De maneira análoga ao encontrado nos experimentos de redox, o deslocamento para o azul encontrado nos experimentos de irradiação de QTX poderia ser atribuído a sua oxidação. ${ }^{30} \mathrm{O}$ desaparecimento de QTX em função do tempo de irradiação foi monitorado pela diminuição da banda de absorção em 402 nm e está representado na Figura 5. 


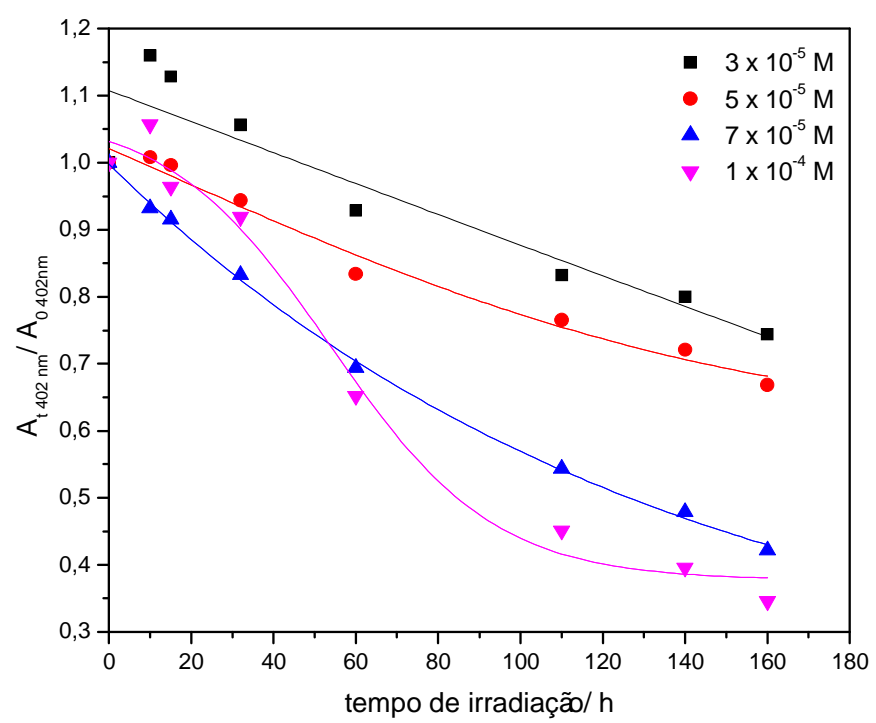

Figura 5. Mudança da absorção a $402 \mathrm{~nm}$ durante a irradiação de diferentes concentrações QTX em solução aquosa.

Através da Figura 5 é possível notar que inicialmente (tempos inferiores a 15 horas), ocorre um aumento na banda de absorção centrada em $402 \mathrm{~nm}$ para quase todas as concentrações de QTX em solução aquosa. Esse comportamento pode sugerir que espécies intermediárias geradas pelo processo de degradação poderiam absorver na mesma região. Porém, para a identificação dessas espécies ou a elucidação deste mecanismo é necessária uma investigação mais detalhada.

O comportamento de desaparecimento de QTX durante a irradiação pode ser explicado considerando que o mecanismo de degradação na presença de oxigênio. O Esquema 8 ilustra as reações de formação de espécies ativas de oxigênio em presença do corante excitado. 


$$
\begin{aligned}
& { }^{3} \mathrm{D}^{3} \mathrm{O}_{2} \rightarrow \mathrm{D}_{0}+{ }^{1} \mathrm{O}_{2} \\
& { }^{3} \mathrm{D}+{ }^{3} \mathrm{O}_{2} \rightarrow \mathrm{D}-\mathrm{OO} \\
& \mathrm{D}-\mathrm{OO}+\mathrm{D}-\mathrm{H} \rightarrow \mathrm{D}-\mathrm{OOH}+\mathrm{D}^{\bullet} \\
& \mathrm{D}-\mathrm{OOH} \rightarrow \mathrm{D}_{0}+\mathrm{HO}_{2}^{\bullet}
\end{aligned}
$$

Esquema 8. Mecanismo de degradação de uma molécula de corante na presença de oxigênio.

No qual, $D_{0}$ e ${ }^{3} \mathrm{D}$ representam o estado fundamental, estado triplete, respectivamente. O corante no estado triplete reage com o oxigênio no estado triplete $\left({ }^{3} \mathrm{O}_{2}\right)$ gerando o oxigênio singlete; ${ }^{1} \mathrm{O}_{2} \cdot{ }^{31} \mathrm{O}{ }^{3} \mathrm{D}$ também pode reagir com o ${ }^{3} \mathrm{O}_{2}$ formando uma espécie intermediária $\mathrm{D}-\mathrm{OO}^{\circ}$, que pode abstrair um hidrogênio de outra molécula de QTX, formando um hidroperóxido, e conseqüentemente formando o $\mathrm{HO}_{2}{ }^{\circ}$. Assim, espécies formadas durante o processo de degradação como ${ }^{1} \mathrm{O}_{2} \mathrm{e}$ $\mathrm{HO}_{2}{ }^{\bullet}$ podem voltar a reagir com o corante provocando sua degradação.

A porcentagem de degradação do corante após a $160 \mathrm{~h}$ de irradiação foi calculada através da Equação $22^{32,33}$ considerando a banda centrada em $402 \mathrm{~nm}$, referente à QTX, e os resultados obtidos são apresentados na Tabela 4.

$$
\% \text { de deg radação }=\frac{A(\text { inicial })-A(\text { final })}{A(\text { inicial })} \times 100
$$

Equação 22

Na concentração de $1 \times 10^{-4} \mathrm{M}$ a porcentagem de degradação de QTX durante a fotólise foi o dobro (61\%) quando comparada a porcentagem obtida para as concentrações de $3 \times 10^{-5} \mathrm{M}$ e $5 \times 10^{-5} \mathrm{M}$ (em torno de $30 \%$ ). Em todos os experimentos que serão apresentados a seguir, a concentração de QTX foi fixada em $1 \times 10^{-4} \mathrm{M}$ por apresentar melhor eficiência na degradação. 
Tabela 4- Porcentagem de degradação de diferentes concentrações de QTX em água.

\begin{tabular}{cc}
\hline$[Q T X] / M$ & \% Degradação $(\mathbf{1 6 0 ~ h )}$ \\
\hline $3 \times 10^{-5}$ & 30 \\
$5 \times 10^{-5}$ & 32 \\
$7 \times 10^{-5}$ & 55 \\
$1 \times 10^{-4}$ & 61 \\
\hline
\end{tabular}

\subsubsection{Efeito da variação de pH}

O efeito do pH sobre a solução aquosa de QTX foi investigado em $\mathrm{pH} 3,5,7$ e 9,0 . O pH da solução foi ajustado através da adição de quantidades adequadas de $\mathrm{NaOH} 1 \mathrm{M}$ e/ou $\mathrm{HCl} 1 \mathrm{M}$ e imediatamente irradiada. $\mathrm{O}$ pH 5,8 corresponde à solução de QTX sem nenhum ajuste de pH.

Apesar da molécula de QTX não sofrer protonação ou desprotonação no estado fundamental foi possível observar que ocorre mudança no comportamento espectral quando a solução é irradiada em diferentes meios.

Os espectros de absorção de QTX em solução aquosa em função do tempo de irradiação em diferentes pHs são apresentados nas Figuras $6 \mathrm{a}$ a $6 \mathrm{~d}$. As soluções foram irradiadas com lâmpadas fluorescentes a temperatura ambiente por até $160 \mathrm{~h}$. 
- $\mathrm{pH}=3,5$

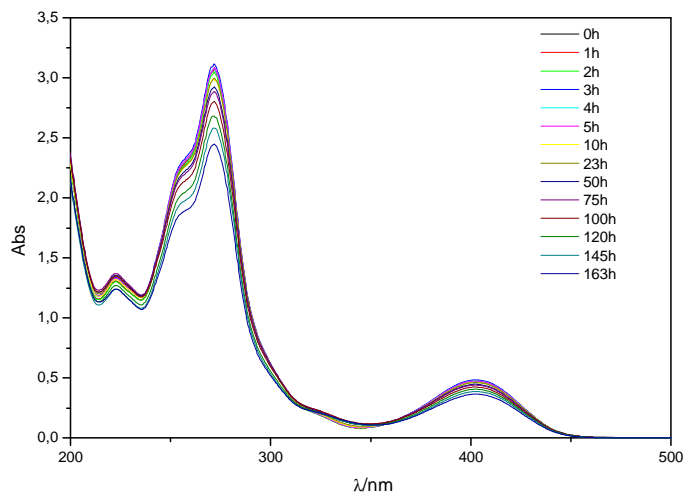

(A)

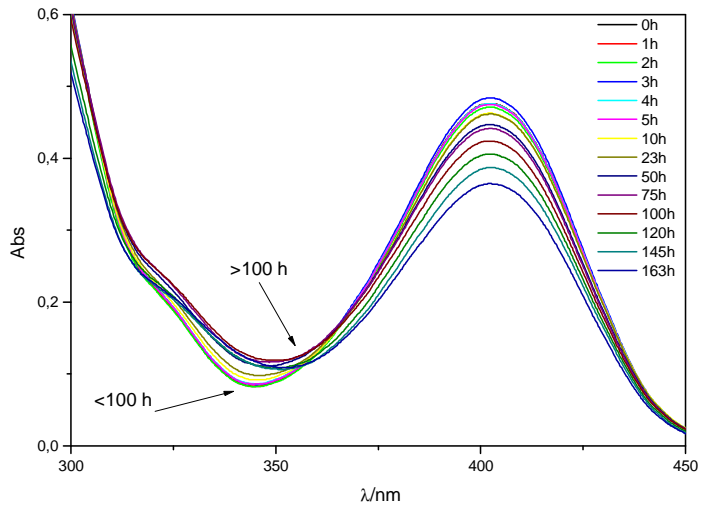

(B)

Figura 6a. Espectro de absorção obtido após a irradiação de $1 \times 10^{-4} \mathrm{M}$ QTX em pH 3,5 (A) de 200 a $500 \mathrm{~nm}$ e (B) de 300 a $450 \mathrm{~nm}$.

- $\mathrm{pH}=5,8$

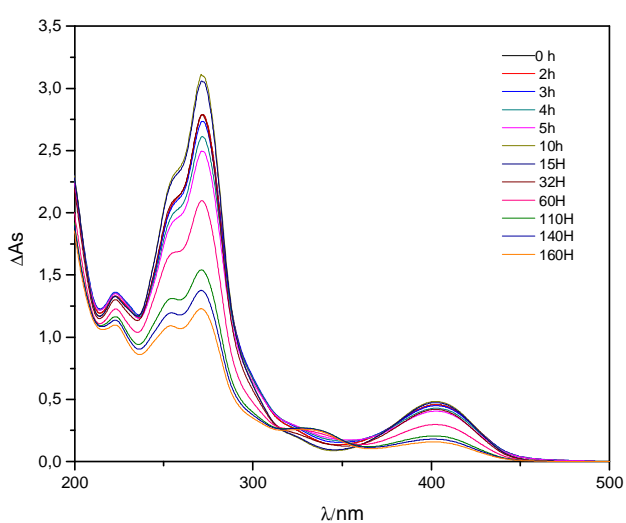

(A)

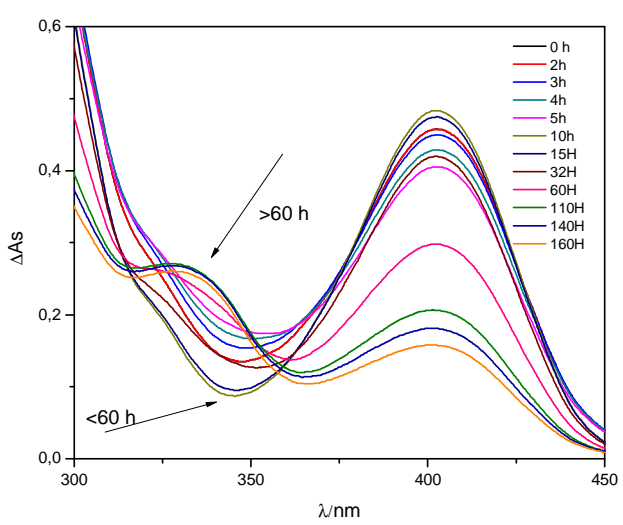

(B)

Figura 6b. Espectro de absorção obtido após a irradiação de $1 \times 10^{-4} \mathrm{M}$ QTX em pH 5,8 (A) de 200 a $500 \mathrm{~nm}$ e (B) de 300 a $450 \mathrm{~nm}$. 
- $\mathrm{pH}=7,0$

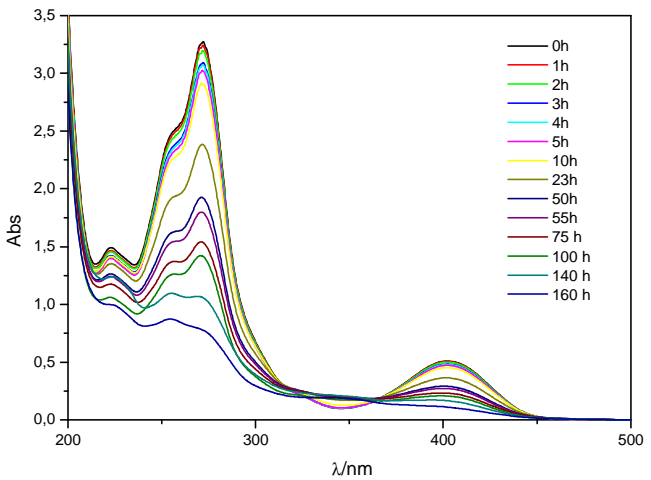

(A)

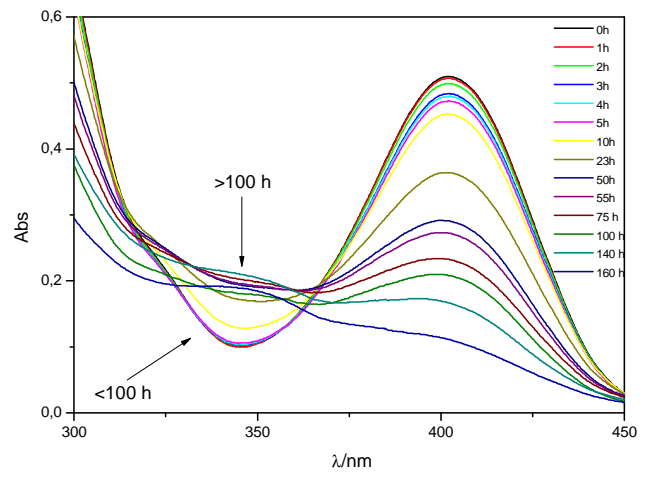

(B)

Figura 6c. Espectro de absorção obtido após a irradiação de $1 \times 10^{-4} \mathrm{M}$ QTX em pH 7,0 (A) de 200 a $500 \mathrm{~nm}$ e (B) de 300 a $450 \mathrm{~nm}$.

- $\mathrm{pH}=9,0$

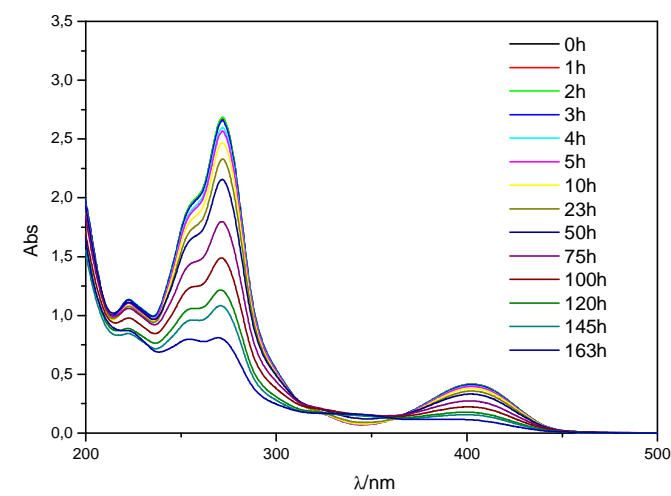

(A)

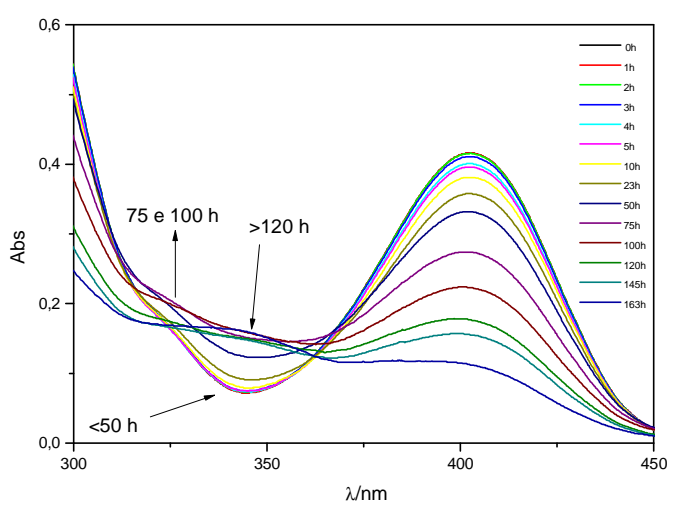

(B)

Figura 6d. Espectro de absorção obtido após a irradiação de $1 \times 10^{-4} \mathrm{M}$ QTX em pH 9,0 (A) de $200 \mathrm{a}$ $500 \mathrm{~nm}$ e (B) de 300 a $450 \mathrm{~nm}$. 
Os espectros de absorção da QTX apresentam três bandas. A primeira em 402 nm, a segunda em $270 \mathrm{~nm}$ e outra em $255 \mathrm{~nm}$. Durante a irradiação, a intensidade dessas bandas foi diminuindo, aparecendo uma nova banda na região entre 300 a $350 \mathrm{~nm}$. A Figura $6 \mathrm{~d}$ é semelhante à Figura 4d uma vez que as condições de trabalho foram as mesmas. Em meio ácido, foi observada uma pequena variação espectral em função do tempo de irradiação na região de 402 nm, ao contrário do que se observa nas soluções neutra e básica. A Figura 7 ilustra a relação das absorções em 402 nm no tempo t e antes da irradiação da banda de QTX em água.

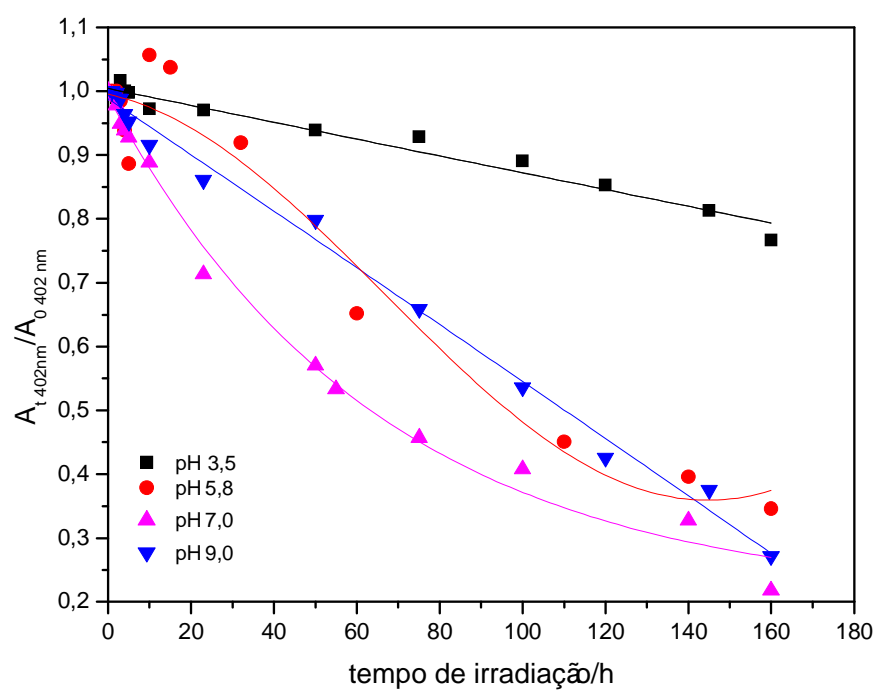

Figura 7. Variação da absorção de QTX em diferentes pHs na região de $402 \mathrm{~nm}$ em função do tempo de irradiação.

Percebe-se que em meio ácido a variação da banda em 402 nm foi menor do que em relação aos outros meios (Figura 7). A porcentagem de degradação de QTX em solução aquosa em diferentes $\mathrm{pHs}$ foi determinada pela Equação 22 
considerando a absorbância em 402 nm no tempo final de irradiação, os valores obtidos estão apresentados na Figura 8.

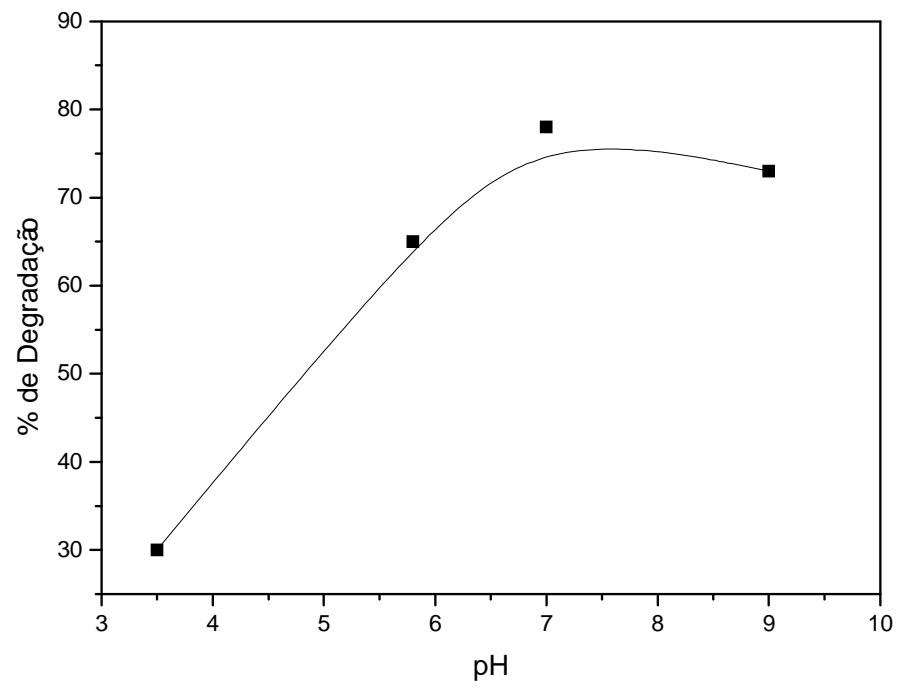

Figura 8. Porcentagem de degradação da solução aquosa de QTX $\left(1 \times 10^{-4} \mathrm{M}\right)$ em função de pH.

A fotodegradação de QTX em água em valores de pH próximos ou superiores a 7,0 foi no mínimo o dobro comparado ao $\mathrm{pH} \mathrm{3,5} \mathrm{(Figura} \mathrm{8).} \mathrm{Este} \mathrm{aumento} \mathrm{da}$ porcentagem de fotodegradação com o aumento nos valores de pH pode ser devido a formação do radical hidroxila $\left(\mathrm{HO}^{\circ}\right)$ e o superóxido $\left(\mathrm{O}_{2}{ }^{\circ-}\right)$, segundo as reações abaixo: ${ }^{19,21}$

$$
D \stackrel{h v}{\longrightarrow}{ }^{*} D
$$

Equação 23

$$
{ }^{*} \mathrm{D}+\mathrm{OH}^{-} \rightarrow \mathrm{D}^{-}+\mathrm{HO}^{\bullet}
$$

$$
D^{-\bullet}+O_{2} \rightarrow D+O_{2}^{\cdot-}
$$


Na região espectral entre 300 a $350 \mathrm{~nm}$ aparece uma banda nova durante a irradiação. Esta banda é atribuída aos possíveis fotoprodutos gerados pelo processo de fotodegradação. Um dos fotoprodutos poderia ser o sulfóxido, mostrado na Figura 9. ${ }^{30}$<smiles></smiles>

Figura 9. Sulfóxido formado na QTX oxidada eletroquimicamente. ${ }^{30}$

Em meio ácido, a absorção na região de fotoproduto vai aumentando conforme o tempo de irradiação até 100 h. Após esse período de irradiação ocorre um deslocamento em torno de $7 \mathrm{~nm}$ dessa banda para região do vermelho.

No caso da solução a pH 5,8 nas 60 primeiras horas de irradiação esta banda aumenta e depois observa-se um deslocamento em torno de $10 \mathrm{~nm}$ para a região do azul. Em meio neutro é verificado que até $100 \mathrm{~h}$ de irradiação a banda centrada em torno de $344 \mathrm{~nm}$ aumenta. Em pH 9, observa-se que até $50 \mathrm{~h}$ de irradiação ocorre aumento da banda ao redor de $344 \mathrm{~nm}$, no intervalo de 75 a $100 \mathrm{~h}$ ocorre um deslocamento de aproximadamente $18 \mathrm{~nm}$ para a região do azul. Depois de $120 \mathrm{~h}$ nota-se um comportamento semelhante ao da solução neutra. Os deslocamentos para a região do azul durante a fotodegradação de QTX poderiam ser atribuídos a sua oxidação. ${ }^{30}$ 


\subsubsection{Efeito de íons sulfato}

O processo de coloração de têxteis requer a adição de sais inorgânicos, os quais possuem diferentes funções de acordo com o corante e a fibra usada. Assim, os resíduos industriais podem conter tanto corantes quanto estes sais. Desta forma, nos estudos envolvendo degradação de corantes são investigados a adição destes sais para o conhecimento da sua influência em diferentes processos de degradação. ${ }^{34,35}$

O efeito do sulfato de sódio foi investigado na degradação de QTX $\left(1,0 \times 10^{-4}\right.$ M) foi estudado variando-se as concentrações de 0,05, 0,10 e 0,20 M. As soluções foram irradiadas com lâmpadas fluorescentes por $160 \mathrm{~h}$ a $25 \pm 1^{\circ} \mathrm{C}$. A Figura $10 \mathrm{a}$ mostra o espectro de absorção da solução de QTX em água em função do tempo de irradiação e as Figuras 10b a 10d apresentam os espectros de absorção das soluções de QTX na presença de íons sulfato durante o processo de fotólise.

- $\left[\mathrm{SO}_{4}{ }^{2-}\right]=0 \mathrm{M}$

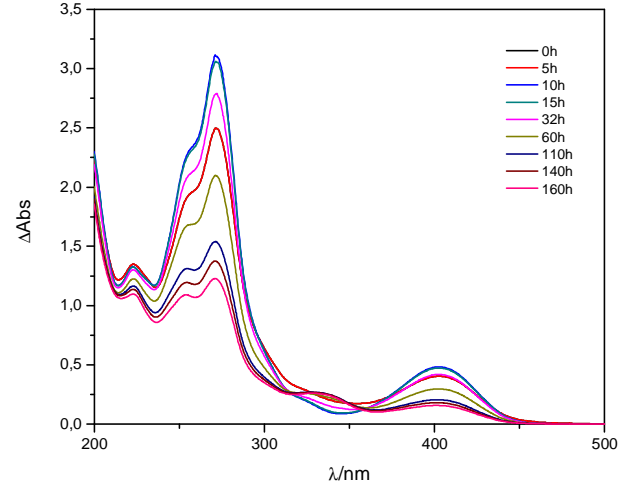

(A)

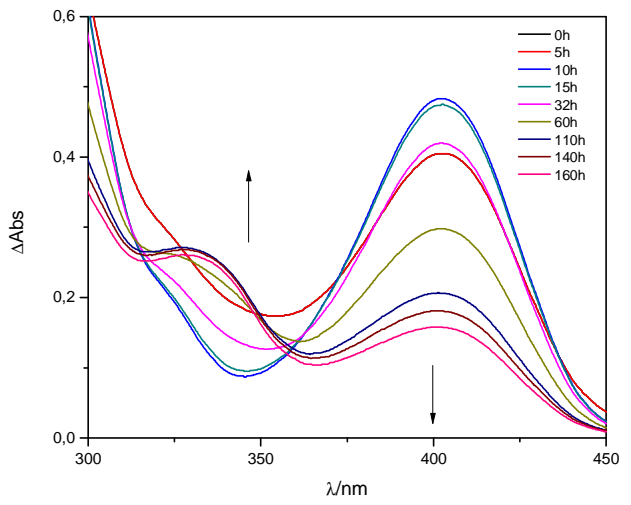

(B)

Figura 10a. Espectros de absorção de QTX em solução aquosa na ausência de íons sulfato de 200 a 500 $\mathrm{nm}(\mathrm{A})$ e 300 a $450 \mathrm{~nm}(\mathrm{~B})$. 
- $\left[\mathrm{SO}_{4}{ }^{2-}\right]=0,05 \mathrm{M}$

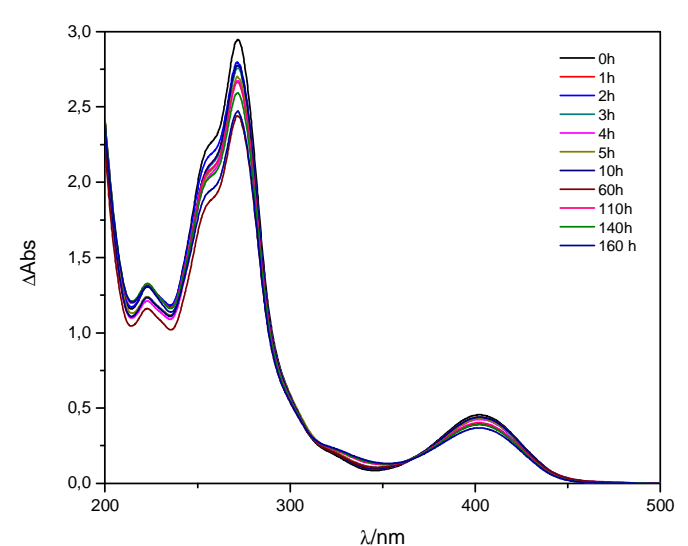

(A)

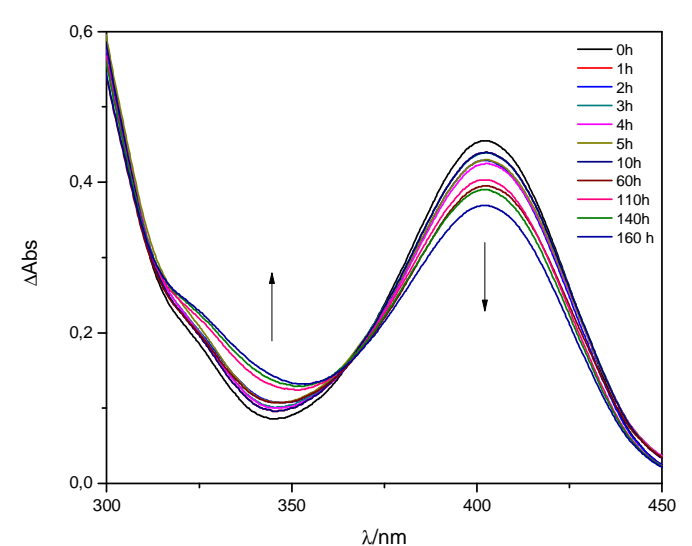

(B)

Figura 10b. Espectro de absorção de QTX em solução aquosa na presença de $0,05 \mathrm{M}$ de $\mathrm{SO}_{4}{ }^{2-}$ de 200 a $500 \mathrm{~nm}(\mathrm{~A})$ e 300 a $450 \mathrm{~nm}(\mathrm{~B})$.

- $\left[\mathrm{SO}_{4}{ }^{2-}\right]=0,10 \mathrm{M}$

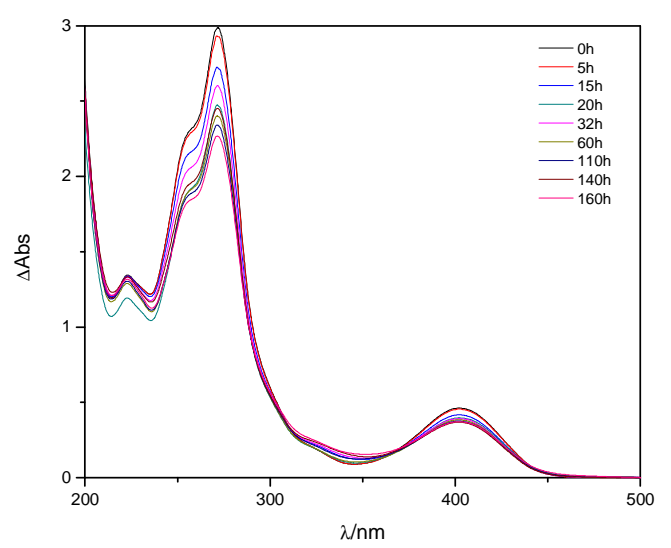

(A)

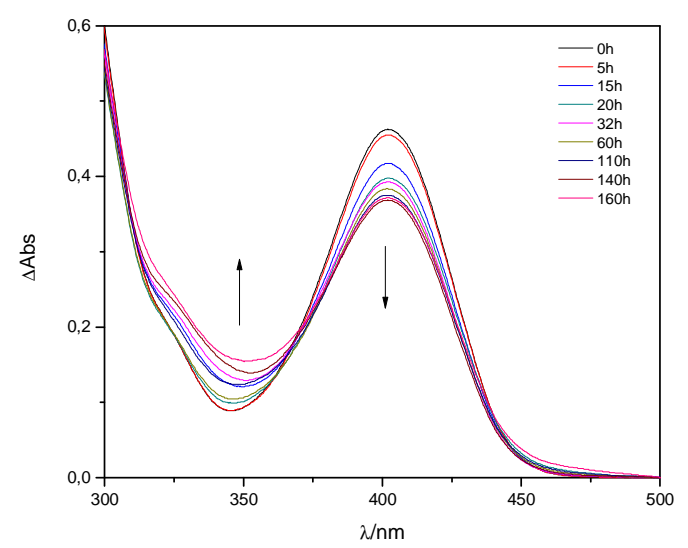

(B)

Figura 10c. Espectro de absorção de QTX em solução aquosa na presença de $0,10 \mathrm{M}$ de $\mathrm{SO}_{4}{ }^{2-}$ de 200 a $500 \mathrm{~nm}(\mathrm{~A})$ e 300 a $450 \mathrm{~nm}(\mathrm{~B})$. 
- $\left[\mathrm{SO}_{4}{ }^{2-}\right]=0,20 \mathrm{M}$

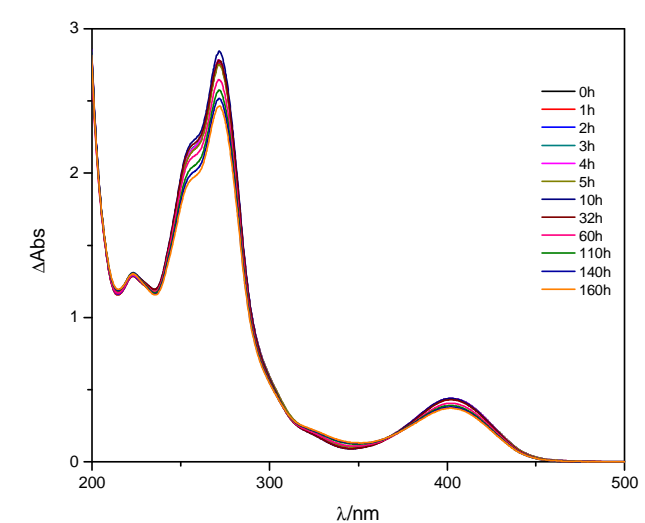

(A)

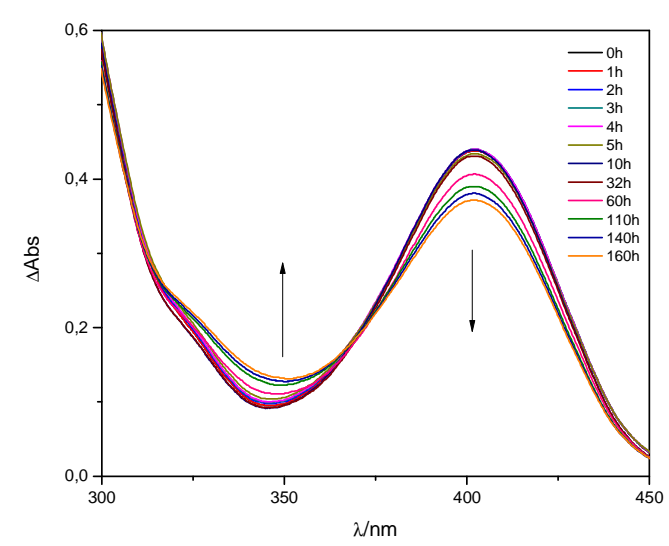

(B)

Figura 10d. Espectro de absorção de QTX em solução aquosa na presença de $0,20 \mathrm{M}$ de $\mathrm{SO}_{4}{ }^{2-}$ de 200 a $500 \mathrm{~nm}(\mathrm{~A})$ e 300 a $450 \mathrm{~nm}(\mathrm{~B})$.

Comparando-se os espectros de absorção acima é possível notar que a presença de íons sulfato causou uma inibição no processo de degradação de QTX em solução aquosa. A porcentagem de degradação das reações determinada pela absorção da banda em 402 nm é apresentada na Figura 11. A presença de íons sulfato causa uma diminuição de até $75 \%$ na degradação de QTX na solução aquosa. O comportamento da degradação de QTX na presença de íons sulfato pode ser explicado pelo fato que estes íons podem reagir com $0^{\circ} \mathrm{OH}$ em solução, resultando na formação de $\mathrm{SO}_{4}{ }^{\circ}$, que é uma espécie menos reativa que o radical hidroxila, diminuindo a degradação de QTX, Equação 27. 36,37

$$
\begin{array}{rr}
\mathrm{NaSO}_{4} \rightarrow 2 \mathrm{Na}^{+}+\mathrm{SO}_{4}^{2-} & \text { Equação } 26 \\
\mathrm{SO}_{4}^{2-}+{ }^{\bullet} \mathrm{OH} \rightarrow \mathrm{SO}_{4}^{\cdot-}+\mathrm{OH}^{-} & \text {Equação } 27
\end{array}
$$




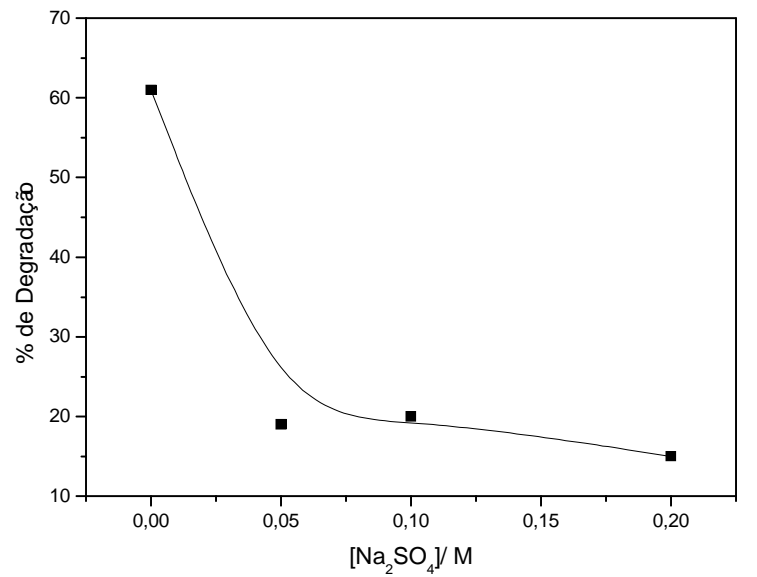

Figura 11. Porcentagem de degradação da solução de QTX em função da concentração de íons sulfato.

\subsubsection{Efeito da adição de sorbato de potássio}

A investigação do efeito de adição de sorbato de potássio na degradação de QTX em água foi realizada na finalidade de verificar se a degradação é afetada pela supressão do estado triplete do corante, uma vez que este dieno é usado como supressor de estado triplete. ${ }^{38}$ As concentrações utilizadas neste experimento foram escolhidas de acordo com o experimento de supressão que será discutido em 4.1.6.3. Todas as irradiações foram feitas como descrito em 3.3.1. As fotodegradações de QTX em água estão mostradas na Figura 12A e a porcentagem de degradação destes sistemas em 12B, respectivamente. 


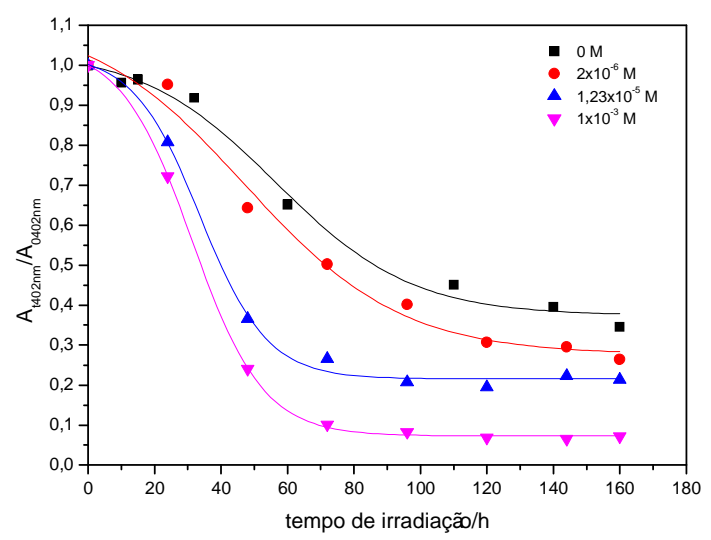

(A)

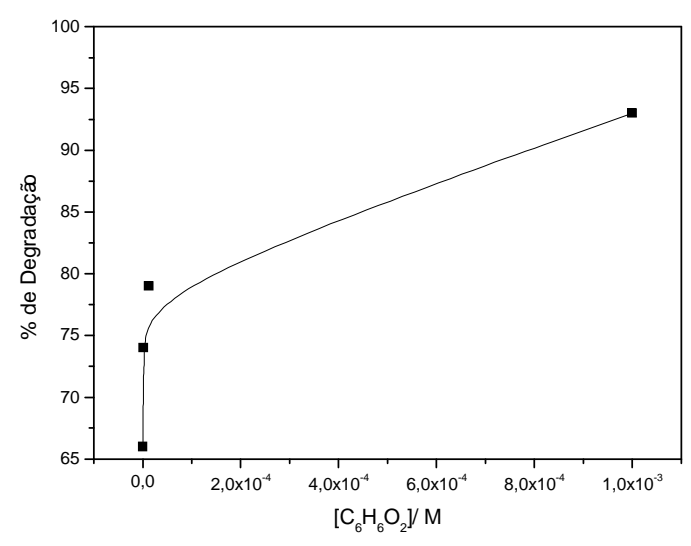

(B)

Figura 12. (A) Variação da absorção de QTX na presença de sorbato de potássio na região de 402 nm em função do tempo de irradiação (B) porcentagem de degradação deste sistema.

A banda em $402 \mathrm{~nm}$, atribuída ao corante, foi diminuindo conforme o tempo de irradiação. A presença de sorbato de potássio dobrou a degradação do corante em 48 horas de irradiação quando se adicionou $1,23 \times 10^{-5} \mathrm{M}$ de sorbato na solução. A concentração de corante residual depois de 160 h de irradiação na ausência de sorbato foi de $3,87 \times 10^{-5} \mathrm{M}$, enquanto que na maior concentração utilizada de sorbato, $1 \times 10^{-3} \mathrm{M}$, foi de $0,81 \times 10^{-5} \mathrm{M}$, atingindo uma porcentagem de degradação de $95 \%$.

Para uma visualização do efeito de sorbato de potássio na solução de QTX em água, a Figura 13 ilustra o corante em tempo zero e as soluções irradiadas até 160h na ausência e na presença de dieno. É possível notar que conforme a concentração de sorbato adicionado nas soluções ocorre uma perda de coloração. Isto confirma a degradação de QTX em água. 


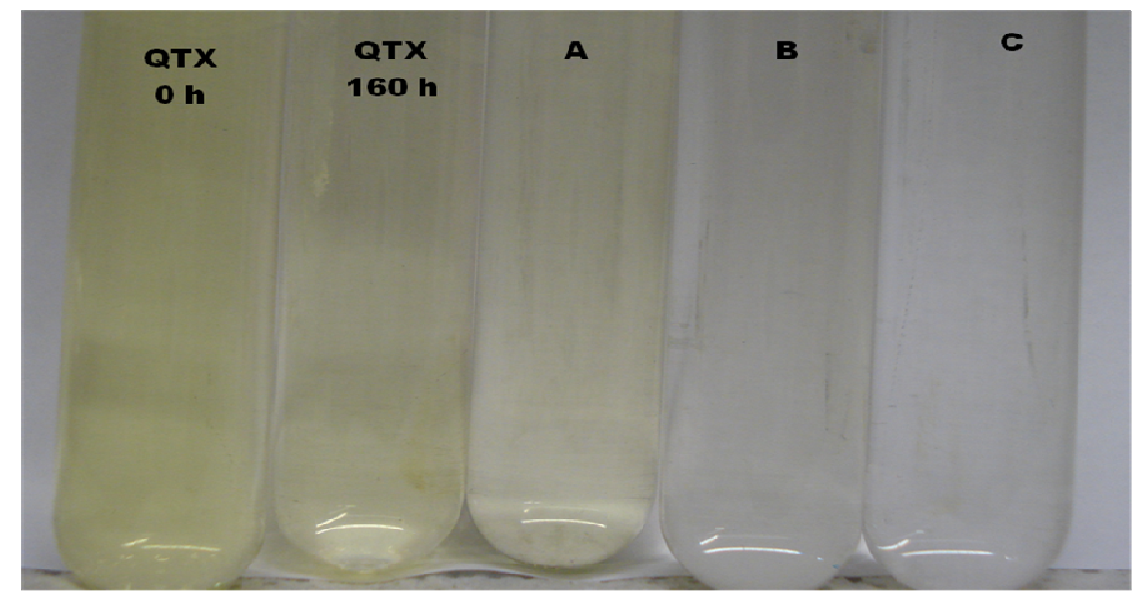

Figura 13. Soluções de $1 \times 10^{-4} \mathrm{M}$ de QTX em água sem irradiação $(0 \mathrm{~h})$ e irradiada por $160 \mathrm{~h}(160 \mathrm{~h})$ na ausência de sorbato de potássio. $O$ tubo $(A)$, (B) e (C) representam a solução de $1 \times 10^{-4} \mathrm{M}$ de QTX na presença de $2 \times 10^{-6}, 1,23 \times 10^{-5}$ e $1 \times 10^{-3} \mathrm{M}$ de sorbato, respectivamente, irradiadas por $160 \mathrm{~h}$.

\subsubsection{Determinação dos fotoprodutos gerados na fotólise de QTX em solução aquosa}

Uma das principais dificuldades de estudar o mecanismo de degradação de corantes é a eficiência extremamente baixa de alguns processos. Durante o processo de degradação os fotoprodutos podem gerar reações secundárias, dificultando o isolamento e a identificação de fotoprodutos primários. ${ }^{20}$

Os fototoprodutos da degradação de QTX $\left(1,0 \times 10^{-4} \mathrm{M}\right)$ em solução aquosa gerados pela irradiação de lâmpadas fluorescentes por 160 horas a $25 \pm 1^{\complement} \mathrm{C}$ foram investigados pela técnica de cromatografia líquida de alta eficiência acoplado ao detector de arranjo de fotodiodos ajustado em $254 \mathrm{~nm}$ e ao detector de massa por spray de elétrons. Para realizar o experimento foi necessário fazer uma préconcentração da amostra usando o equipamento de evaporação à vácuo com centrifugação, uma vez que a concentração de QTX utilizada foi muito baixa. 
Os cromatogramas de QTX não irradiada em água estão mostrados nas Figuras 14 e 15. A Figura 16 mostra o espectro de massa QTX antes da irradiação. O pico em m/z 372,2 corresponde à massa de QTX sem a presença de cloro.

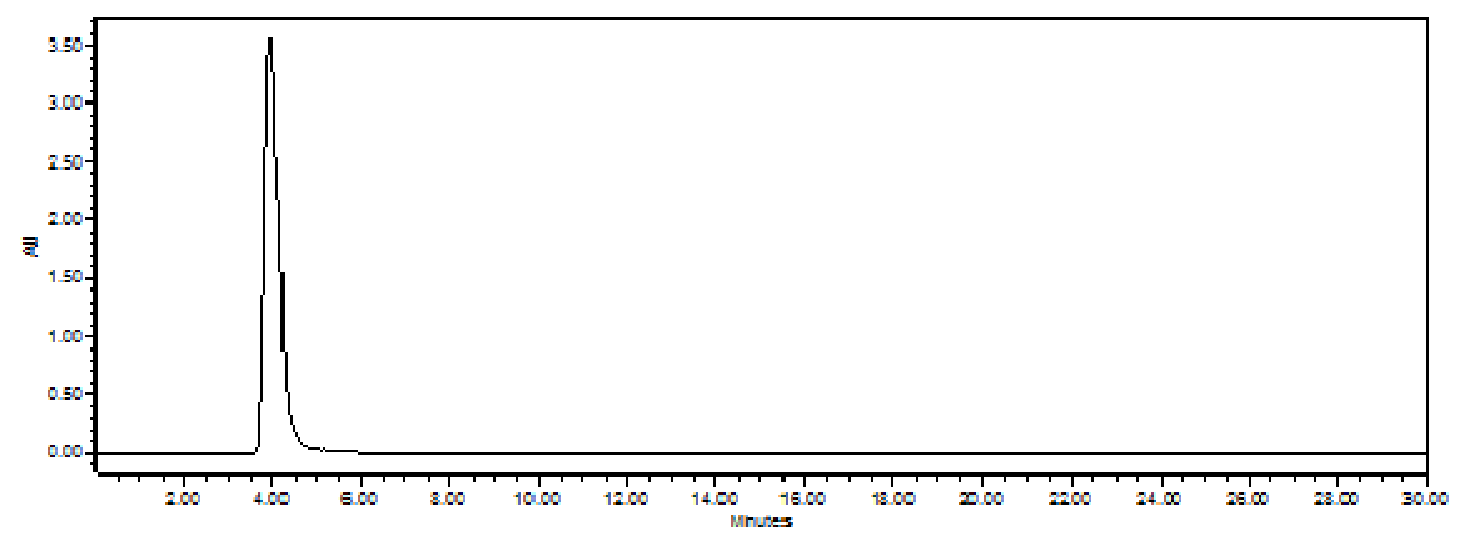

Figura 14. Cromatograma de absorção em 254 nm de QTX não irradiada. Detector UV-Vis.

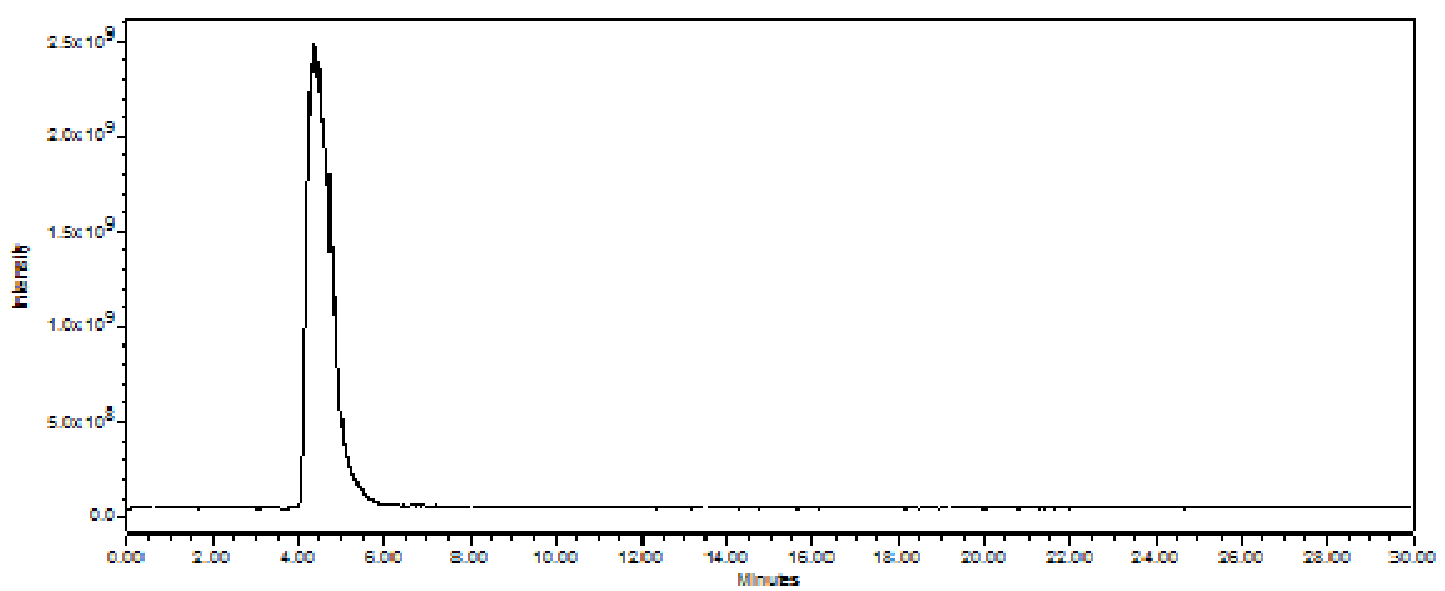

Figura 15. Cromatograma de QTX não irradiada. Detector de massas. 


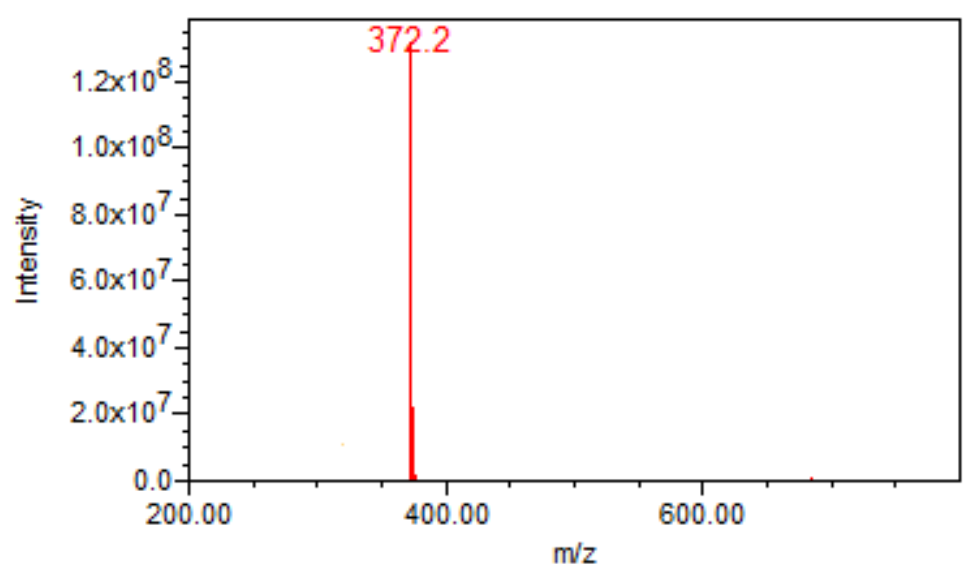

Figura 16. Fragmentograma de QTX não-irradiada.

O cromatograma de QTX irradiada por 160 horas em água a $25^{\circ} \pm 1^{\circ} \mathrm{C}$ obtido com o detector de UV está apresentado na Figura 17. O cromatograma possui mais picos em relação ao cromatograma de QTX não irradiada apresentado na Figura 14, que apresentava apenas um pico com tempo de retenção em torno de 4 min. Os outros picos correspondem aos fotoprodutos gerados a partir da fotólise.

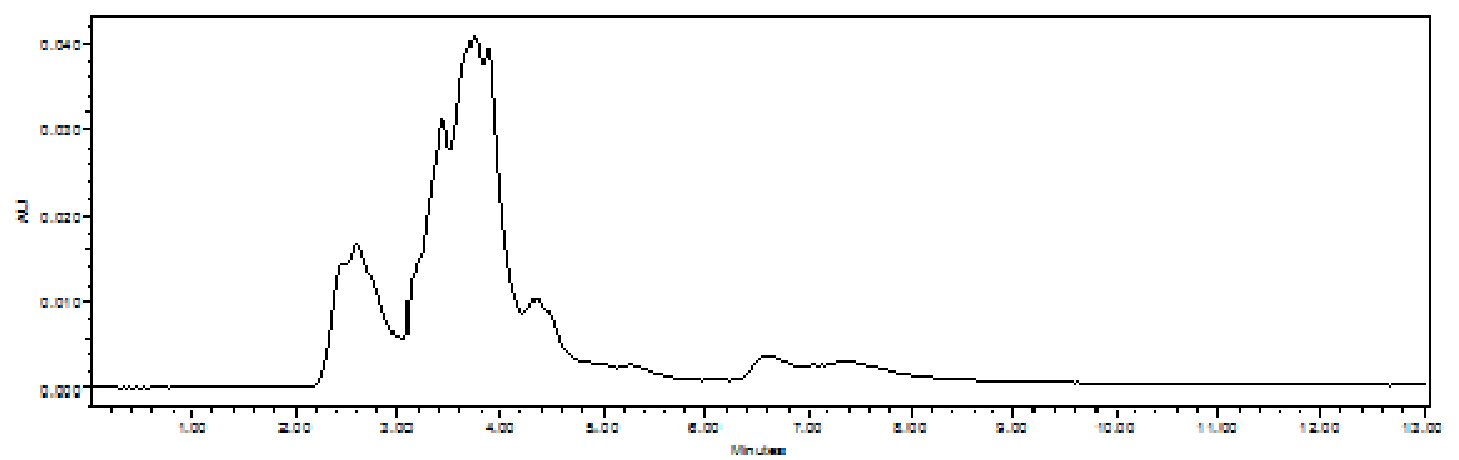

Figura 17. Cromatograma de absorção em $254 \mathrm{~nm}$ de QTX irradiada por $160 \mathrm{~h}$.

A Figura 18 mostra o cromatograma de QTX irradiada e a partir dessa Figura são apresentados os fragmentogramas de fotoprodutos formados a partir da QXT. 
Os fotoprodutos foram identificados conforme as fragmentações obtidas pelo detector de massa.
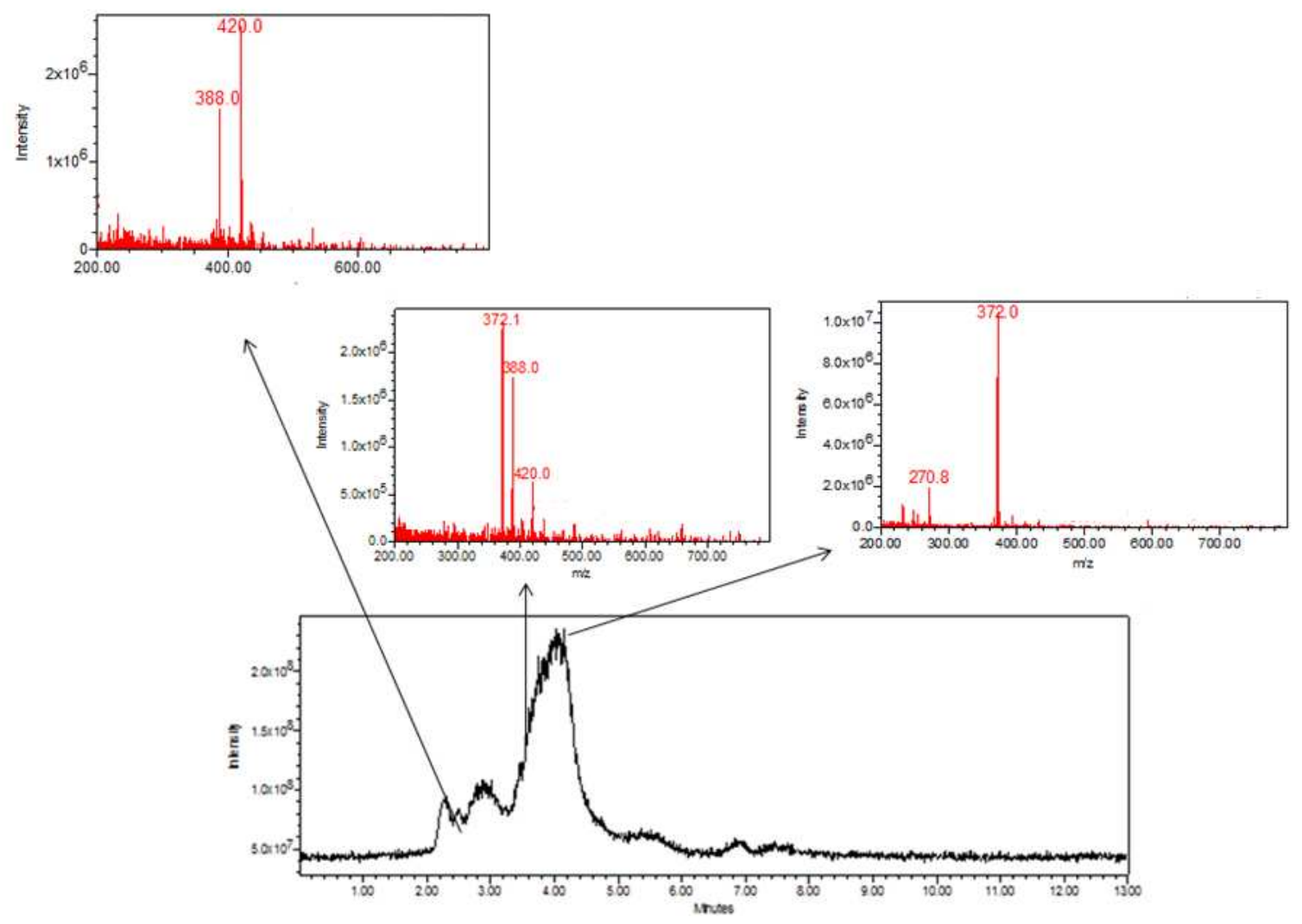

Figura 18. Cromatograma de massa e espectro de fragmentação de QTX irradiada por $160 \mathrm{~h}$.

A Figura 18 mostra os espectros de massa de QTX irradiada e nesses espectros é possível notar picos de massa em m/z 388, 420 e 270 referentes à fotoprodudos da QTX, sendo que m/z 372 corresponde à massa de QTX não degradada.

O pico de m/z 388 pode ser atribuído à formação de dupla ligação de enxofre com o oxigênio, Esquema 9. Kinart e colaboradores propuseram a formação dessa espécie quando o corante é eletrooxidado ou eletrorreduzido em solução aquosa. ${ }^{30}$ 
<smiles>Cc1c(OCC(O)C[N+](C)(C)C)cc2c(=O)c3ccccc3sc2c1C</smiles>

$(\mathrm{m} / \mathrm{z} 372)$<smiles>Cc1c(OCC(O)C[N+](C)(C)C)cc2c(c1C)S(=O)c1ccccc1C2=O</smiles>

$(\mathrm{m} / \mathrm{z} 388)$

Esquema 9. Fotoprodutos da fotólise de QTX de m/z 388 detectados por CLAE-EM.

O pico em m/z 420 sugere a incorporação de três oxigênios na molécula de QTX. O Esquema 10 ilustra os possíveis fotoprodutos de QTX com $\mathrm{m} / \mathrm{z} 420$. Nesse esquema sugere-se a formação de um grupo sulfóxido e a introdução de uma hidroxila no grupo metila na posição 3 ou na posição 4, representado pelos números 1 e 2, respectivamente. Alternativamente, pode-se propor a formação de um grupo sulfona e a introdução de duas hidroxilas nas duas metilas, nas posições 3 e 4, representado no esquema pelo número 3. 
<smiles>Cc1c(OCC(O)C[N+](C)(C)C)cc2c(=O)c3ccccc3sc2c1COCCO</smiles><smiles>Cc1c(CO)c(OCC(O)C[N+](C)(C)C)cc2c1S(=O)(=O)c1ccccc1C2=O</smiles>

Esquema 10. Fotoprodutos da fotólise de QTX de m/z 420 detectados por CLAE-EM.

$\mathrm{Na}$ literatura, a preparação de sulfóxidos e sulfonas é processada pela oxidação dos sulfetos correspondentes. As sulfonas são normalmente fácies de preparar. O permanganato de potássio ou peróxido de hidrogênio em excesso converte quantitativamente os sulfóxidos em sulfonas. ${ }^{39}$

Kissinger e colaboradores investigaram a eletroquímica da tioxantona e observaram a formação de um sulfóxido quando se aplica um de potencial de 1,67 V e de uma sulfona no potencial de 2,08 V. O Esquema 11 mostra esta reação. ${ }^{40}$ 
<smiles>O=c1c2ccccc2sc2ccccc12</smiles><smiles>O=C1c2ccccc2S(=O)(=O)c2ccccc21</smiles><smiles>O=C1c2ccccc2S(=O)(=O)c2ccccc21</smiles>

Esquema 11. Tioxantona oxidada eletroquimicamente. ${ }^{40}$

O pico em $\mathrm{m} / \mathrm{z}$ de 270 sugere que o oxigênio singlete reage com a QTX abstraindo o hidrogênio do carbono ligado a hidroxila, e eliminando o grupo amino. Rearranjos da molécula de QTX levam ao produto de $\mathrm{m} / \mathrm{z}$ de 270 . O Esquema 12 mostra este mecanismo de quebra da QTX irradiada. 
<smiles>Cc1c(OCC(O)C[N+](C)(C)CO[18O])cc2c(=O)c3ccccc3sc2c1C</smiles><smiles>Cc1c(OC[C@@H](O)C[N+]([O-])([O-])O)cc2c(=O)c3ccccc3sc2c1C</smiles>

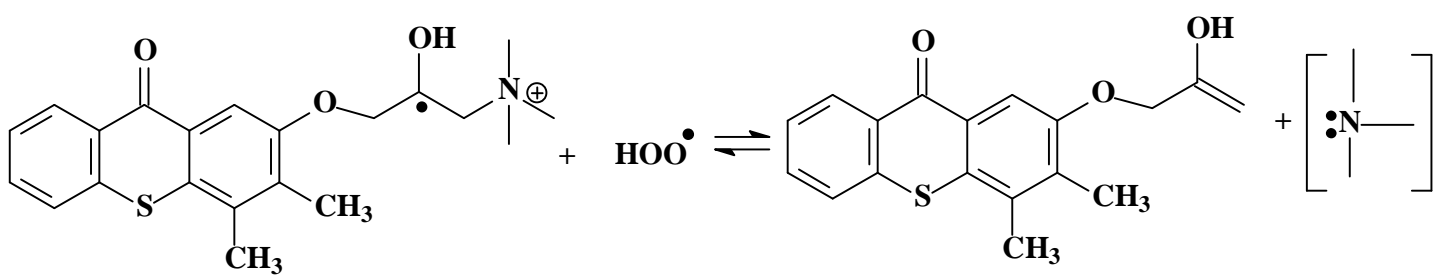<smiles>C=C(O)COc1cc2c(=O)c3ccccc3sc2c(C)c1C</smiles><smiles>Cc1c(OCC2(O)CCCCC2)cc2c(=O)c3ccccc3sc2c1C</smiles><smiles></smiles><smiles>Cc1c(OCC(O)(CO)CO)cc2c(=O)c3ccccc3sc2c1C</smiles><smiles>COc1cc2c(=O)c3ccccc3sc2c(C)c1C</smiles>

Esquema 12. Formação de fotoproduto da fotólise de QTX de m/z 270 obtida por CLAE-EM. 


\subsubsection{Estudo das reações elementares de QTX em água}

Os estudos das reações elementares individuais que ocorrem no sistema reacional ajudam no entendimento das reações envolvidas no processo global de degradação de QTX. A técnica de fotólise por pulso de laser é uma excelente ferramenta que permite a caracterização de intermediários de tempo vida na ordem de $\mu$ s e reações de supressão de espécies transientes. Essa técnica envolve a medida dos estados excitados da amostra após a sua geração por um pulso intenso de radiação. A monitoração das mudanças é feita usando a absorção da amostra.

O comportamento espectral e os tempos de vida de triplete da QTX em água e em diferentes solventes foram investigados por esta técnica. Posteriormente, foram determinadas as constantes de supressão de triplete deste corante em presença de hidroquinona e sorbato de potássio. Determinou-se o tempo de vida de singlete de QTX em água e a constante de supressão do estado singlete de QTX por sulfato de cobre. Os estudos de supressão foram importantes para determinar as concentrações que devem ser utilizadas nos experimentos da fotodegradação de QTX em água e na presença de poliestirenossulfonato de sódio.

\subsubsection{Estudo dos transientes da QTX em água}

O transiente de QTX em água foi investigado em três atmosferas: em atmosfera de nitrogênio, em oxigênio e em ar. A concentração de QTX em água foi

de $2,5 \times 10^{-4} \mathrm{M}$, que corresponde a uma absorção de 0,3 na região de excitação do laser (355nm). 
A Figura 19 ilustra o espectro de absorção do triplete de QTX em solução aquosa e em atmosfera de nitrogênio e seu decaimento monitorado em 600 nm.

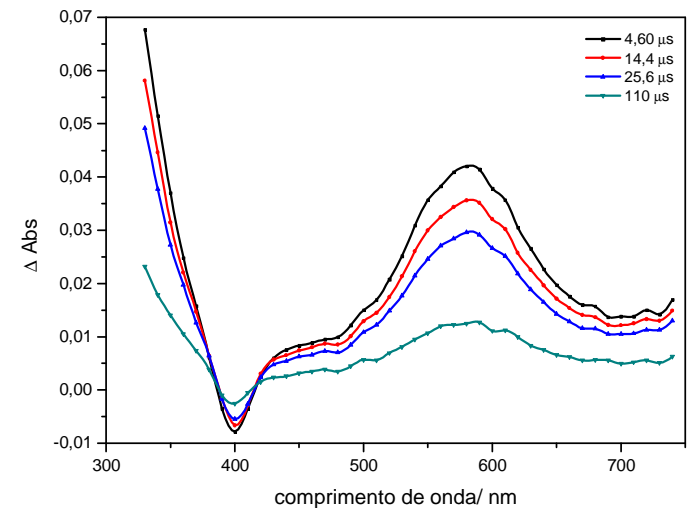

(A)

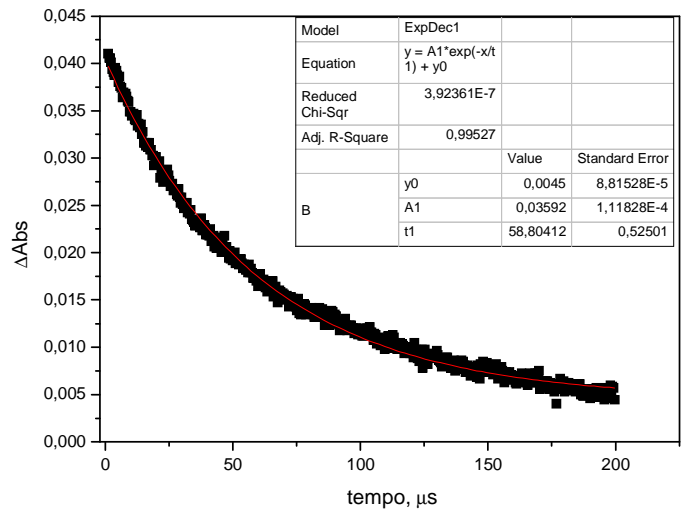

(B)

Figura 19. Espectro de absorção do transiente de QTX em água em atmosfera de $N_{2}(A)$. Decaimento de absorção do transiente de QTX em água, em $600 \mathrm{~nm}$ em atmosfera de $\mathrm{N}_{2}$ (B).

O espectro de absorção do transiente de QTX em água apresenta uma intensa absorção na região de 500 a 700 nm com o máximo em 580 nm. Essa região corresponde à absorção triplete-triplete. A região de $300 \mathrm{~nm}$ corresponde a superposição da absorção triplete-triplete. ${ }^{41}$ Em presença de doadores de hidrogênio é observada a banda na região de 400 a 450 nm, que é associada à formação de radical cetila formado por abstração de um átomo de hidrogênio. ${ }^{42} \mathrm{~A}$ absorção negativa a $400 \mathrm{~nm}$ se deve ao descoramento do estado fundamental de QTX $\left(\lambda_{\text {máx }}=402 \mathrm{~nm}\right)$.

Todos os decaimentos na região de $600 \mathrm{~nm}$ foram de primeira ordem. $O$ tempo de vida do estado triplete de QTX em água foi de $58 \mu$ s em atmosfera inerte e de 1,6 $\mu$ s em ar. Quando as soluções foram saturadas com oxigênio foram obtidos 
espectros de absorção similares, embora o tempo de vida de triplete foi reduzido para $0,5 \mu$ s devido a que o oxigênio é um eficiente supressor de estado triplete.

\subsubsection{Estudo dos transientes da QTX em diferentes solventes}

Os espectros de absorção de transientes da QTX foram obtidos em diferentes solventes para verificar a influência da polaridade, como mostrado nas Figuras $20 \mathrm{~A}$ a 25A. Os respectivos decaimentos do triplete de QTX foram medidos em $600 \mathrm{~nm}$ e são mostrados nas Figuras 20B a 25B. Em todos os experimentos a concentração de QTX correspondeu uma absorbância em torno de 0,3 em 355 nm, na finalidade de evitar o processo de auto supressão. As soluções foram desoxigenadas por no máximo $30 \mathrm{~min}$. Os solventes utilizados foram de grau HPLC e usados sem purificação prévia.

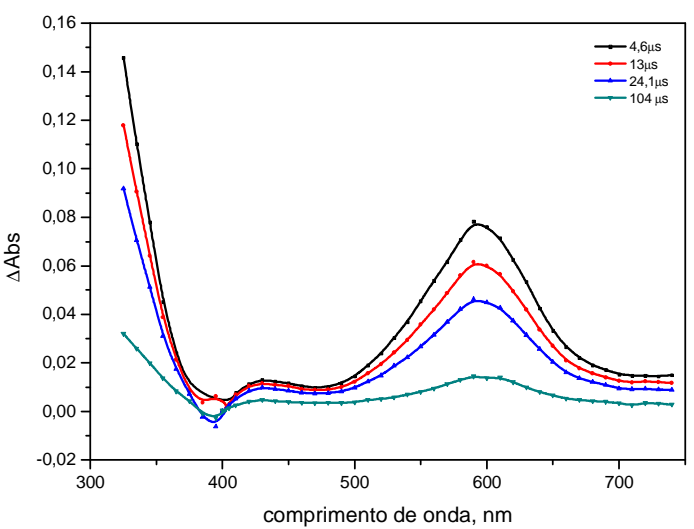

(A)

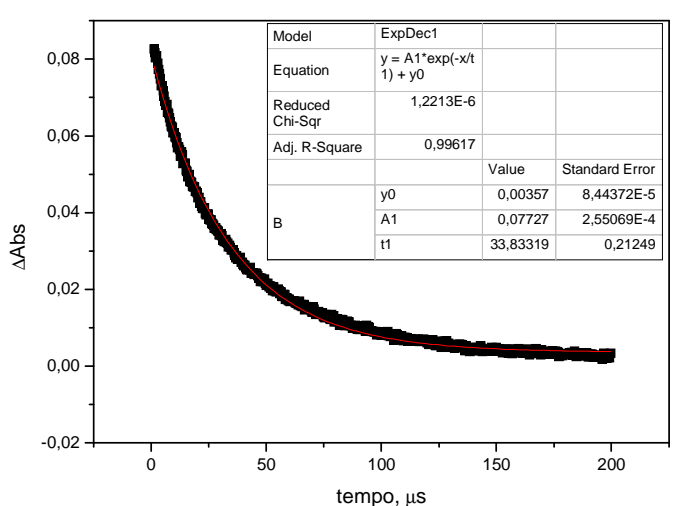

(B)

Figura 20. Espectro de absorção do transiente de QTX em etanol em atmosfera de $N_{2}(A)$. Decaimento de absorção do transiente de QTX em etanol, em $600 \mathrm{~nm}$ em atmosfera de $\mathrm{N}_{2}$ (B). 


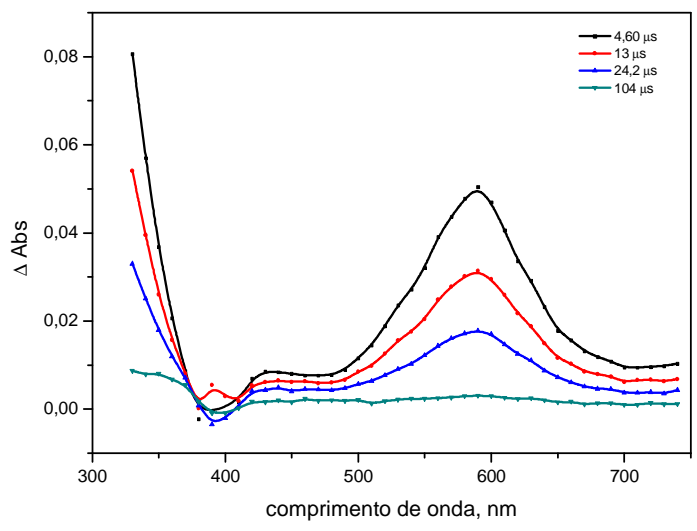

(A)

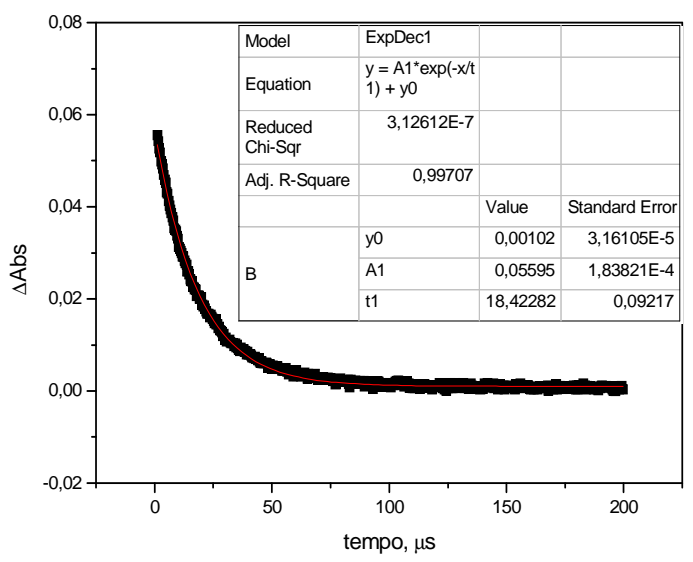

(B)

Figura 21. Espectro de absorção do transiente de QTX em metanol em atmosfera de $N_{2}(A)$. Decaimento de absorção do transiente de QTX em metanol, em $600 \mathrm{~nm}$ em atmosfera de $\mathrm{N}_{2}(B)$.

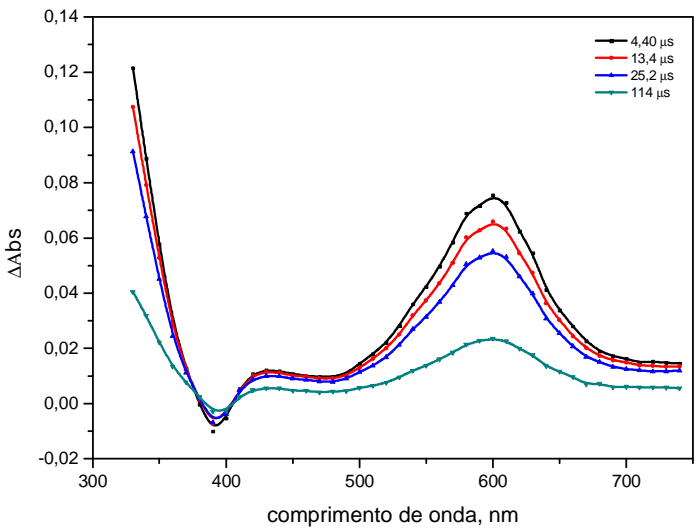

(A)

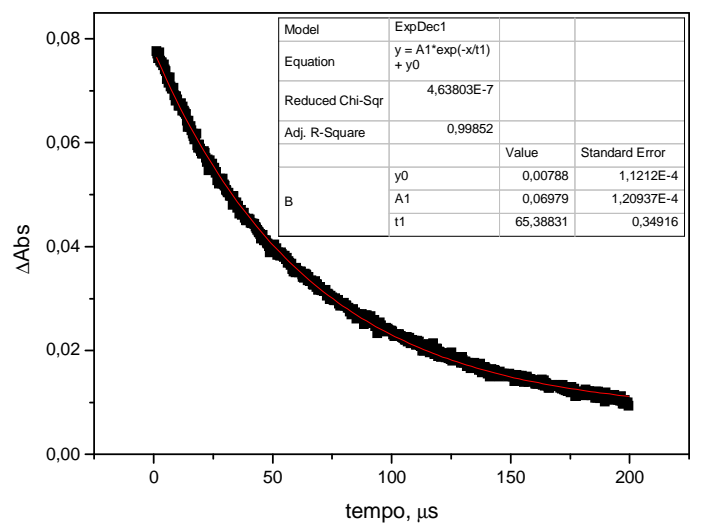

(B)

Figura 22. Espectro de absorção do transiente de QTX em 1-propanol em atmosfera de $\mathrm{N}_{2}(A)$. Decaimento de absorção do transiente de QTX em 1-propanol, em $600 \mathrm{~nm}$ em atmosfera de $\mathrm{N}_{2}$ (B). 


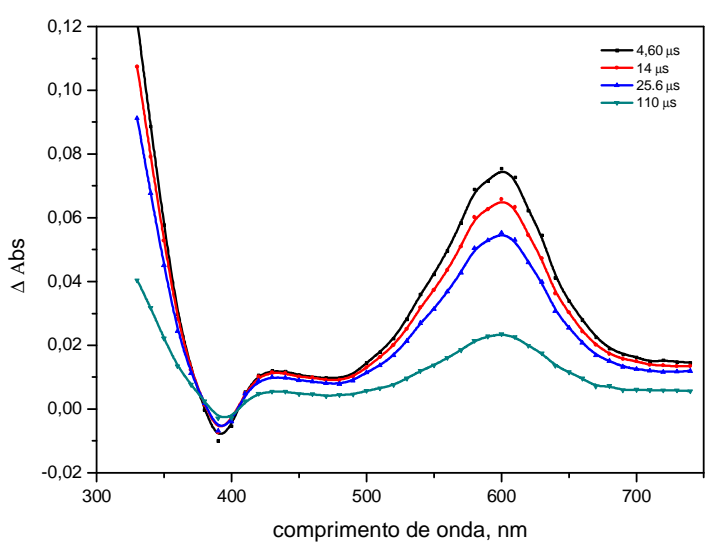

(A)

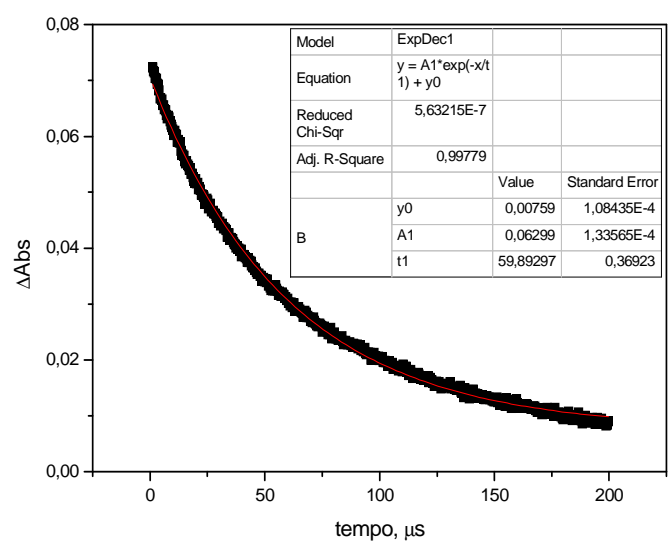

(B)

Figura 23. Espectro de absorção do transiente de QTX em 2-propanol em atmosfera de $N_{2}(A)$. Decaimento de absorção do transiente de QTX em 2-propanol, em $600 \mathrm{~nm}$ em atmosfera de $\mathrm{N}_{2}$ (B).

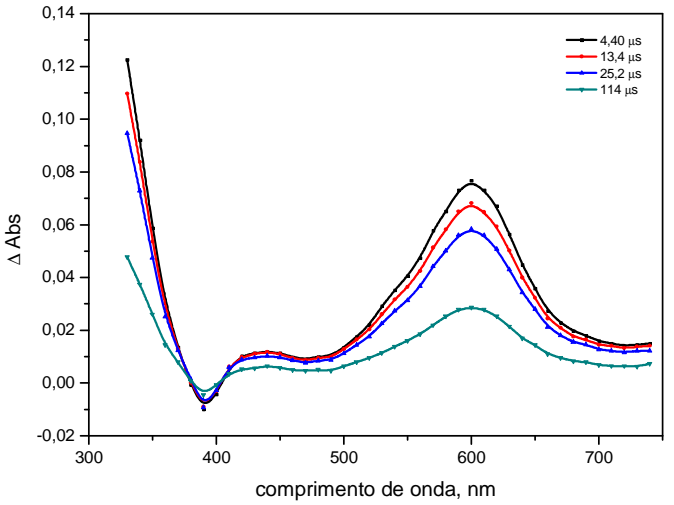

(A)

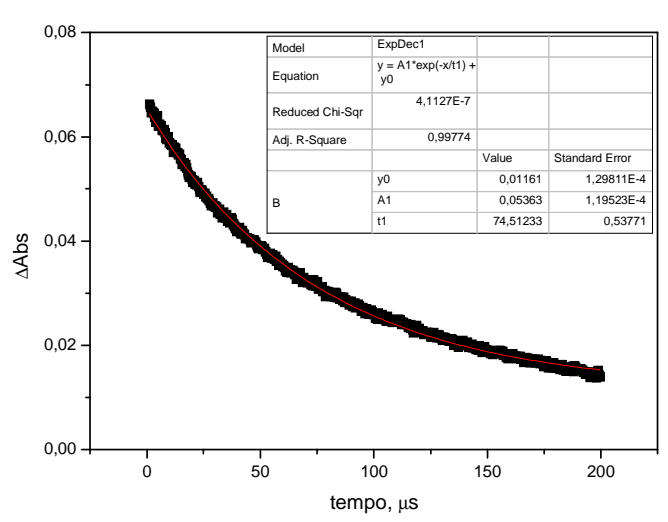

(B)

Figura 24. Espectro de absorção do transiente de QTX em 1-butanol em atmosfera de $N_{2}(A)$. Decaimento de absorção do transiente de QTX em 1-butanol, em $600 \mathrm{~nm}$ em atmosfera de $\mathrm{N}_{2}(\mathrm{~B})$. 


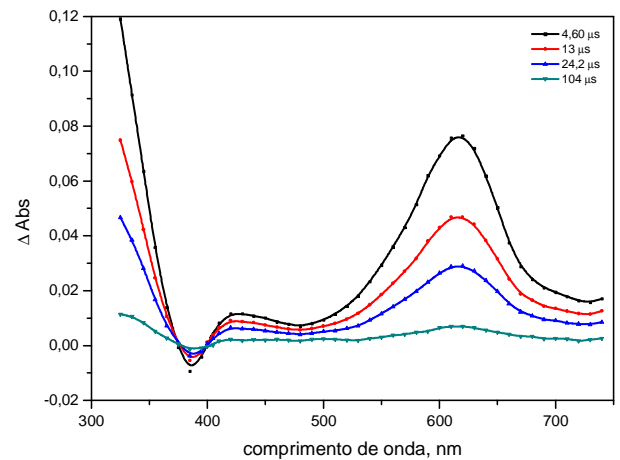

(A)

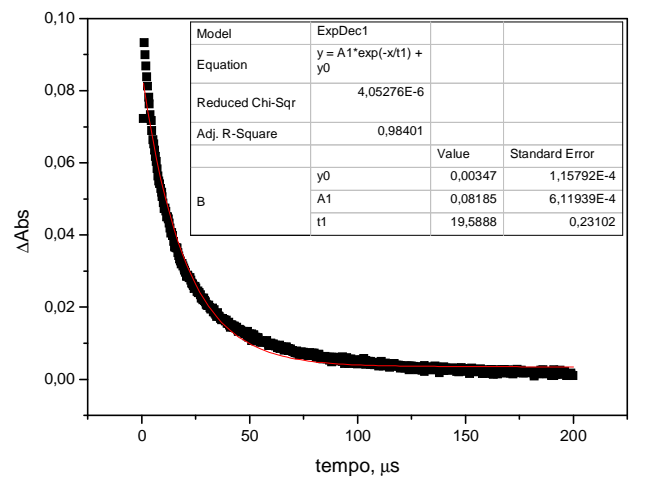

(B)

Figura 25. Espectro de absorção do transiente de QTX em acetonitrila em atmosfera de $N_{2}(A)$. Decaimento de absorção do transiente de QTX em acetonitrila, em $600 \mathrm{~nm}$ em atmosfera de $\mathrm{N}_{2}$ (B).

A partir dos espectros de absorção dos transientes de QTX em diferentes solventes é possível notar que houve um deslocamento de acordo com o solvente.

Em geral, os solventes podem ser classificados em polares a apolares. Os solventes polares podem ser divididos em solventes polares hidroxílicos e polares não hidroxílicos, como exemplo dos polares não hidroxílicos pode-se citar a acetonitrila, e no caso dos polares hidroxílicos os alcoóis. ${ }^{43}$

Nos espectros de absorção mostrados acima ocorreu um deslocamento para o azul no máximo absorção do triplete quando se compara um solvente polar não hidroxílico como a acetonitrila $\left(\lambda_{\text {máx. }}=615 \mathrm{~nm}\right)$ com um solvente polar hidroxílico como etanol $\left(\lambda_{\text {máx. }}=594 \mathrm{~nm}\right)$.

O estado triplete de xantonas é relativamente longo (cerca de ms) em solventes polares, onde tem um caráter $\pi \pi^{*}$, porém não é muito reativo na abstração do átomo de hidrogênio. O espectro de absorção triplete-triplete de xantonas mostra um deslocamento para o azul quando a polaridade do solvente aumenta, por exemplo, o máximo de absorção em isopropanol é $616 \mathrm{~nm}$ e em água $580 \mathrm{~nm}$. O 
deslocamento para o azul devido ao efeito de solvente pode ser relacionado com a variação do momento de dipolo, que ocorre durante a transição. ${ }^{25}$

Outra forma de verificar a influência de diferentes solventes no espectro de absorção dos transientes de QTX é a relação do máximo da absorção do triplete na região de $600 \mathrm{~nm}$ em função parâmetro de polaridade do solvente $\left(E_{T} 30\right),{ }^{44}$ como mostrado na Figura 26.

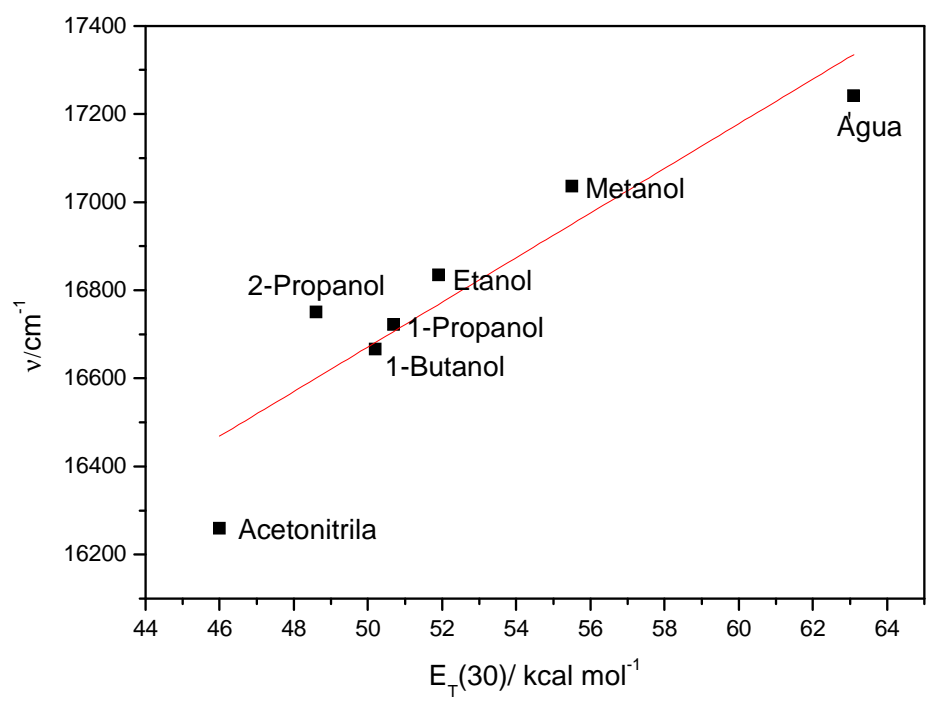

Figura 26. Máximos de absorção na região de $600 \mathrm{~nm}$ em função do parâmetro de polaridade $\mathrm{E}_{\mathrm{T}}(30)$.

O tempo de vida de triplete da QTX em diferentes solventes também mudou para diferentes solventes como mostrado na Tabela 5. Comportamento semelhante foi mostrado para a tioxantona, onde o tempo de vida de triplete em $600 \mathrm{~nm}$ para a acetonitrila foi menor do que em alcoóis. Isso foi atribuído ao caráter $\pi \pi^{\star}$ nesses solventes. ${ }^{41}$ 
Tabela 5- Absorção máxima de estado triplete e o tempo de vida de QTX em diferentes solventes.

\begin{tabular}{ccc}
\hline solventes & $\lambda_{\text {máx }} / \mathbf{n m}$ & $\tau / \boldsymbol{\mu s}$ \\
\hline água & 580 & 58 \\
metanol & 587 & 18 \\
etanol & 594 & 33 \\
1-propanol & 598 & 65 \\
2-propanol & 597 & 60 \\
1-butanol & 600 & 74 \\
acetonitrila & 615 & 19 \\
\hline
\end{tabular}

\subsubsection{Determinação das constantes de supressão de QTX em água}

O sistema de fotólise por pulso de laser permite a obtenção das constantes de velocidade para o decaimento de triplete.

Os experimentos de supressão foram realizados usando hidroquinona e sorbato de potássio excitando as amostras em $355 \mathrm{~nm}$. O efeito desses supressores na solução de QTX $\left(2,5 \times 10^{-4} \mathrm{M}\right)$ em água foi determinado pela comparação dos tempos de decaimento a $600 \mathrm{~nm}$ (correspondente à região de absorção T-T). As soluções foram desoxigenadas por 30 min para o estudo de atmosfera inerte. $\mathrm{O}$ gráfico de Stern-Volmer da supressão de QTX em água usando hidroquinona e sorbato de potássio estão mostrados nas Figuras 27A e 27B, respectivamente. 


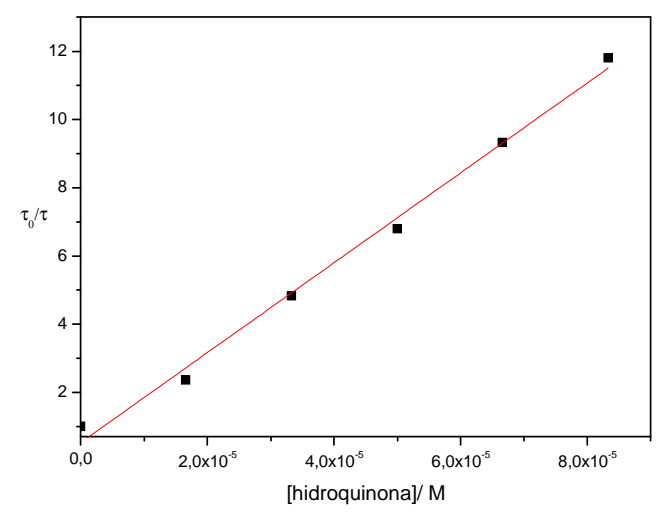

(A)

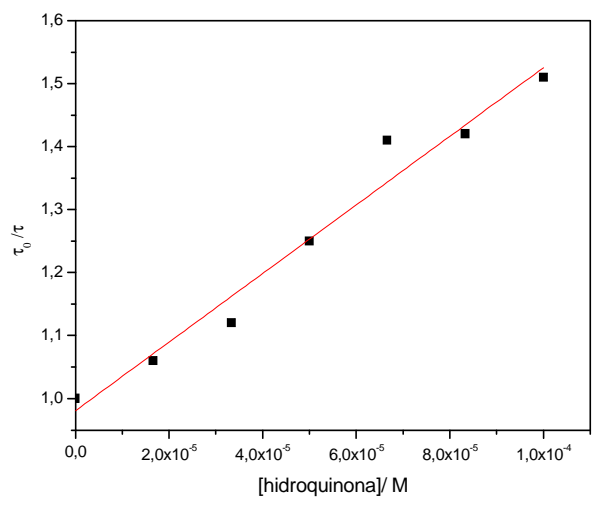

(B)

Figura 27. Gráficos de Stern-Volmer para a supressão de QTX em água por hidroquinona em atmosfera de nitrogênio, (B) em ar.

O valor obtido para a supressão de QTX por hidroquinona em atmosfera de nitrogênio foi de $\mathrm{k}_{\mathrm{q}}=2,93 \times 10^{9} \mathrm{M}^{-1} \mathrm{~s}^{-1}$ e de $\mathrm{k}_{\mathrm{q}}=3,60 \times 10^{9} \mathrm{M}^{-1} \mathrm{~s}^{-1}$ em ar.

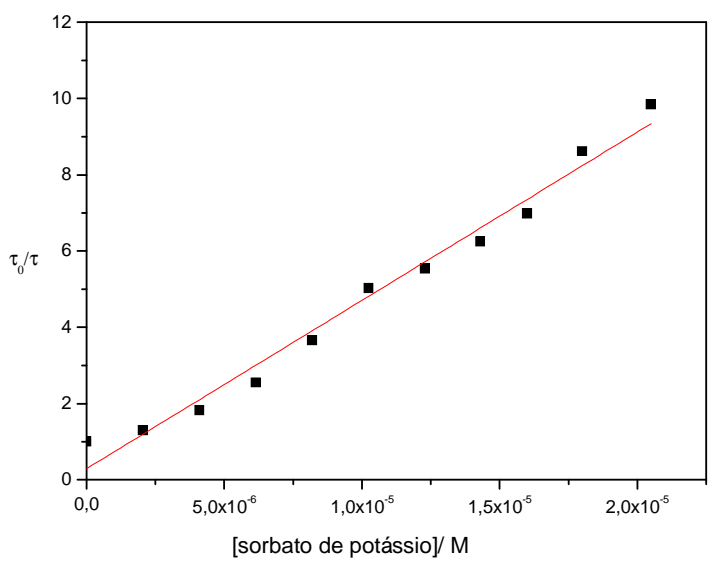

Figura 28. Gráfico de Stern-Volmer da supressão de QTX em água por sorbato de potássio.

O sorbato de potássio possui alta solubilidade em água e foi usado para suprimir o estado triplete da QTX. Foi observada uma eficiente supressão na adição deste dieno (Figura 28). O gráfico de supressão mostrou uma correlação linear e a 
inclinação indicou uma constate de supressão, $\mathrm{k}_{\mathrm{q}}$ de $7,6 \times 10^{9} \mathrm{M}^{-1} \mathrm{~s}^{-1}$. Tanto com o sorbato ou como com hidroquinona como supressores de QTX em água, as constantes de supressão obtidas ficaram próximas à constante difusional.

\subsubsection{Determinação das constantes de supressão de QTX por $\mathrm{CuSO}_{4}$}

A emissão de fluorescência de QTX $\left(1,0 \times 10^{-4} \mathrm{M}\right)$ em água na presença de sulfato de cobre foi investigada no intervalo de 0 a $0,1 \mathrm{M}$. O corante foi excitado em $404 \mathrm{~nm}$ e a emissão medida em $478 \mathrm{~nm}$. A Figura 29A mostra o espectro de fluorescência deste sistema e a Figura 29B mostra o gráfico de Stern-Volmer obtido a partir da Equação 5.

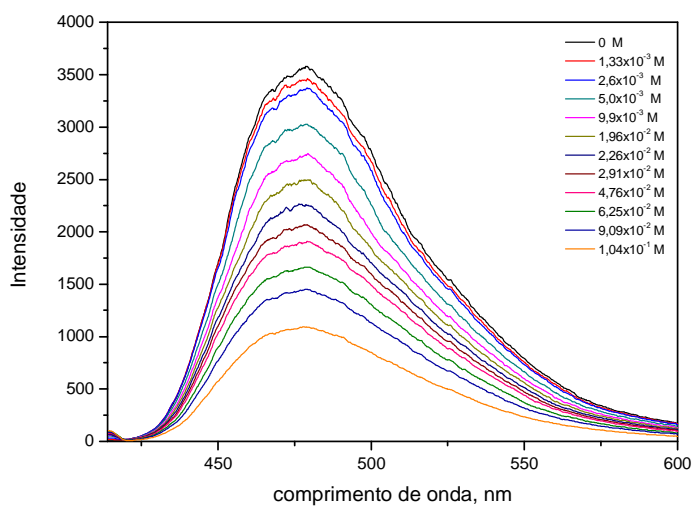

(A)

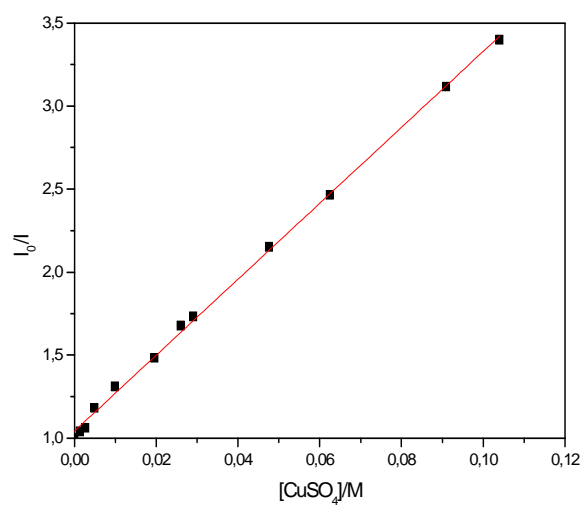

(B)

Figura 29. (A) Espectro de fluorescência de QTX na presença de diferentes concentrações de $\mathrm{CuSO}_{4}$. (B) Gráfico de Stern-Volmer da supressão de QTX em água por sulfato de cobre.

A constante de Stern-Volmer, Ksv, obtida a partir da inclinação da Figura 29B foi de $22 \mathrm{M}^{-1}$. O tempo de vida do estado excitado singlete de QTX foi determinado na ausência de supressor no equipamento Easy Life e o valor obtido foi de 10,4 ns, 
sendo que na literatura o valor encontrado foi de 14,4 ns. ${ }^{45}$ Assim, a constante de supressão de estado singlete de QTX é de $2,2 \times 10^{9} \mathrm{M}^{-1} \mathrm{~s}^{-1}$.

\subsubsection{Mecanismo proposto de fotodegradação de QTX em água}

Com a combinação dos resultados obtidos da fotodegradação de QTX em água e das reações elementares é proposto um mecanismo de fotodegradação de QTX em solução aquosa.

O corante absorve luz, é excitado para o estado singlete e por cruzamento intersistema passa para o estado excitado triplete (Equação 28). No estado triplete, pode reagir com uma molécula de oxigênio triplete $\left({ }^{3} \mathrm{O}_{2}\right)$ produzindo a molécula de oxigênio singlete $\left({ }^{1} \mathrm{O}_{2}\right)$ e desativando o corante para o estado fundamental, (Equação 29).

$$
\begin{array}{ll}
D \stackrel{h v}{\longrightarrow} D \stackrel{C I S}{\longrightarrow}{ }^{3} D & \text { Equação } 28 \\
{ }^{3} \mathrm{D}+{ }^{3} \mathrm{O}_{2} \rightarrow D+{ }^{1} \mathrm{O}_{2} & \text { Equação } 29
\end{array}
$$

O corante no estado triplete pode ainda reagir com o oxigênio, formando um novo radical $\left({ }^{\bullet} \mathrm{O}-\mathrm{D}-\mathrm{OO}^{\bullet}\right)$. Este radical pode abstrair hidrogênio de uma molécula de QTX (QTX-H), formando a espécie ${ }^{\bullet} \mathrm{O}-\mathrm{D}-\mathrm{OOH}$ e posteriormente 0 radical hidroperoxila $\left(\mathrm{HO}_{2}^{\circ}\right)$. Essa etapa é mostrada no Esquema 13. O hidrogênio abstraído da molécula de QTX poderia ser de uma das metilas ligadas ao anel benzênico ou o hidrogênio do carbono ligado ao grupo hidroxila, como mostrado no Esquema 10. A 
abstração de hidrogênio do solvente é pouco provável, uma vez que, a água não é um bom doador de hidrogênio.<smiles>Cc1c(OCC(O)CN(C)C)cc2c(=O)c3ccccc3sc2c1C</smiles><smiles>Cc1c(OCC(O)C[N+](C)(C)C)cc2c(c1C)Sc1ccccc1C2(O)O[13C](C)(C)C[18OH]</smiles>

Esquema 13. Mecanismo de desativação do estado excitado de QTX por oxigênio.

Apesar de ser comum para as cetonas aromáticas a reação ocorrer no estado triplete, quando se utilizou o supressor de triplete, sorbato de potássio, observou-se que a porcentagem de fotodegradação de QTX em água aumentou. Isso sugere que estado triplete da QTX não seja a principal via de degradação deste corante.

No estado singlete de QTX, o corante excitado pode também abstrair o hidrogênio de outra molécula de corante, formando o radical cetila $\left(\mathrm{DH}^{\circ}\right)$. $\mathrm{Na}$ presença de oxigênio, pode formar o radical hidroperoxila $\left(\mathrm{HO}_{2}{ }^{\circ}\right)$, responsável pela degradação. O Esquema 14 mostra esta etapa. 
<smiles>Cc1c(OCC(O)C[N+]2(C)CC2)cc2c(=O)c3ccccc3sc2c1C</smiles><smiles>Cc1c(OCC(O)C[N+](C)(C)C)cc2c(=O)c3ccccc3sc2c1C</smiles><smiles>[TeH][TeH]</smiles><smiles>Cc1c(OCC(O)C[N+]2(C)CC2)cc2c(c1C)Sc1ccccc1C2O</smiles><smiles>Cc1c(OCC(O)C[N+]2(C)CC2)cc2c(=O)c3ccccc3sc2c1C</smiles>

Esquema 14. Mecanismo de formação de radical hidroperoxila.

$\mathrm{Na}$ presença de íon hidróxido, o corante excitado pode formar o radical hidroxila e o corante semi reduzido, Equação 24. O corante semi reduzido pode reagir com o oxigênio formando o radical superóxido, responsável pela aceleração do processo de degradação em meio básico, Equação $25 .^{19,21}$

$$
{ }^{1} \mathrm{D}+H \mathrm{O}^{-} \rightarrow \mathrm{D}^{\bullet}+H \mathrm{O}^{\bullet}
$$

Equação 24

$$
D^{-\bullet}+O_{2} \rightarrow D+^{-\bullet} O_{2}
$$


$\mathrm{Na}$ presença de íons sulfato, o processo de degradação é inibido considerando que o radical hidroxila reage com os íons sulfato produzindo espécies menos reativas: ${ }^{36,37}$

$$
\mathrm{SO}_{4}^{2-}+{ }^{\bullet} \mathrm{OH} \rightarrow \mathrm{SO}_{4}^{\bullet-}+\mathrm{OH}^{-}
$$

O Esquema 15 mostra todas as etapas do mecanismo de fotodegradação de QTX em água.

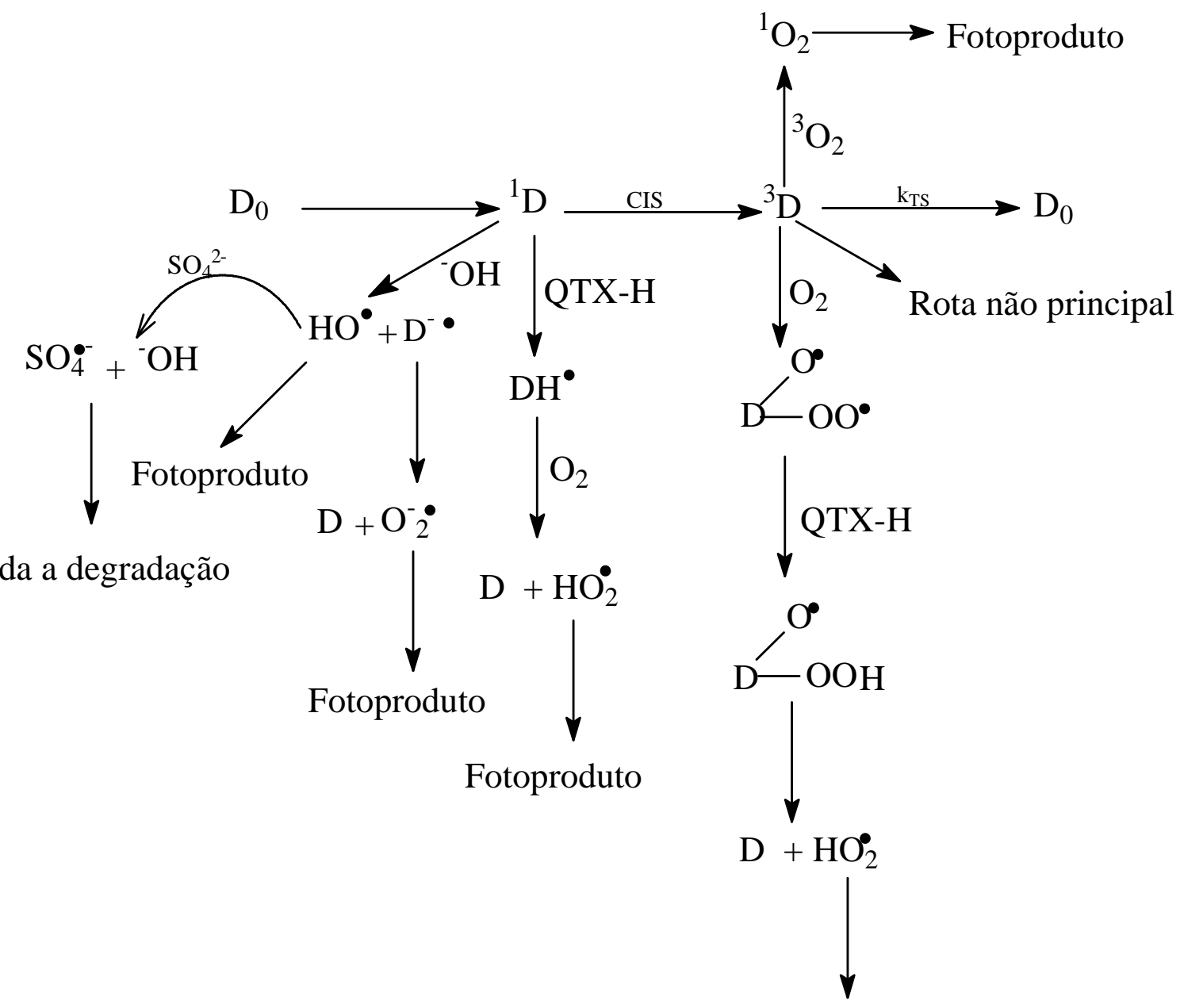

Fotoproduto

Esquema 15. Mecanismo proposto da fotodegradação de QTX em solução aquosa. 


\subsection{Fotodegradação de poliestirenossulfonato de sódio em água}

A fotodegradação de poliestirenossulfonato de sódio em água foi estudada com o objetivo de investigar se a irradiação incidente seria capaz de iniciar o processo de fotodegradação do polímero sozinho. A irradiação foi realizada como descrito em 3.3.1. A concentração de PSS foi mantida constante em $1,0 \mathrm{gL}^{-1}$. Foi monitorada a degradação deste polímero em atmosfera de oxigênio e em ar. O efeito salino foi estudo através da adição de sulfato de sódio, cloreto de sódio e sulfato de cobre e em diferentes $\mathrm{pHs}$. $\mathrm{O}$ ajuste do $\mathrm{pH}$ da solução foi realizado com a metodologia descrita em 4.1.2.

Para avaliar esses sistemas foram usadas as técnicas de espectroscopia de absorção UV-Vis, viscosidade e a cromatografia por exclusão de tamanho. A espectroscopia de absorção UV-Vis monitora mudanças causadas na região de 310 a $350 \mathrm{~nm}$ que pode ser atribuída à formação de fotoprodutos como dienos e carbonilas provenientes da degradação do polímero. ${ }^{46}$

Em todos os sistemas estudados não foram observadas mudanças tanto nos espectros de absorção UV-Vis quanto na distribuição da massa molecular em função do tempo de irradiação. Apesar do poliestirenossulfonato de sódio apresentar uma pequena absorção $(0,08)$ na região acima de $300 \mathrm{~nm}$ (região de emissão de lâmpadas fluorescentes), essa absorção não foi suficiente para iniciar o processo de fotodegradação do polímero. Alguns resultados dos sistemas investigados estão ilustrados na Tabela 6. A massa molar ponderal média de PSS determinada em tempo zero foi em média 84.900. Esses resultados indicam que a fotodegradação de poliestirenossulfonato de sódio não ocorre na ausência de QTX. 
Tabela 6- Massa molar ponderal média de poliestirenossulfonato de sódio em diferentes sistemas em função do tempo de irradiação.

\begin{tabular}{ccc}
\hline sistemas & tempo de irradiação/h & $\overline{M w}$ \\
\hline atmosfera ar & 160 & 83200 \\
atmosfera $\mathrm{O}_{2}$ & 96 & 82500 \\
$\mathrm{pH} 3,5$ & 115 & 81800 \\
$\mathrm{pH} 7,0$ & 115 & 83500 \\
$\mathrm{pH} 9,0$ & 115 & 82300 \\
$\mathrm{CuSO}_{4}\left(1 \times 10^{-2} \mathrm{M}\right)$ & 96 & 81900 \\
\hline
\end{tabular}




\subsection{Fotodegradação de poliestirenossulfonato de sódio com QTX}

Os resultados da fotodegradação do poliestirenossulfonato de sódio sensibilizado por QTX foram divididos em três partes. A primeira parte dos resultados abordará a quebra de cadeia polimérica monitorada pelas técnicas de viscosimetria e cromatografia de exclusão de tamanho. A segunda parte apresenta o estudo de QTX na presença de poliestirenossulfonato de sódio a partir dos espectros de absorção UV-Vis. Por fim, a técnica de fotólise por pulso de laser foi utilizada para investigar as reações elementares envolvidas no sistema fotoquímico PSS/QTX.

\subsubsection{Primeira parte: degradação do PSS na solução de QTX}

\subsubsection{Variação da concentração de QTX}

Investigou-se a fotodegradação de poliestirenossulfonato de sódio em diferentes concentrações de QTX através das técnicas de viscosimetria e cromatografia de exclusão de tamanho, na finalidade de encontrar a concentração ótima de fotossensibilizador para iniciação mais efetiva do processo de degradação. As soluções de polímero contendo $1,0 \mathrm{gL}^{-1}$ em diferentes concentrações de QTX foram irradiadas por lâmpadas fluorescentes até 160 h a $25 \pm 1^{\circ} \mathrm{C}$.

As medidas viscosimétricas são normalmente feitas pela comparação entre o tempo de escoamento $t$, requerido para um dado volume de solução polimérica 
passe através de um capilar, e o tempo requerido para o escoamento de solvente puro $t_{0}$. Todas as viscosidades de solução de poliestirenossulfonato de sódio foram determinadas usando um viscosímetro Viscoboy 2. O capilar utilizado foi de tipo Ubbelohde, $\mathrm{K}=9,521 \times 10^{-9} \mathrm{~m}^{2} / \mathrm{s}^{2}$ a $30 \pm 1^{\circ} \mathrm{C}$.

O processo de degradação polimérica pode ser estudado pelo número médio de quebras na cadeia do polímero $(S)$. Esse número médio de quebras na cadeia está relacionado com a massa molar numérica média do polímero não degradado $\left(\overline{M n}_{0}\right)$ e a com a massa molar numérica média do polímero irradiado em tempo $t$ $\left(\bar{M}_{t}\right)$, como mostra a Equação abaixo:

$$
S=\frac{w}{\overline{M n}_{0}}\left(\frac{\overline{M n}_{0}}{\overline{M n}_{t}}-1\right)
$$

onde, $w$ é a massa em gramas do polímero irradiado. Na quebra aleatória de cadeia, o valor de $S$ está também relacionado com $0 \quad \bar{M} v_{0}$ (massa molar viscosimétrica média para polímeros não degradados), e com $\bar{M} v_{t}$ (massa molar viscosimétrica média para polímeros irradiados no tempo $t$ ), segundo a Equação $31:^{13,47}:$

$$
S=\left(2 W / \bar{M}_{0}\right) x\left\{\left(\bar{M}_{0} / \bar{M}_{t}\right)\right\}-1
$$

A massa molar viscosimétrica média é dada pela Equação de Mark- Houwink: 
onde, [ $\eta$ é a viscosidade intrínseca e $K$ e $\alpha$ são constantes da Equação de MarkHouwink. Portanto, o número médio de quebra de cadeia (S) pode ser determinado a partir das medidas viscosimétricas de acordo com a Equação 33. As viscosidades intrínsecas do polímero antes e após a irradiação são $[\eta]_{0}$ e $[\eta]_{t}$, respectivamente ${ }^{18}$

$$
S=\left([\eta]_{0} /[\eta]_{t}\right)^{1 / \alpha}-1
$$

Equação 33

A constante $\alpha$ está relacionada com a rigidez das cadeias poliméricas. ${ }^{48}$ Geralmente, o intervalo entre $0,5 \geq \alpha \geq 0,8$ é encontrado para conformações de cadeias flexíveis, enquanto que $0,8 \geq \alpha \geq 1,0$ para cadeias rígidas. $\mathrm{O}$ valor de $K$ e $\alpha$ foi calculado para o poliestrenossulfonato de sódio usando a equação de MarkHouwink em conjunto com a equação Pitsyn-Eizner: ${ }^{49}$

$$
\log M_{2}=\left(\frac{1}{1+\alpha_{2}}\right) \log \left(\frac{K_{1}}{K_{2}}\right)+\left(\frac{1+\alpha_{1}}{1+\alpha_{2}}\right) \log M_{1}
$$

Na equação 34, utilizam-se valores de $M_{1}, K_{1}$ e $\alpha_{1}$ de um polímero conhecido, no caso, o poliestireno. $M_{2}, K_{2}$ e $\alpha_{2}$ são referentes ao polímero de interesse (poliestirenossulfonato de sódio).

As constantes ( $\alpha_{2}$ e $K_{2}$ ) para o poliestirenossulfonato de sódio foram determinadas pela correlação dos valores da massa molar ponderal média determinadas por SEC relativos a padrões de poliestirenossulfonato de sódio $\left(\mathrm{M}_{2}\right)$ 
com os correspondentes valores da massa molar ponderal média do poliestireno $\left(M_{1}\right) .{ }^{50}$ Através dos valores de $M_{1}$ e $M_{2}$ construiu-se o gráfico da Figura 30 . Os valores de $K_{1}$ e $\alpha_{1}$ utilizados neste trabalho para o poliestireno monodisperso foram $1,10 \times 10^{-2} \mathrm{~g} \mathrm{~mL}^{-1}$ e 0,725 , respectivamente. ${ }^{50}$

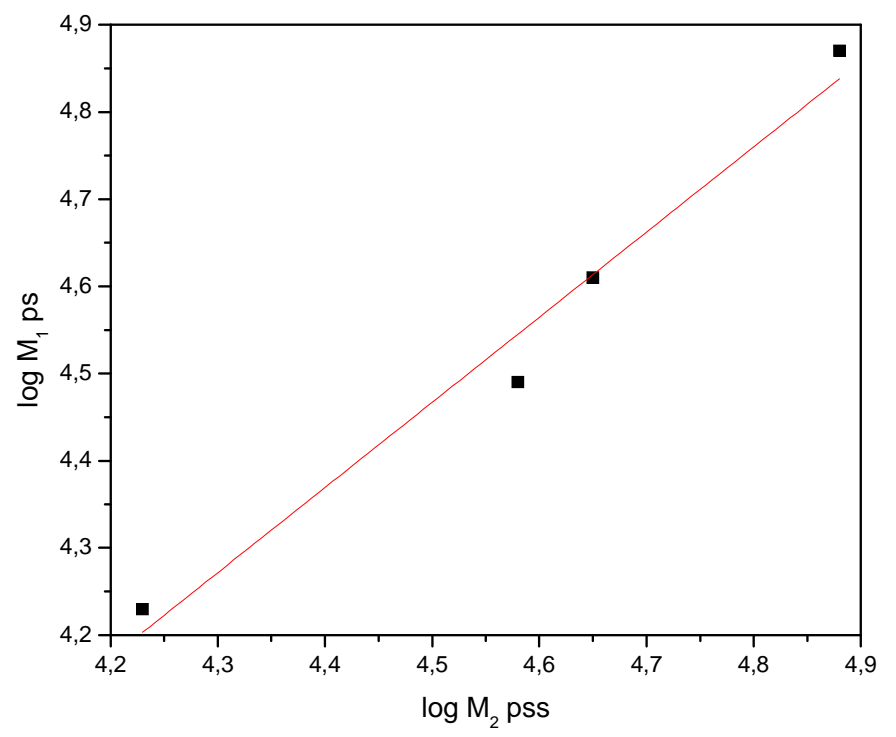

Figura 30. $\log \mathrm{Mw}_{1}$ de poliestireno vs. Log $\mathrm{Mw}_{2}$ de poliestirenossulfonato de sódio.

Os valores de $K_{2}$ e $\alpha_{2}$ obtidos para PSS foram $4,61 \times 10^{-2} \mathrm{~g} \mathrm{~mL}^{-1}$ e 0,76 , respectivamente. $\mathrm{O}$ valor do expoente $\alpha$ está de acordo com a literatura, que indica valores para esta constante no intervalo entre $0,5-1,0 .^{50,51}$

A Figura 31 mostra o número médio de quebra de cadeia (S) em função do tempo de irradiação para diferentes concentrações de QTX. Os valores de S foram calculados através de medidas viscosimétricas, utilizando-se a Equação 33. 


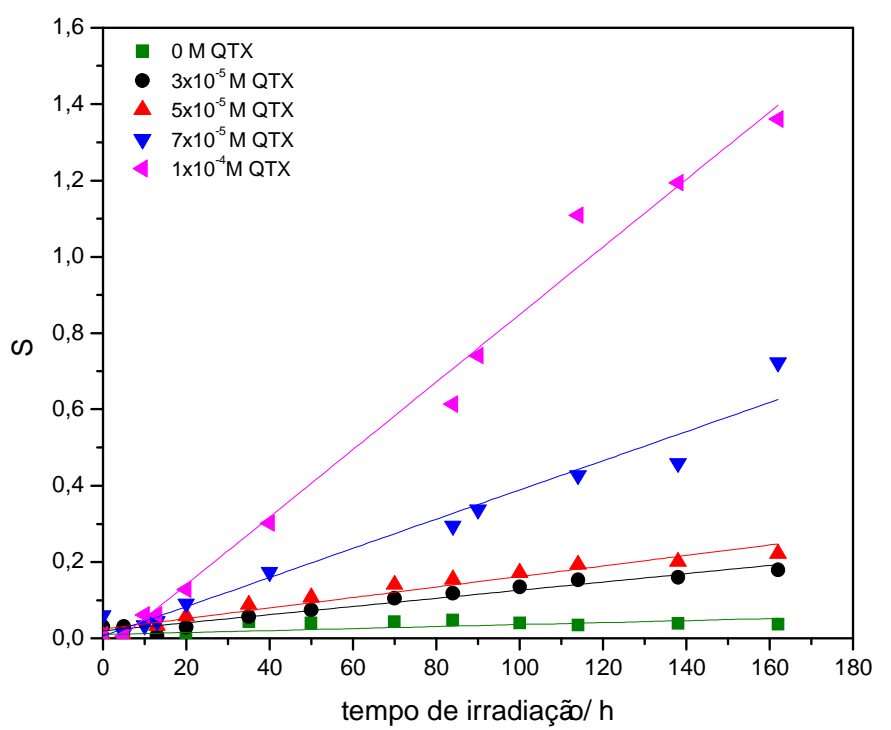

Figura 31. Número médio de quebra de cadeia de PSS $\left(1,0 \mathrm{gL}^{-1}\right)$ em diferentes concentrações de corante em função do tempo de irradiação.

Observa-se que ao longo do processo de fotodegradação ocorre uma diminuição no tamanho da cadeia polimérica, caracterizada pelas medidas viscosimétricas, as quais permitem verificar que o número médio de quebra de cadeia polimérica aumenta com o tempo de irradiação (Figura 31). Das quatro concentrações utilizadas, a maior quebra de cadeia de PSS ocorreu na concentração de $1,0 \times 10^{-4} \mathrm{M}$ de QTX. Isto pode ser explicado considerando que a degradação é mais efetiva devido à maior produção de radicais a partir do fotossensibilizador, o qual é responsável pelo início da degradação através da abstração do átomo de hidrogênio da cadeia polimérica. ${ }^{18}$

A linearidade de (S) em função de tempo nos primeiros estágios de degradação significa uma quebra de cadeia aleatória. A quebra de cadeia tem sido geralmente atribuída à reação de $\beta$-cisão, que resulta da fragmentação da cadeia polimérica com a formação de um grupo carbonila e macrorradical alquila (Equação 
35) ou formação de um grupo aldeído e macrorradical alquila (Equação 36). Ainda pode-se incluir a decomposição do $\mathrm{POOH}$ levando à formação de dupla ligação na cadeia polimérica, onde $\mathrm{R}=\mathrm{H}$ ou $\mathrm{CH}_{3}$ (Equação 37$) .{ }^{18}$<smiles>[R]C(=O)CCCCC([R])CC([R])([O-])CCC</smiles><smiles>CCC[C+]([O-])CCCCCC(=O)CC</smiles><smiles>[R]C(=O)[CH+]C=C([R])[CH+]CCCC([R])CC([R])OO</smiles>

Equação 37

Onu e col. investigaram a fotodegradação de poliamidahidroxiuretana na presença e na ausência de corantes (rodamina B, azul de metileno, eosina, laranja de acridina, riboflavina, na concentração de $\left.1,0 \times 10^{-4} \mathrm{M}\right)$. Verificou-se por viscosidade que houve um aumento na média de quebra de cadeia em função do tempo, principalmente na presença de riboflavina. ${ }^{31}$

Sabe-se que a fotodegradação envolve dois processos: quebra de cadeia e/ ou formação de ligações cruzadas, que podem mudar a massa molar ponderal média $(\overline{M w})$, massa molar numérica média $(\overline{M n})$ e a polidispersividade $(\overline{M w} / \overline{M n})$. As mudanças na massa molar do polímero também foram verificadas através SEC, 
que é uma técnica simples e efetiva para monitorar mudanças na distribuição do peso molecular durante o processo de degradação. ${ }^{18,52}$

David e col. investigaram a fotooxidação e fotólise a vácuo do poliestireno e observaram mudanças na massa molar do polímero por SEC. Com irradiação de 253,7 nm, as ligações cruzadas foram predominante na fotólise no vácuo; enquanto que na presença de oxigênio ocorreram simultaneamente a formações de ligações cruzadas e quebras de cadeia. ${ }^{53}$

A Figura 32 mostra a variação da massa molar numérica média do PSS na presença de QTX com o tempo de irradiação. O coeficiente de velocidade de degradação, k, foi determinado usando a Equação 38, deduzida através de um modelo teórico. ${ }^{54}$

$$
\left(\overline{M n}_{0} / \overline{M n}_{t}\right)-1=k \overline{M n}_{0} t
$$

onde, $\overline{M n}_{0}$ e $\overline{M n}_{t}$ são a massa molar numérica média do PSS antes e depois da irradiação, respectivamente, $k$ é o coeficiente de velocidade de degradação e $t$ é o tempo de irradiação. 


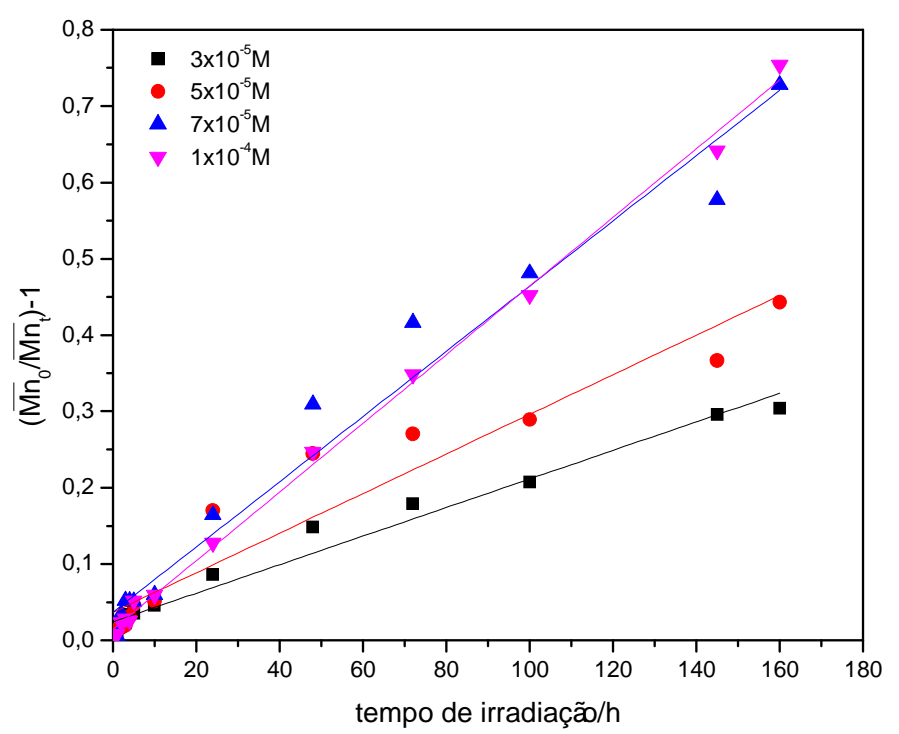

Figura 32. Variação de $\left(\overline{M n}_{0} / \overline{M n}_{t}\right)-1$ em função do tempo de irradiação para PSS $\left(1,0 \mathrm{gL}^{-1}\right)$ em diferentes concentrações de QTX.

Como se pode notar, a variação da massa molar numérica média de PSS na presença de QTX diminui conforme o tempo de irradiação. Segundo Torikai e Hasegawa, a diminuição na massa molar numérica média do cloreto de polivinila (PVC), indicou a quebra de cadeia deste polímero durante o processo de degradação. 55

A concentração de QTX interferiu na velocidade de fotodegradação do polímero estudado. Quanto maior a concentração do corante mais rápida é a cinética de fotodegradação do polímero. A concentração de $1 \times 10^{-4} \mathrm{M}$ praticamente duplicou o coeficiente de velocidade de degradação em relação à menor concentração empregada do corante $\left(3 \times 10^{-5} \mathrm{M}\right)$, que está de acordo com os resultados obtidos por viscosimetria. 
A porcentagem de redução massa molar ponderal média de PSS $\left(1,0 \mathrm{gL}^{-1}\right)$ com diferentes concentrações de QTX foi determinada considerando $\overline{M w}$ inicial e depois de 160 h, (Equação 39).

Porcentagem de redução de $\overline{M w}=\frac{\overline{M w}_{0}-\overline{M w}_{t}}{\overline{M w}_{0}} \times 100 \%$

Equação 39

O coeficiente de velocidade de degradação e a porcentagem de redução de massa molar de PSS em função da concentração de corante na degradação de PSS estão ilustrados na Figura 33. O comportamento de $\overline{M w}$ e $k$ em função da concentração de QTX foram similares.

De acordo com a Tabela 7, é possível observar que a porcentagem de redução da massa molar ponderal média e o coeficiente de velocidade aumentam com o aumento da concentração de QTX. Para as maiores concentrações de QTX, $7 \times 10^{-5} \mathrm{M}$ e $1 \times 10^{-4} \mathrm{M}$, os valores de porcentagem de redução da $\overline{M w}$ e $k$ foram próximos.

Tabela 7- Coeficientes de velocidade de fotodegradação e porcentagem de redução da massa molar de PSS para diferentes concentrações de QTX em função do tempo de irradiação.

[QTX]/M \% de Redução de $\overline{M w} \quad \boldsymbol{k} / \mathbf{h}^{-1}$

\begin{tabular}{ccc}
\hline $3 \times 10^{-5}$ & 38 & $0,53 \times 10^{-7}$ \\
$5 \times 10^{-5}$ & 40 & $0,73 \times 10^{-7}$ \\
$7 \times 10^{-5}$ & 60 & $1,21 \times 10^{-7}$ \\
$1 \times 10^{-4}$ & 61 & $1,27 \times 10^{-7}$ \\
\hline
\end{tabular}




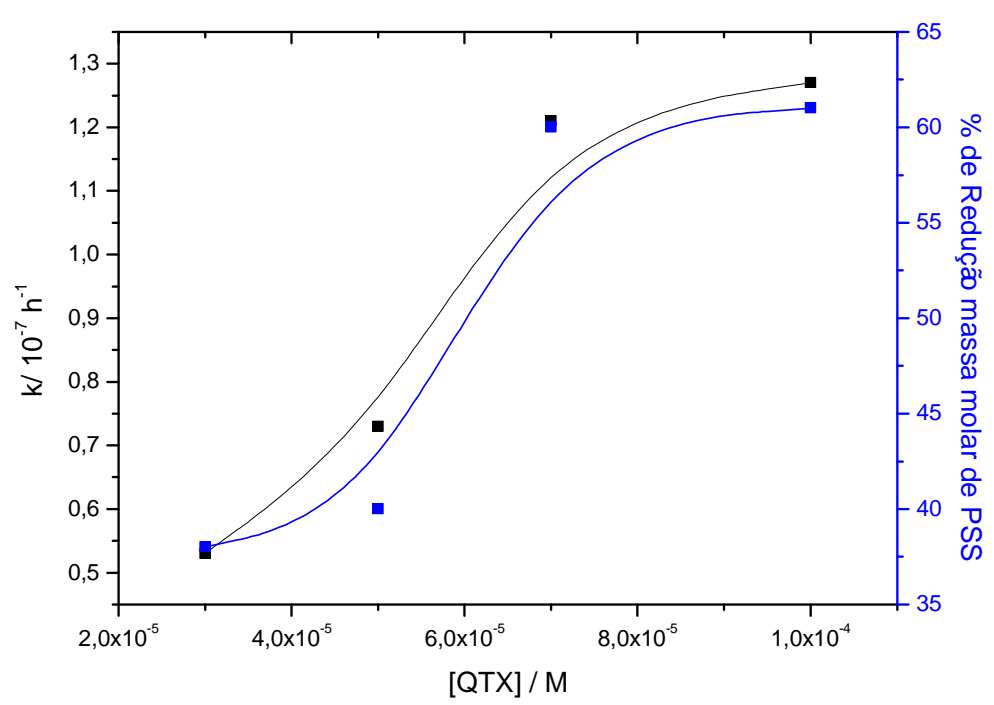

Figura 33. Coeficiente de degradação e porcentagem de redução da massa molar ponderal média de PSS para diferentes concentrações de QTX em função do tempo de irradiação.

Outra forma de investigar o processo de degradação polimérica é em termos do número de eventos de cisão por grama de material $\left(\mathrm{N}_{\mathrm{t}}\right)$, que é expressa pela Equação $40 .^{18}$

$$
N_{t}=\frac{1}{\overline{M n_{t}}}-\frac{1}{\overline{M n}_{0}}
$$

A Figura 34 apresenta uma relação da massa molar ponderal média $\overline{M w}$ com o número de eventos por grama do polímero $\left(\mathrm{N}_{\mathrm{t}}\right)$ em função do tempo de irradiação. É possível observar que conforme ocorre a diminuição de $\overline{M w}$, devido a quebra na cadeia polimérica, o número de eventos por grama do polímero $\left(\mathrm{N}_{\mathrm{t}}\right)$ aumenta em função do tempo de irradiação. 


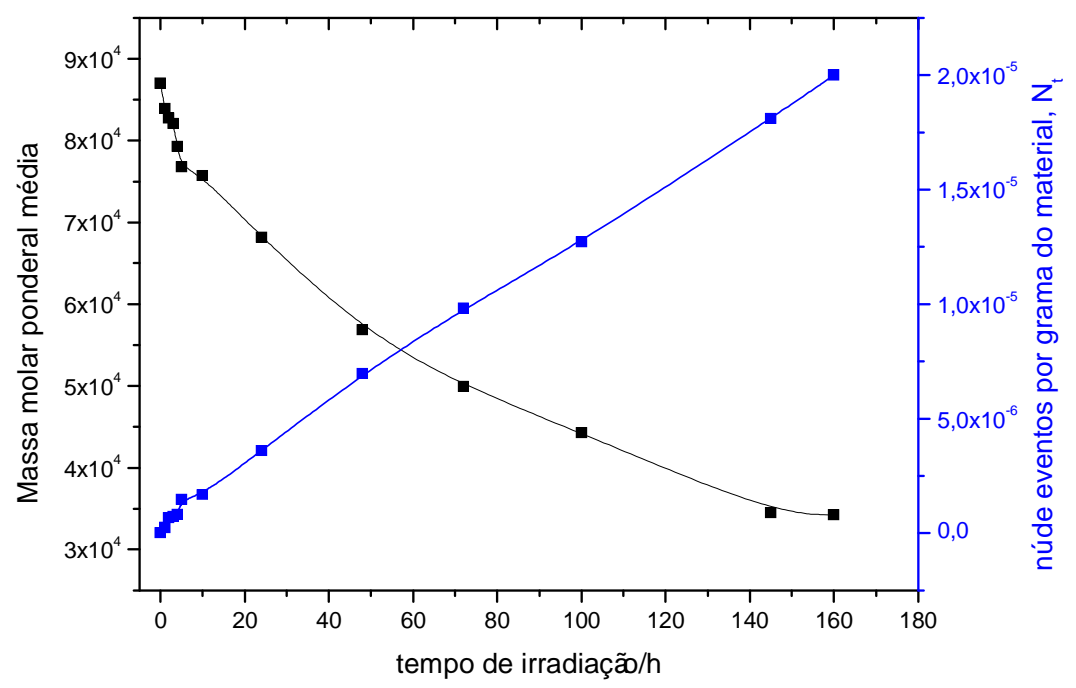

Figura 34. Variação da massa molar ponderal média e o número de quebra de cadeia de PSS na presença de $1,0 \times 10^{-4} \mathrm{M}$ QTX em função do tempo de irradiação.

\subsubsection{Variação de pH}

A degradação é o conjunto de reações que envolvem quebra de ligações primárias da cadeia principal do polímero e formação de outras, com conseqüente mudança da estrutura química e redução da massa molar. ${ }^{13}$ Desse modo, a variação da massa molar de PSS $\left(1,0 \mathrm{gL}^{-1}\right)$ na presença de corante $\left(1 \times 10^{-4} \mathrm{M}\right)$ em função do $\mathrm{pH}(3,5 ; 6,4 ; 7,0$ e 9,0$)$ foi investigada pela SEC. As soluções foram irradiadas com lâmpadas fluorescentes a $25 \pm 1{ }^{\circ} \mathrm{C}$ por no máximo $160 \mathrm{~h}$. Sem ajuste da acidez o pH ficou em 6,4.

Polímeros podem sofrer quebra de cadeia para formar produtos de menores massas molares. A quebra de cadeia pode ocorrer tanto no final da cadeia, formando um produto específico, quanto em uma posição aleatória da cadeia, gerando massas molares menores que a inicial. ${ }^{56} \mathrm{~A}$ redução na massa molar conforme o tempo de irradiação foi caracterizada pelo deslocamento do pico 
cromatográfico de PSS, provocado pela quebra de cadeia, conforme mostra a Figura 35.

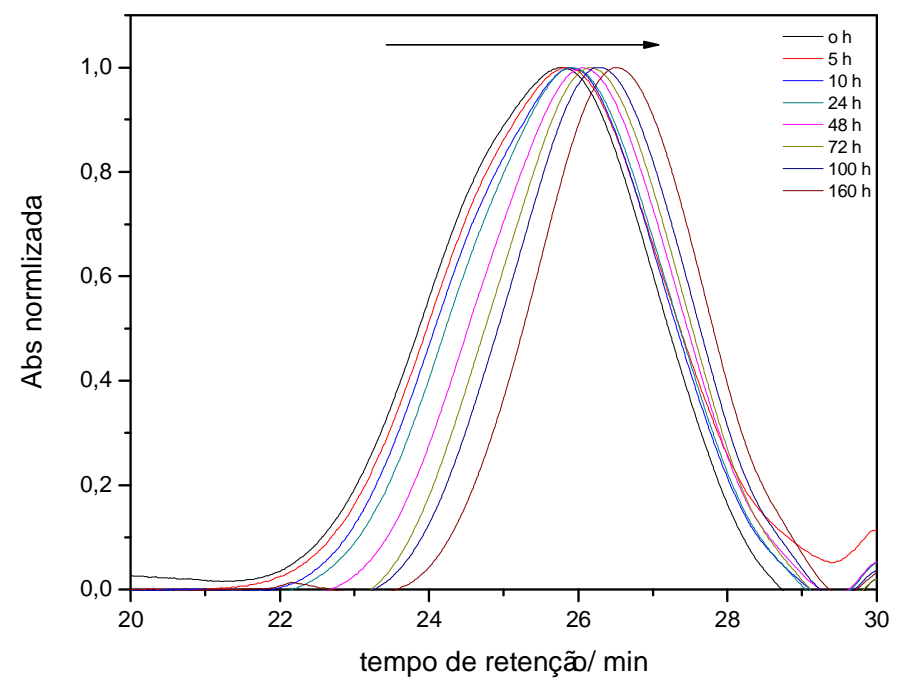

Figura 35. Mudança do pico cromatográfico de PSS $\left(1,0 \mathrm{gL}^{-1}\right)$ irradiado na presença de $1 \times 10^{-4} \mathrm{M}$ de QTX em função do tempo de irradiação.

A cinética de fotodegradação de variação massa molar numérica média poliestirenossulfonato de sódio na presença de QTX em diferentes pHs em função do tempo de irradiação foi determinada usando a Equação $35 .{ }^{54}$ A Figura 36 ilustra esta relação.

Em pH 3,5, a relação da massa molar numérica média diminui apenas 5,6\% após 24 h de irradiação e 17\% depois de 160 horas. Em pH 6,4, esta foi apenas de 11,3\% após 24 h e após 160 horas chegou a 43\%. Em pH 7,0, esta diminuição foi praticamente igual à de $\mathrm{pH} 6,4$, ou seja, em 24 horas foi de $16 \%$ e em 160 horas foi de 44\%. Em pH 9,0, a redução foi mais representativa, sendo que em 24 horas foi de $20 \%$ e depois de 160 horas esta redução foi de $46 \%$. 


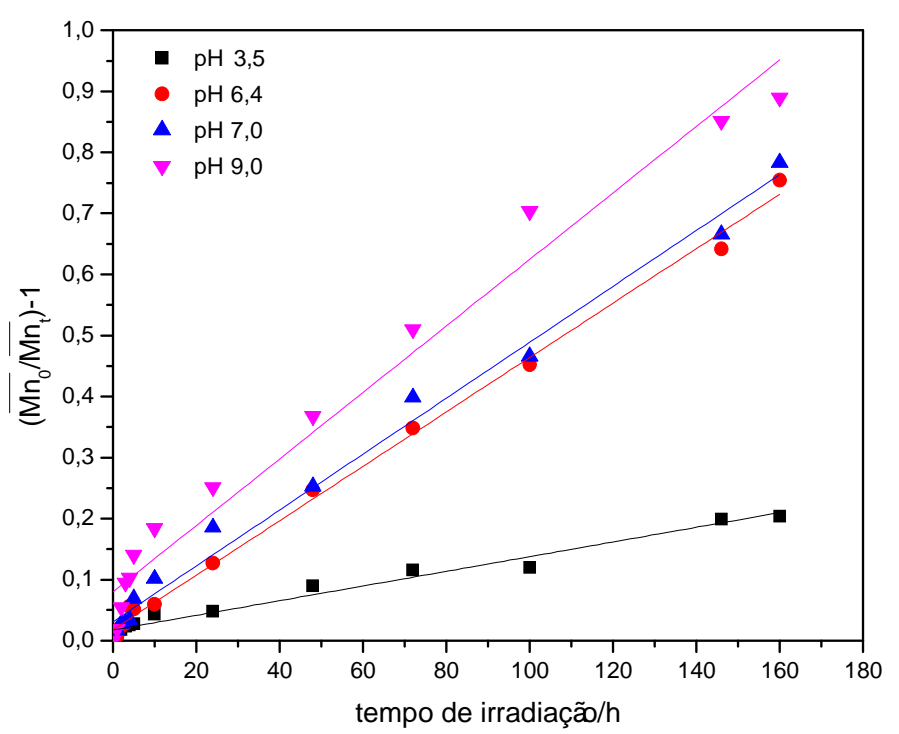

Figura 36. Variação de $\left(\overline{M n}_{0} / \overline{M n}_{t}\right)-1$ em função do tempo de irradiação para PSS $\left(1,0 \mathrm{gL}^{-1}\right)$ na presença de $1,0 \times 10^{-4} \mathrm{M}$ de QTX em diferentes pHs.

Este comportamento pode ser atribuído à quebra de cadeia principal resultante do processo de degradação do polímero, uma vez que na ausência de formação de ligação cruzada os valores de $\overline{M w}$ e $\overline{M n}$ diminuem conforme o tempo de irradiação. $^{57,58}$ Os coeficientes de velocidade de fotodegradação foram determinados dividindo o valor da inclinação do gráfico, Figura 36, pelo valor de $\overline{M n}_{0}$ de cada sistema. A Figura 37 apresenta os valores das constantes de velocidade de fotodegradação de poliestirenossulfonato de sódio irradiado por 160 h na presença de QTX em diferentes pHs. 


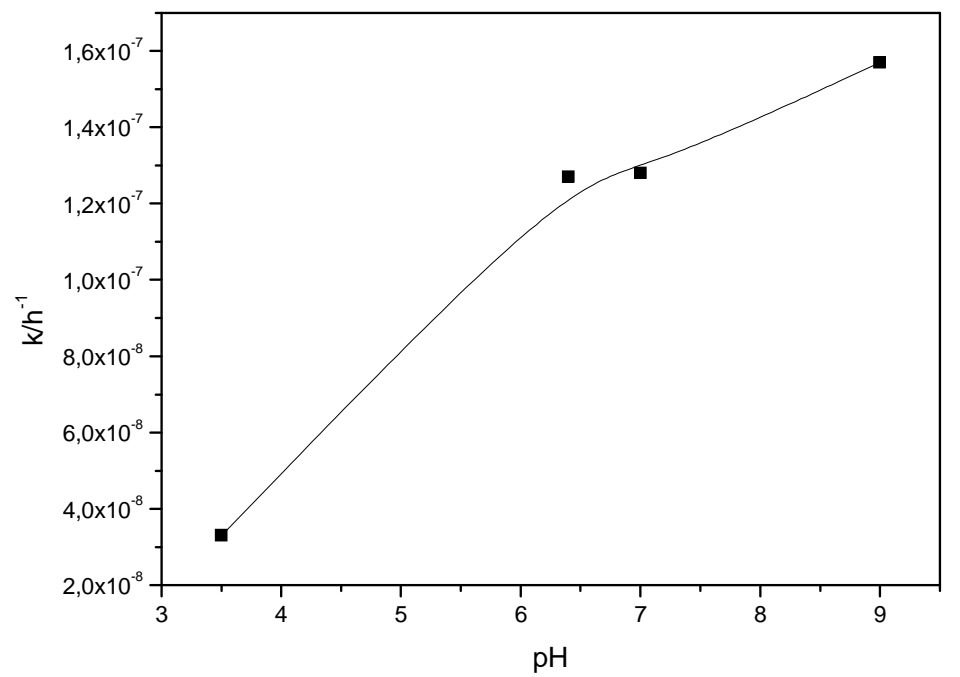

Figura 37. Coeficiente de velocidade de degradação de PSS/QTX em diferentes pHs.

Comparando-se o coeficiente de velocidade de $\mathrm{pH} 3,5$ em relação à de $\mathrm{pH}$ 9,0 observa-se um aumento de cerca de quatro vezes, ou seja, de $0,33 \times 10^{-7} \mathrm{~h}^{-1}$ foi para $1,57 \times 10^{-7} \mathrm{~h}^{-1}$. Por outro lado, em $\mathrm{pH} 6,4 \mathrm{e} \mathrm{pH} \mathrm{7,0}$ os coeficientes de velocidade de fotodegradação apresentaram valores muito próximos.

O efeito de $\mathrm{pH}$ na fotodegradação de PSS pode ser explicado considerando o mecanismo proposto por Bamford e Dewar em 1949, que postula uma reação inicial do corante fotoativo com o polímero, abstraindo um de seus átomos de hidrogênio, gerando um macrorradical $P \cdot$ que se combina com o oxigênio em reações subseqüentes. O meio alcalino provoca a aceleração do processo, pelo fato do corante fotoativo abstrair um elétron do íon hidróxido para produzir um radical hidroxila ativo $\left(\mathrm{HO}^{\circ}\right)$ e o radical aniônico $\left(\mathrm{D}^{*}\right)$. Os radicais responsáveis pela diminuição da massa molar de PSS em função do tempo de irradiação podem ser atribuídas às Equações 43, 44 e 45. O Esquema 16 ilustra o mecanismo proposto por Bamford e Dewar. ${ }^{17,19,21}$ 


$$
\begin{aligned}
& D \stackrel{h v}{\longrightarrow} \text { * } D \\
& \text { Equação } 41 \\
& { }^{*} D P-H \rightarrow D H^{\bullet}+P^{\bullet} \\
& P^{\bullet}+\mathrm{O}_{2} \rightarrow \mathrm{PO}_{2}^{\bullet} \\
& \mathrm{PO}_{2}^{\bullet}+\mathrm{P}-\mathrm{H} \rightarrow \mathrm{PO}_{2} \mathrm{H}+\mathrm{P}^{\bullet} \\
& \mathrm{PO}_{2}^{\bullet}+\mathrm{D}-\mathrm{H}^{\bullet} \rightarrow \mathrm{PO}_{2} \mathrm{H}+\mathrm{D}^{\bullet} \\
& { }^{*} \mathrm{D}+\mathrm{OH}^{-} \rightarrow \mathrm{D}^{-}+\mathrm{HO}^{\bullet} \\
& \mathrm{HO}^{\bullet}+\mathrm{P}-\mathrm{H} \rightarrow \mathrm{H}_{2} \mathrm{O}+\mathrm{P}^{\bullet}
\end{aligned}
$$

Esquema 16. Mecanismo de fotodegradação de polímeros sensibilizada por corantes em presença de $\mathrm{O}_{2}$ e $\mathrm{H}_{2} \mathrm{O}$, segundo Bamford e Dewar.

Segundo Bhardwaj e colaboradores o radical hidroxila pode reagir via abstração do átomo de hidrogênio da cadeia alifática do polímero. A reação de abstração de hidrogênio leva à formação de dois tipos de radicais, um na posição $\beta$ ou na a como mostra o Esquema $17 .^{5}$

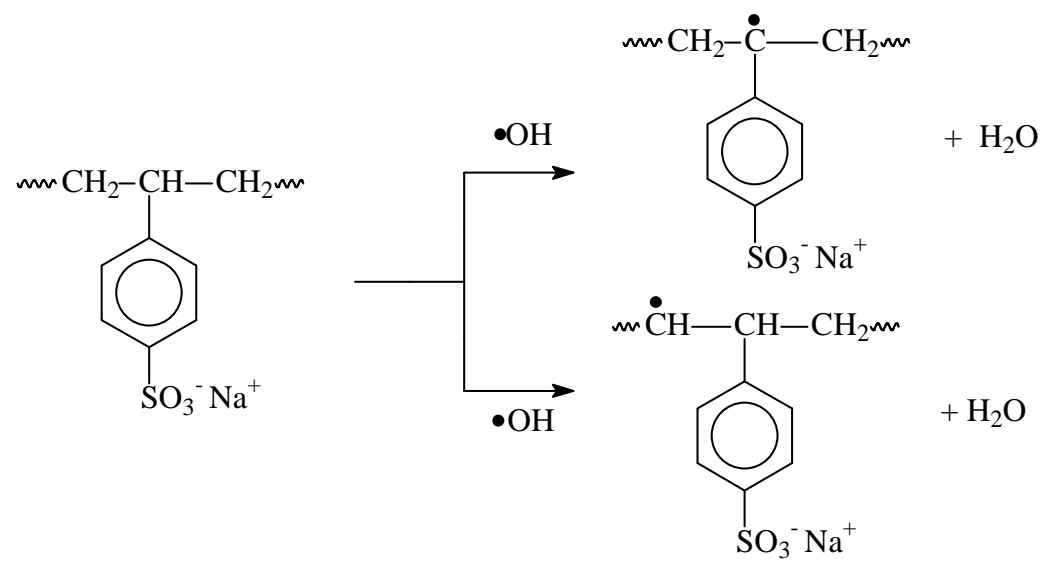

Esquema 17. Macrorradicais de PSS formados pela abstração de hidrogênio por radicais hidroxila. ${ }^{5}$ 


\subsubsection{Diferentes atmosferas}

O oxigênio é uma espécie química altamente reativa que é gerada e participa de várias reações durante os processos de degradação. A fim de avaliar seu efeito na fotodegradação de PSS/QTX foram realizados estudos em sistemas em ar, nitrogênio e em oxigênio puro. As soluções contendo $1,0 \mathrm{gL}^{-1}$ de PSS na presença de $1,0 \times 10^{-4} \mathrm{M}$ de QTX foram irradiadas por $160 \mathrm{~h}$ sob lâmpadas fluorescentes a temperatura ambiente.

O número médio de quebra de cadeia, $S$, foi determinado a partir das medidas viscosimétricas de acordo com a Equação 33 usando o valor $\alpha$ igual a 0,76..$^{50,51}$ Os valores obtidos de $S$ em função do tempo de irradiação de poliestirenossulfonato de sódio na presença de QTX em diferentes atmosferas são mostrados na Figura 38.

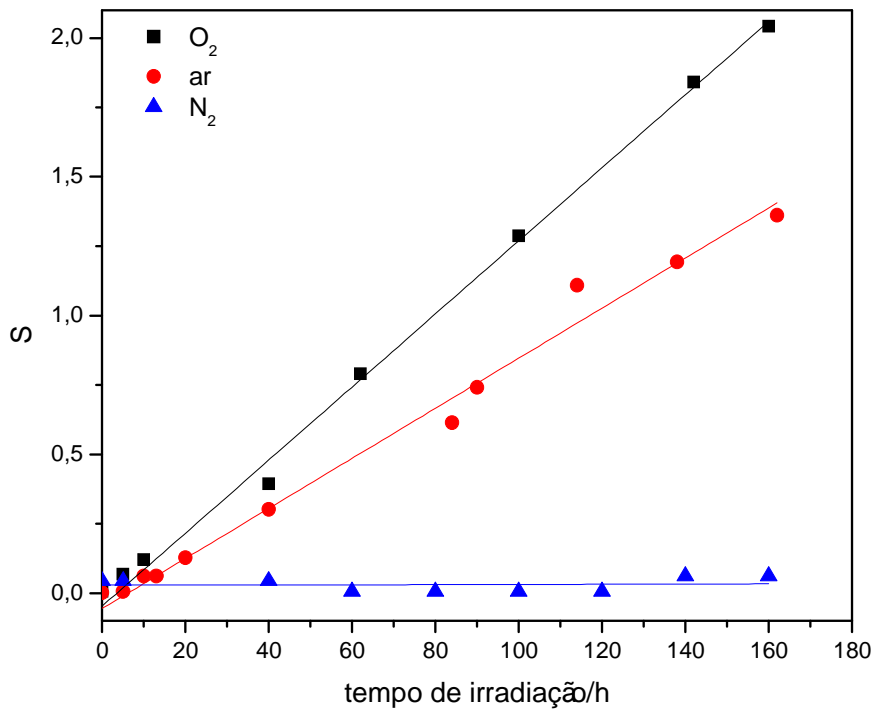

Figura 38. Número de médio de quebra na cadeia de PSS/QTX em diferentes atmosferas em função do tempo de irradiação. 
O número de quebra de cadeia de PSS foi mais intenso quando a solução foi borbulhada com oxigênio, apresentando um valor de $S$ após $160 \mathrm{~h}$ de irradiação aproximadamente 33 vezes maior com relação ao número médio de quebras de cadeia em atmosfera inerte, e 1,5 vezes maior que em ar. Esses resultados são esperados uma vez que as cisões de cadeia são favorecidas pelas reações de oxidação gerando radicais que favorecem a fotodegradação do poliestirenossulfonato de sódio.

Como o oxigênio é um eficiente seqüestrador de radicais livres, podem ser formados grupos hidroperóxidos ou peróxidos, que pode ser incorporados na cadeia polimérica. Os peróxidos têm um papel importante na maioria de polímeros, como mostram as reações abaixo, Esquema 18. ${ }^{59}$

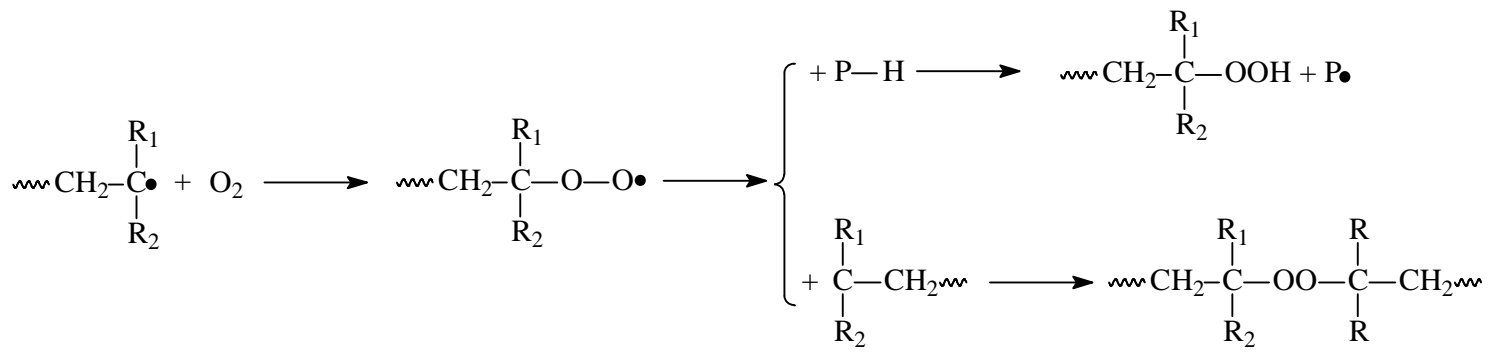

Esquema 18. Reação de oxigênio com a cadeia polimérica.

A fraca ligação $\mathrm{PO}-\mathrm{OH}$ pode ser quebrada por dissociação térmica, pela absorção direta de luz ou por transferência de energia através de um sensibilizador. Os radicais alcoxila e peroxila formados contribuem para a degradação do polímero. A abstração de hidrogênio da cadeia polimérica pelo corante excitado e a decomposição de peróxidos promovem a auto-oxidação do polímero. ${ }^{59}$ 


$$
\mathrm{POOH} \stackrel{h v}{\longrightarrow} \mathrm{PO}^{\bullet}+{ }^{\circ} \mathrm{OH} \quad \text { Equação } 48
$$

$P O O R \stackrel{h v}{\longrightarrow} P O^{\bullet}+{ }^{\circ} \mathrm{OR}$

Equação 49

De acordo com Bhardwaj e col. a degradação de poliestrenossulfonato de sódio, $M w=70.000$, por radiólise é mais rápida em atmosfera de oxigênio do que em atmosfera de nitrogênio. O aumento da degradação de PSS foi atribuído a quebra de cadeia principal através da formação de radical peroxila que leva a fragmentação da cadeia polimérica. $^{5}$

No caso de filmes de PVC, Shi e col. observaram que as quebras causadas por irradiação contribuem para que o oxigênio se incorpore mais facilmente no polímero, levando à rápida quebra de cadeia. ${ }^{60}$

Weir e col. investigaram a fotooxidação térmica de poliestireno em diferentes pressões de oxigênio e os resultados mostraram que a presença de oxigênio influencia na quebra de cadeia, embora não influencie no processo inicial da fotoreação. ${ }^{61}$

\subsubsection{Efeito de sais inorgânicos}

Os sais inorgânicos foram estudados com objetivo de investigar o efeito de íons cloreto ou sulfato de sódio no processo de fotodegradação de PSS através da geração de radicais provenientes desses sais. O sulfato de cobre é usado como supressor dos estados singlete e triplete de xantonas. ${ }^{38}$ Os estudos com sulfato de 
cobre foram realizados para verificar se a degradação de PSS ocorre quando o estado singlete da QTX é suprimido.

Para investigar esse efeito adicionaram-se separadamente sulfato de sódio, sulfato de cobre ou cloreto de sódio à solução de poliestirenossulfonato de sódio $\left(1,0 \mathrm{gL}^{-1}\right)$ na presença de QTX $\left(1,0 \times 10^{-4} \mathrm{M}\right)$. As concentrações de $\mathrm{Na}_{2} \mathrm{SO}_{4}$ utilizadas foram $0,05,0,10$ e $0,20 \mathrm{M}$. Para o $\mathrm{CuSO}_{4}$ foram de $3 \times 10^{-4}, 3 \times 10^{-3}$ e $3 \times 10^{-2} \mathrm{M}$. E de $\mathrm{NaCl}$ foram de $0,05,0,10$ e $0,50 \mathrm{M}$. Todos os sistemas foram irradiados com lâmpadas fluorescentes por $160 \mathrm{~h}$ a $25^{\circ} \mathrm{C} \pm 1$. A cinéti ca de fotodegradação de PSS foi determinada através da cromatografia por exclusão de tamanho. As Figuras 39A, $\mathrm{B}$ e C apresentam as cinéticas de fotodegradação de PSS na presença de $\mathrm{Na}_{2} \mathrm{SO}_{4}$, $\mathrm{CuSO}_{4}$ e $\mathrm{NaCl}$ em função do tempo de irradiação, respectivamente. A Figura 39D apresenta os coeficientes de velocidade de degradação de PSS para cada sistema estudado. 


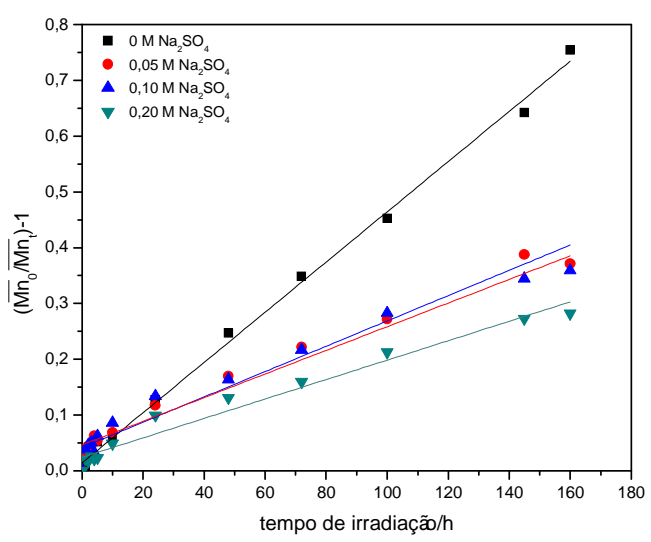

(A) $\mathrm{Na}_{2} \mathrm{SO}_{4}$

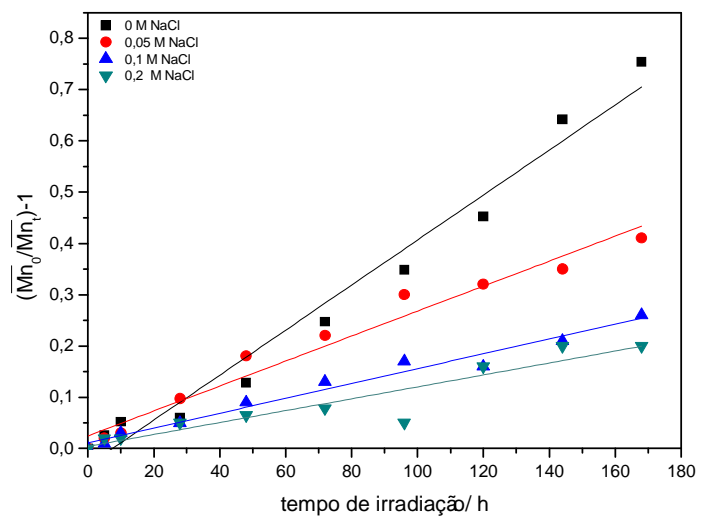

(C) $\mathrm{NaCl}$

Figura 39. Variação de $\left(\overline{M n}_{0} / \overline{M n}_{t}\right)-1$ em função do tempo de irradiação para PSS $\left(1,0 \mathrm{gL}^{-1}\right)$ na presença de QTX e em diferentes sais inorgânicos. (D) Coeficiente de velocidade de degradação de PSS/QTX em função da concentração desses sais inorgânicos.

A presença de sais inorgânicos diminuiu o processo de degradação de PSS, (Figura 39D). Na ausência de sal, o coeficiente de velocidade de degradação foi de $1,4 \times 10^{-7} \mathrm{~h}^{-1}$. A adição de $0,05 \mathrm{M}$ de $\mathrm{Na}_{2} \mathrm{SO}_{4}$ à solução de PSS/QTX levou a uma redução no valor do coeficiente de velocidade de degradação, $k=0,27 \times 10^{-7} \mathrm{~h}^{-1}$. Acima de 0,05 $\mathrm{M}$ de $\mathrm{Na}_{2} \mathrm{SO}_{4}$ o coeficiente de velocidade de degradação permaneceu praticamente constante (Figura 39D).

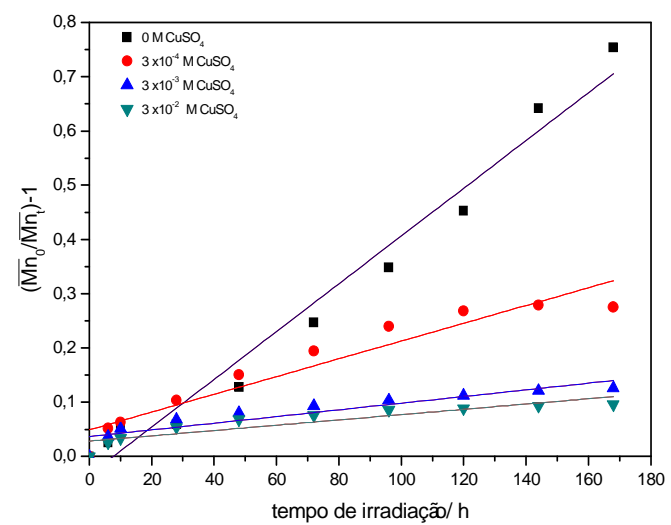

(B) $\mathrm{CuSO}_{4}$

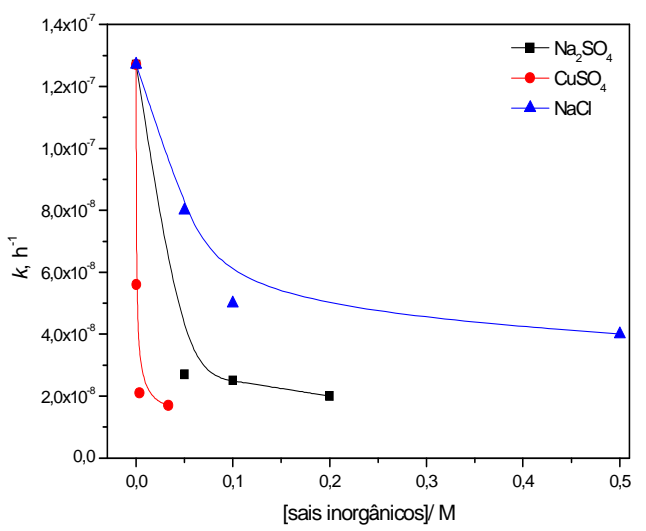

(D) 
No caso do sulfato de cobre, quando se adicionou $3 \times 10^{-4} \mathrm{M}$, o coeficiente de degradação de PSS foi $k=0,56 \times 10^{-7} \mathrm{~h}^{-1}$. Para $3 \times 10^{-2} \mathrm{M}$ de $\mathrm{CuSO}_{4} \mathrm{O}$ valor de $k$ foi de $0,17 \times 10^{-7} \mathrm{~h}^{-1}$. Sabe-se que a reações entre íons sulfato e radical hidroxila podem produzir radicais menos reativos (Equação 27), diminuindo assim o processo de quebra de cadeia do PSS. Os resultados com sulfato de cobre foram muito importantes para confirmar que a degradação de PSS é influenciada pelo estado singlete da QTX, responsável pelo processo de fotodegradação. É importante ressaltar que na ausência da QTX o PSS não sofre fotodegradação.

Na presença de 0,05 $\mathrm{M}$ de íons cloreto ocorreu um decréscimo de $30 \%$ no coeficiente de velocidade de degradação. Esta redução continuou conforme a adição de íons cloreto na solução de PSS/QTX. Outra justificativa para a diminuição do coeficiente de velocidade de degradação na presença de $\mathrm{NaCl}$ seria considerar a reação do íon cloreto reagir com o radical hidroxila, formando o radical $\mathrm{HOCl}^{-}$, como mostra a Equação $50:^{35}$

$$
\mathrm{Cl}^{-}+{ }^{\circ} \mathrm{OH} \rightarrow \mathrm{HOCl}^{-}
$$

A quebra na cadeia principal resultante do processo de degradação do polímero causa a diminuição nos valores de $\overline{M w}$ e $\overline{M n}$ conforme o tempo de irradiação já que não ocorre a formação de ligação cruzada. ${ }^{18,56,58}$ 


\subsubsection{Efeito de sorbato de potássio}

O sorbato de potássio foi usado para suprimir o triplete de QTX em água nos experimentos de fotólise por pulso de laser. A adição de $1,23 \times 10^{-5} \mathrm{M}$ deste dieno ocasionou uma supressão de $82 \%$ do estado triplete de QTX em água. A fotodegradação de PSS $\left(1,0 \mathrm{gL}^{-1}\right)$ em presença de QTX $\left(1,0 \times 10^{-4} \mathrm{M}\right)$ e sorbato de potássio foi realizada para verificar se a supressão do estado triplete do corante poderia afetar este processo. Soluções de PSS/QTX na presença e na ausência de sorbato foram irradiadas na câmara de irradiação nas mesmas condições apresentadas em 3.3.1.

A Figura 40A mostra a variação da massa molar numérica média do PSS/QTX em diferentes concentrações de sorbato em função do tempo de irradiação. O coeficiente de velocidade de degradação, $k$, foi determinado usando a Equação 38.

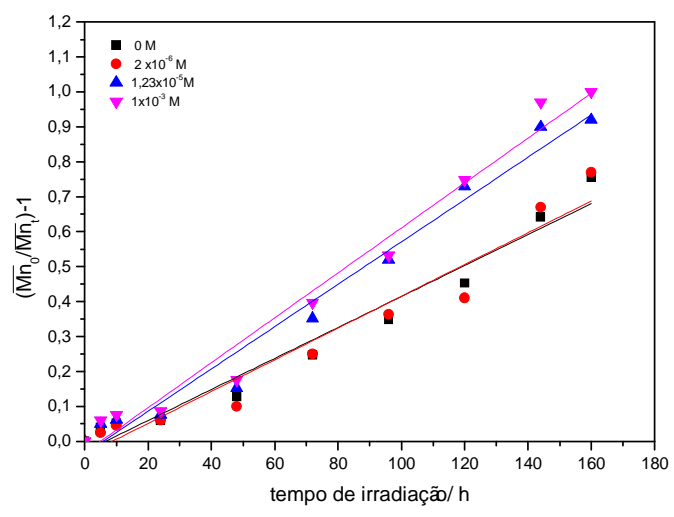

(A)

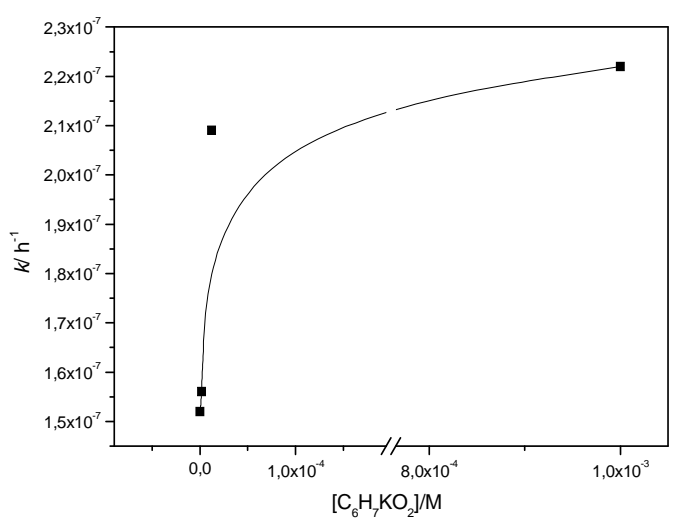

(B)

Figura 40. (A) Variação de $\left(\overline{M n}_{0} / \overline{M n}_{t}\right)-1$ em função do tempo de irradiação para PSS $\left(1,0 \mathrm{gL}^{-1}\right)$ em diferentes concentrações de sorbato de potássio. (B) Coeficiente de velocidade de degradação em função da concentração de sorbato. 
Para todas as concentrações de sorbato de potássio foi observado o aumento do coeficiente de velocidade de fotodegradação (Figura 40B). Na ausência do dieno o $k$ obtido foi de $1,52 \times 10^{-7} \mathrm{~h}^{-1}$, enquanto que na maior concentração investigada, $1 \times 10^{-3} \mathrm{M}$, o coeficiente obtido foi de $2,2 \times 10^{-7} \mathrm{~h}^{-1}$.

A degradação do PSS/QTX ocorreu mesmo na presença do sorbato, indicando fortemente que este processo de fotodegradação provavelmente deve ocorrer pela abstração de hidrogênio do polímero pelo estado singlete da QTX. Desta forma, o estado triplete da QTX não seria a principal rota para fotodegradação do PSS. Esse comportamento não é comum para cetonas alifáticas, onde as reações do estado triplete são predominantes. ${ }^{62}$ Esses resultados de fotodegradação usando sorbato estão de acordo com os resultados obtidos com sulfato de cobre, que inibiu o proceso de degradação da PSS/QTX. Vale lembrar que o sulfato de cobre é supressor do estado singlete da QTX.

\subsubsection{Segunda parte: Fotodegradação de QTX na presença de PSS}

\subsubsection{Variação de concentração de QTX}

Soluções de QTX $\left(1,0 \times 10^{-4} \mathrm{M}\right)$ na presença de poliestirenossulfonato de sódio foram irradiadas por diferentes tempos e as variações espectrais foram acompanhadas por espectroscopia UV-Vis. A Figura 41 apresenta os espectros de absorção das soluções com diferentes concentrações de QTX na presença de PSS $\left(1,0 \mathrm{~g} \mathrm{~L}^{-1}\right)$. 
- $[\mathrm{QTX}]=3 \times 10^{-5} \mathrm{M}$

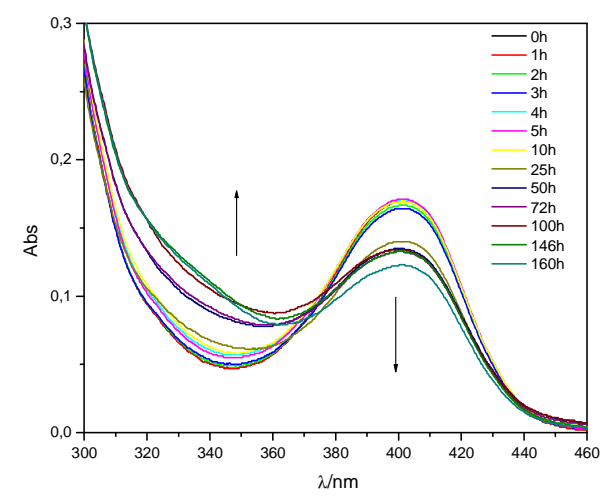

- $[\mathrm{QTX}]=7 \times 10^{-5} \mathrm{M}$

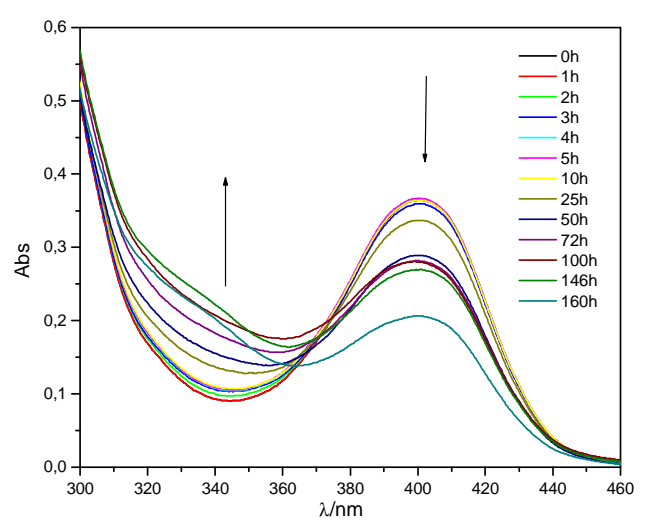

- $[\mathrm{QTX}]=5 \times 10^{-5} \mathrm{M}$

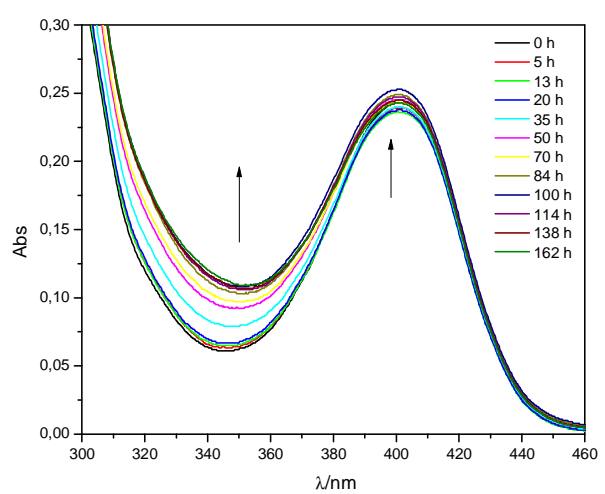

- $[\mathrm{QTX}]=1 \times 10^{-4} \mathrm{M}$

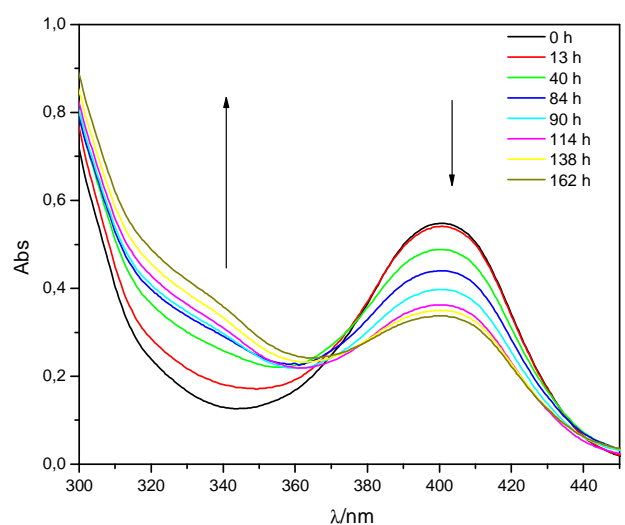

Figura 41. Espectros de absorção obtidos após a irradiação de diferentes concentrações de QTX em presença de PSS $1,0 \mathrm{gL}^{-1}$.

$\mathrm{Na}$ maioria das concentrações ocorreu a diminuição da banda centrada em 402 nm e um aumento da absorção na região 300-350 nm.

A região de 300 a 350 nm é atribuída aos fotoprodutos de QTX em solução aquosa. Porém, nesta região também aparecem fotoprodutos derivados do polímero degradado. 
Resultados semelhantes foram obtidos por Zamotayev \& Granchak que observaram mudanças no espectro de absorção de tioxantona em filmes de polietileno depois de irradiado. A ação de luz UV resulta na diminuição na intensidade de bandas de absorção de tioxantona no polietileno, e aparecimento de bandas nas regiões de $280-355 \mathrm{~nm} .{ }^{63}$

A absorção na região de $275-350 \mathrm{~nm}$ pode ser devida à formação de fotoprodutos como polienos, ${ }^{46}$ e a de $240 \mathrm{~nm}$ a alguns grupos de acetofenonas, também formados na fotodegradação de polímero. ${ }^{64,65}$ No caso da fotooxidação de poliestireno observam-se mudanças nos espectros de absorção decorrentes da formação de compostos carbonílicos na região entre 255 a 350 nm. ${ }^{66}$

O Esquema 19 representa o mecanismo clássico de degradação oxidativa do poliestireno (PS) irradiado com luz UV. Quando o poliestireno é irradiado a $\lambda<300$ nm, há formação do macrorradical PS (Equação 51), que na presença de oxigênio resulta em um radical alquil peroxila e posteriormente em um hidroperóxido, $\mathrm{POOH}$ (Equação 52). A fotólise do $\mathrm{POOH}$ gera a formação de um radical alcoxila e hidroxila (Equação 53). O radical alcoxila ( $\mathrm{PO}^{\bullet}$ ) leva a formação de cadeias menores e espécies com grupos carbonila (Equação 51). ${ }^{46}$

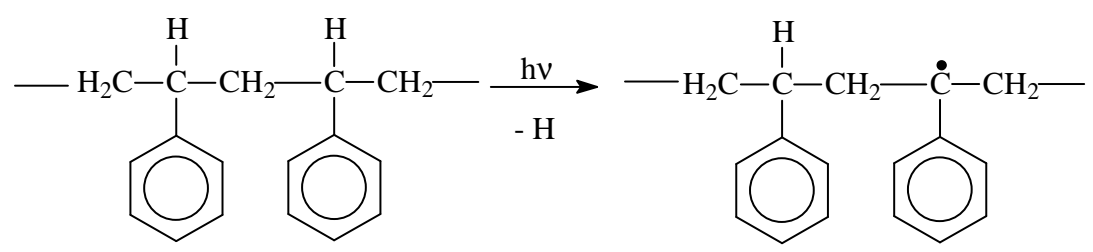

[PS]

[PS ] 


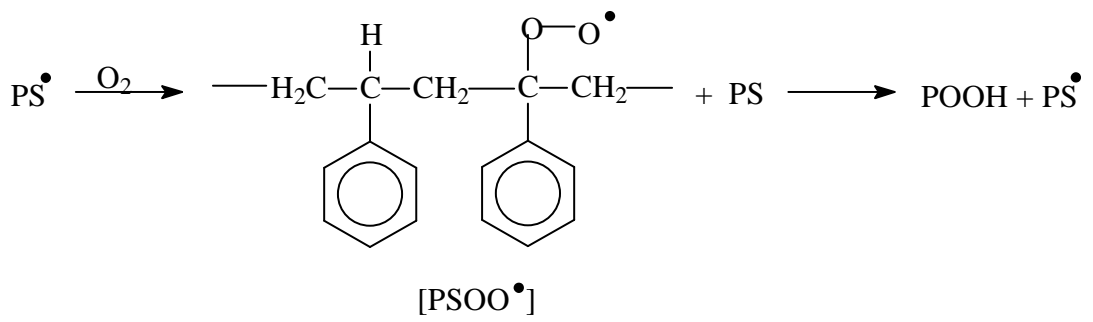

Equação 52

$\mathrm{PSOOH} \stackrel{\mathrm{hv}}{\longrightarrow} \mathrm{PSO}^{\bullet}+\mathrm{HO}^{\bullet}$

Equação 53
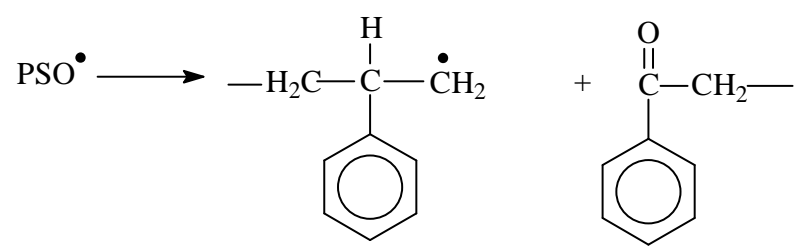

Equação 54

Esquema 19. Mecanismo clássico de fotodegradação de poliestireno. ${ }^{46}$

A Figura 42 ilustra a variação da absorção de QTX em solução de PSS $(1,0$ $\mathrm{gL}^{-1}$ ) provocada pela irradiação nas regiões de $402 \mathrm{~nm}$ (região de degradação de QTX) e 347 nm (região de formação de fotoprodutos). Como podem ser notado em todos os sistemas apresentam mudanças espectrais nesta região, porém são mais pronunciadas para QTX $1,0 \times 10^{-4} \mathrm{M}$.

Resultados similares foram observados para o Nylon 66 na presença de acid blue. A degradação do corante aumentou com o aumento da concentração do corante devido à extensa absorção na região de luz visível. ${ }^{67}$ 


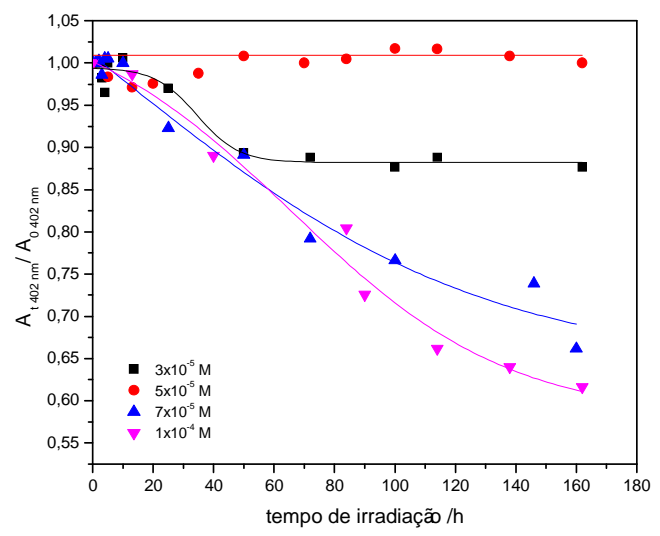

(A)

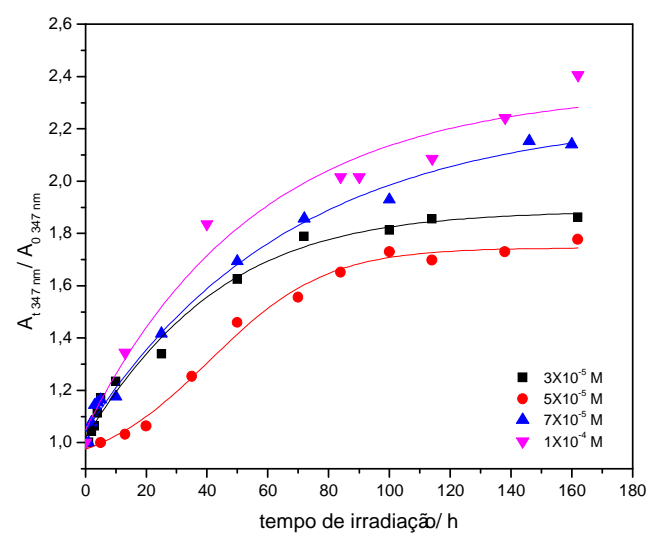

(B)

Figura 42. Mudança da absorção de QTX durante a irradiação de diferentes concentrações QTX em solução aquosa contendo 1,0 $\mathrm{gL}^{-1}$ PSS (A) em $402 \mathrm{~nm}$ e (B) em $347 \mathrm{~nm}$.

\subsubsection{Efeito do $\mathrm{pH}$}

A influência do $\mathrm{pH}$ na solução de QTX $\left(1,0 \times 10^{-4} \mathrm{M}\right)$ em poliestirenossulfonato de sódio $\left(1,0 \mathrm{gL}^{-1}\right)$ foi investigada a $\mathrm{pH} 3,5,6,4,7$ e 9 . O ajuste de $\mathrm{pH}$ foi realizado como descrito em 4.3.1.3. As soluções foram irradiadas com lâmpadas fluorescentes a temperatura ambiente por $160 \mathrm{~h}$.

Os espectros de absorção UV-Vis das soluções de QTX $1,0 \times 10^{-4} \mathrm{M}$ na presença de poliestirenossulfonato de sódio (PSS/QTX) a diferentes pHs são apresentados na Figura 43. 
- $\mathrm{pH}=3,5$

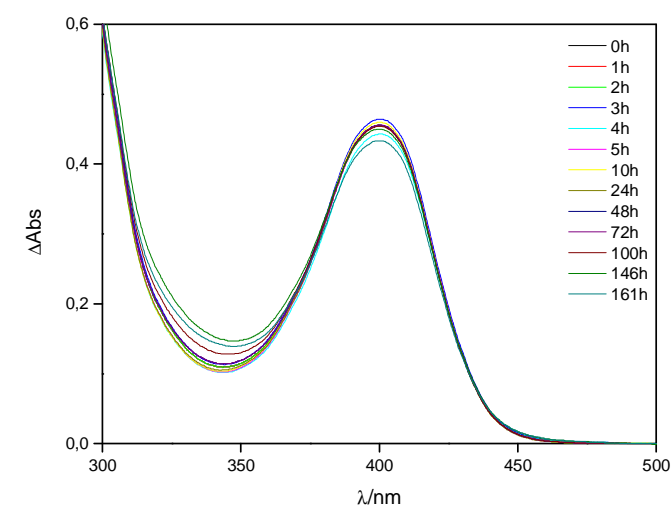

- $\mathrm{pH}=7,0$

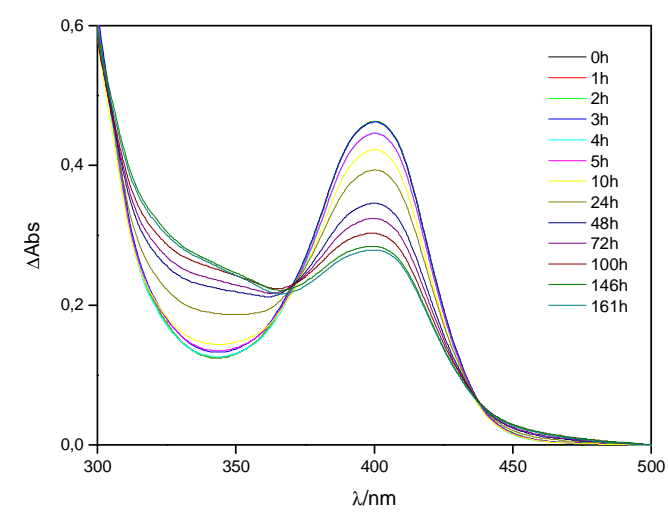

- $\mathrm{pH}=6,4$

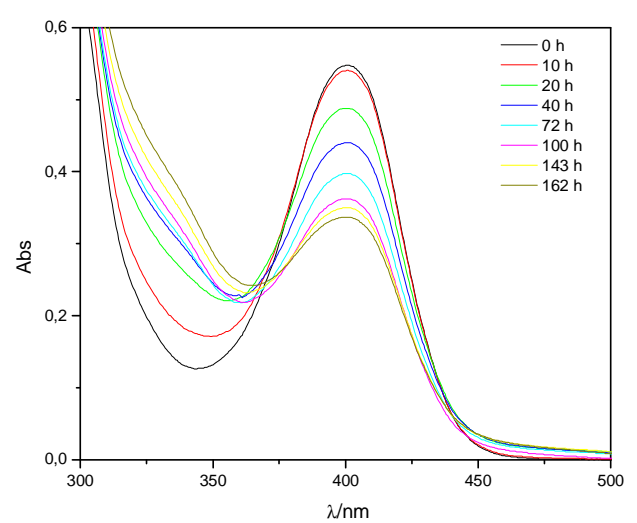

- $\mathrm{pH}=9,0$

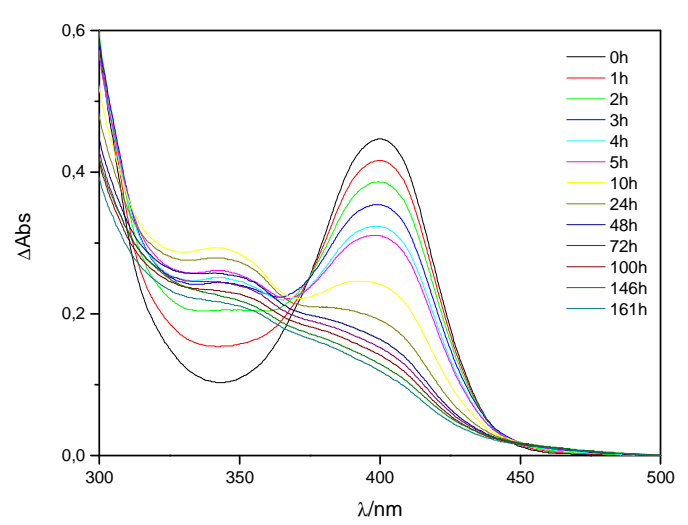

Figura 43. Espectros de absorção obtidos na irradiação de PSS/QTX em diferentes pHs.

Verifica-se que há pouca variação espectral na solução de QTX em presença de PSS quando irradiada em meio ácido. Por outro lado, conforme o pH do sistema vai aumentando, é possível notar que a banda em $402 \mathrm{~nm}$ vai diminuindo conforme o tempo de irradiação. Na região de fotoprodutos, 300-350 nm é possível verificar a formação de uma nova banda. Esse comportamento é mais pronunciado em $\mathrm{pH}$ 
mais básico. A Figura 44 ilustra as mudanças ocorridas no espectro de absorção em 402 nm no sistema de PSS/QTX provocada pela irradiação em diferentes pHs.

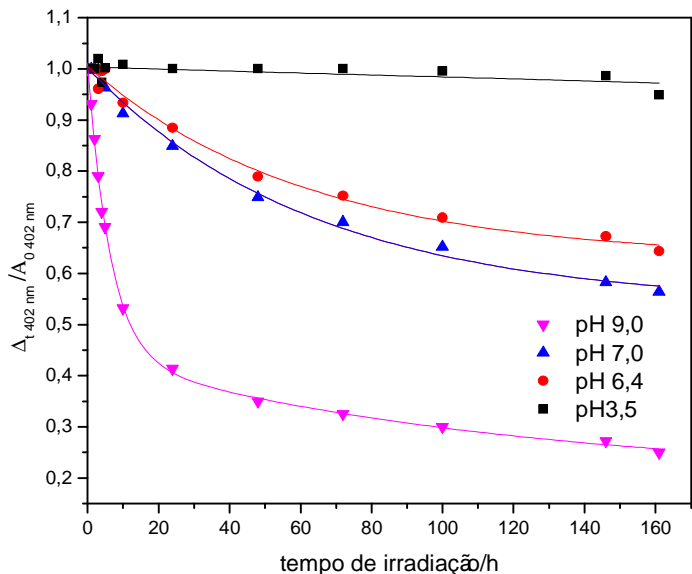

(A)

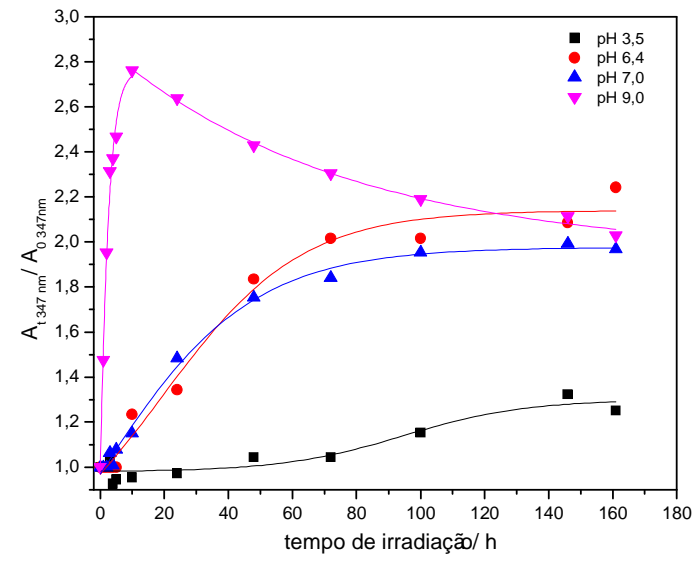

(B)

Figura 44. Mudança da absorção de QTX em solução aquosa contendo 1,0 $\mathrm{gL}^{-1} \mathrm{PSS}$ em diferentes pHs (A) em 402 nm e (B) em $347 \mathrm{~nm}$.

Na Figura 44A é possível observar que em meio básico o decaimento de QTX em solução polimérica foi mais rápido que em nos outros meios. Este comportamento pode ser explicado considerando que o corante pode não apenas fotossensibiliza a degradação do polímero, mas também participar das etapas de propagação das reações em meio alcalino, como foi discutido no efeito de $\mathrm{pH}$ na degradação de PSS pelo mecanismo proposto por Bamford e Dewar (Esquema 16), onde o corante fotoativo pode abstrair um elétron do íon hidróxido para produzir um radical hidroxila ativo $\left(\mathrm{HO}^{\circ}\right)$, acelerando assim o processo de degradação.

Como conseqüência da degradação, a absorção na região dos fotoprodutos aumentou em função do tempo de irradiação. Em meio alcalino, observa-se que nas dez primeiras horas de irradiação ocorre um aumento na variação de absorção em $347 \mathrm{~nm}$ e depois deste tempo de irradiação ocorre uma pequena diminuição na absorção. 
A porcentagem de degradação de QTX em solução aquosa contendo PSS 1,0 $\mathrm{gL}^{-1}$ em função do $\mathrm{pH}$ foi praticamente linear. (Figura 45). Este resultado está de acordo com os resultados obtidos em pH básico mostrados em 4.3.1.3.

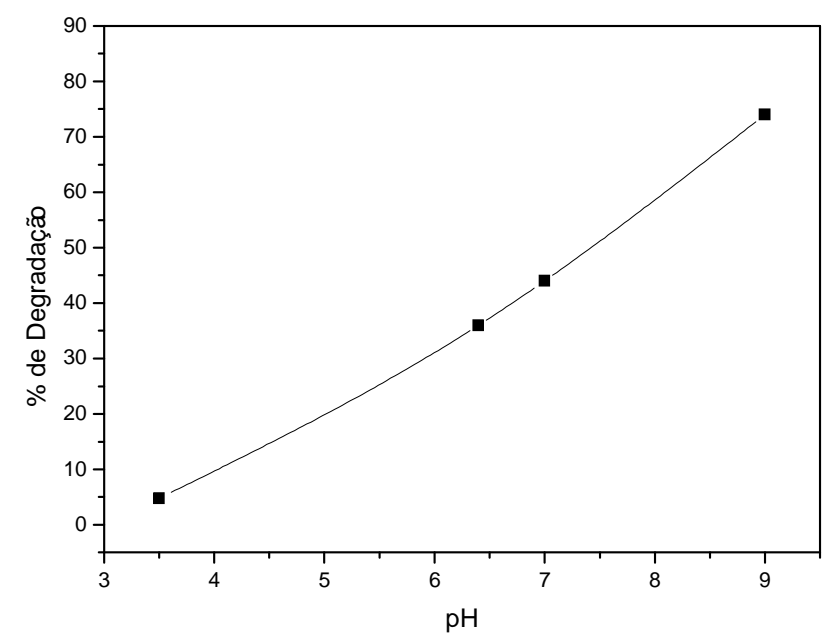

Figura 45. Porcentagem de degradação de QTX em solução aquosa contendo PSS $1,0 \mathrm{gL}^{-1} \mathrm{em}$ função da variação de $\mathrm{pH}$.

\subsubsection{Atmosferas diferentes}

É bem conhecido que a sensibilização de reações fotoquímicas de compostos macromoleculares procede na presença de corantes, usualmente, envolvendo o estado excitado triplete do corante. ${ }^{31}$

A Figura 46A ilustra a variação de banda em $402 \mathrm{~nm}$ referente ao consumo de QTX $\left(1,0 \times 10^{-4} \mathrm{M}\right)$ na presença de PSS $\left(1,0 \mathrm{gL}^{-1}\right)$ em função do tempo de irradiação para diferentes atmosferas $\left(\mathrm{ar}, \mathrm{O}_{2}\right.$ e $\left.\mathrm{N}_{2}\right)$ e a Figura 46B ilustra a variação de banda em $347 \mathrm{~nm}$ referentes à formação de fotoprodutos tanto do corante como do polímero gerados pelo processo de fotodegradação. 


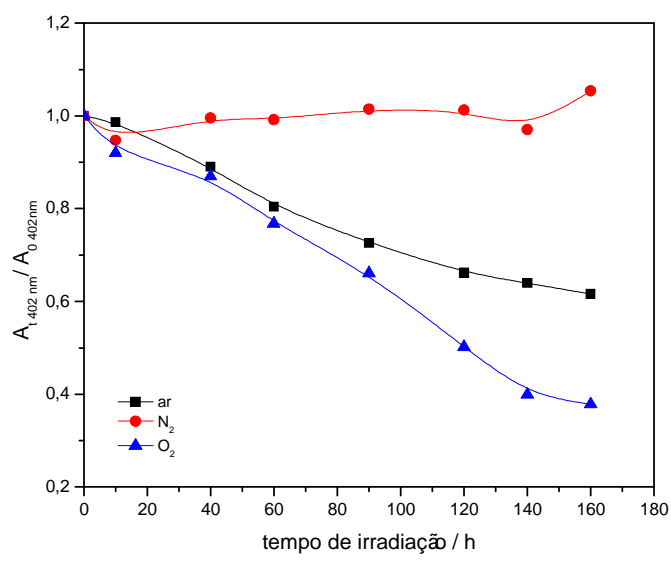

(A)

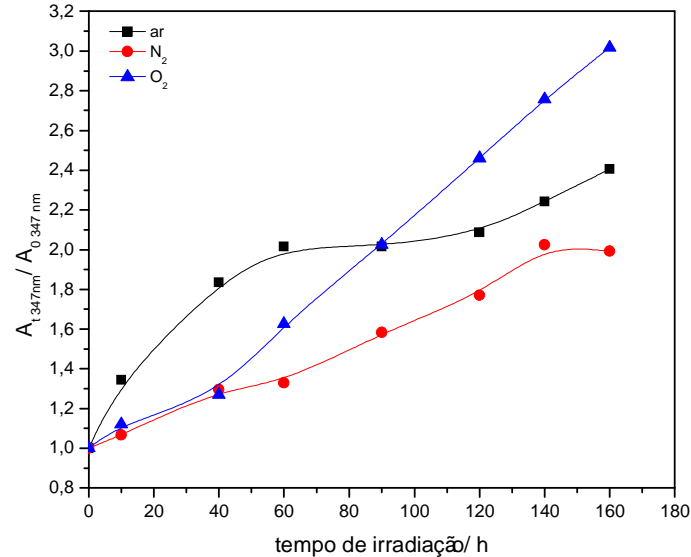

(B)

Figura 46. Mudança da absorção em 402 nm (A) e em 347 nm (B) durante a irradiação de PSS/QTX em ar, na presença de $\mathrm{N}_{2}$ ou na presença de $\mathrm{O}_{2}$.

$\mathrm{Na}$ Figura 46A observa-se que a banda em 402 nm diminui consideravelmente na presença de oxigênio. Em atmosfera inerte, este comportamento é muito menor. Como conseqüência da fotodegradação, ocorre o aparecimento de uma banda de absorção na região de 325 a 350 nm correspondente aos fotoprodutos formados pela interação entre o fotossensibilizador e o polímero durante a irradiação. A absorção na região de 325 a 350 nm pode ser atribuída à formação de grupos sulfóxido e sulfonas, decorrentes da oxidação de QTX ou também pela formação de hidroperóxidos ${ }^{68}$, polienos ${ }^{46}$, acetofenonas, ${ }^{64,65}$ e cetonas alifáticas resultantes da oxidação do átomo de carbono secundário da cadeia alifática de polímero. ${ }^{69}$

A porcentagem de degradação de QTX em solução de poliestirenossulfonato de sódio em diferentes atmosferas foi calculada conforme a Equação 22 A maior porcentagem de degradação (62\%) ocorreu quando a solução PSS/QTX foi borbulhada com oxigênio. Seguida da solução PSS/QTX em ar com a porcentagem de 38\%. Para a solução de QTX em poliestirenossulfonato de sódio em atmosfera 
de nitrogênio não foi possível calcular a porcentagem de degradação, uma vez que praticamente não houve variação na banda de máxima absorção de QTX.

A partir dos Esquemas 4 e 5, é possível prever que na presença de oxigênio pode ocorrer a formação de espécies reativas como o ${ }^{1} \mathrm{O}_{2}, \mathrm{H}_{2} \mathrm{O}_{2}$ e $\mathrm{PO}_{2}^{\bullet}$, as quais podem contribuir para o processo de degradação. Isso poderia justificar as mudanças observadas nos espectros de absorção de PSS/QTX na presença de ar e em atmosfera saturada de oxigênio.

Em atmosfera inerte a contribuição para a degradação do polímero seria apenas a abstração do hidrogênio pelo corante excitado, como foi observado por Hult \& Ranby na fotoredução da ITX (2-iso-propiltioxantona) em filmes de poli(metil metacrilato), Esquema 20. ${ }^{59}$<smiles>CC(C)c1ccc2c(c1)[C@H](O)c1ccccc1S2</smiles>

Esquema 20. Mecanismo de fotoredução de ITX na presença de poli(metil metacrilato) (PH). ${ }^{59}$

\subsubsection{Efeito de sais inorgânicos}

O efeito dos sais inorgânicos na fotodegradação de QTX $\left(1,0 \times 10^{-4} \mathrm{M}\right)$ na presença de poliestirenossulfonato de sódio $\left(1,0 \mathrm{gL}^{-1}\right)$ foi verificado com as mesmas condições descritas em 4.3.1.5. As Figuras 47, 48 e 49 mostram o comportamento das bandas em 402 nm (degradação de QTX) e 347 nm (formação de fotoprodutos) 
para os sistemas PSS/QTX na presença de sulfato de sódio, sulfato de cobre e cloreto de sódio, respectivamente.

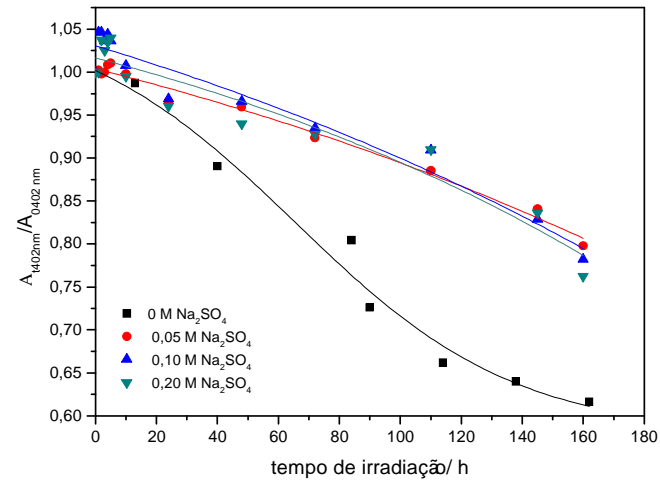

$\mathrm{Na}_{2} \mathrm{SO}_{4}$
(A)

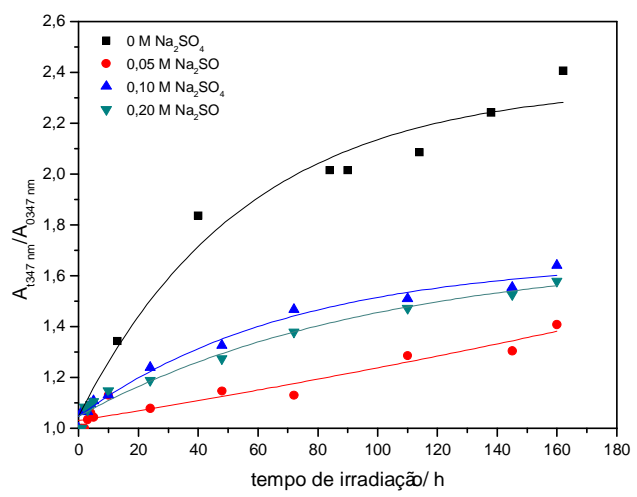

(B)

Figura 47. Mudança da absorção em 402 nm (A) e em 347 nm (B) durante a irradiação de PSS/QTX em presença de sulfato de sódio.

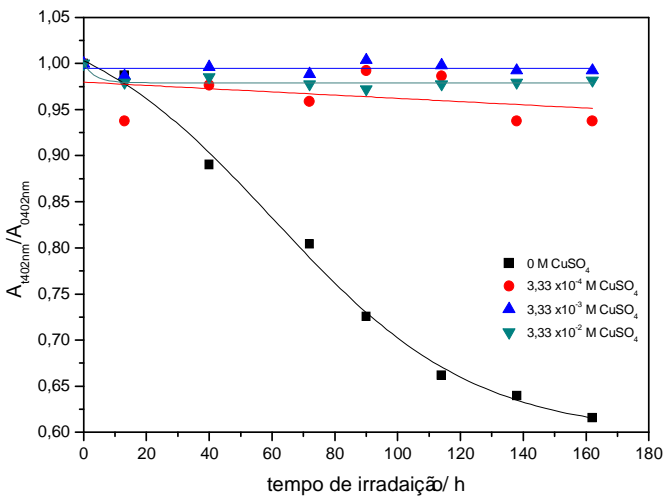

$\mathrm{CuSO}_{4}$

(A)

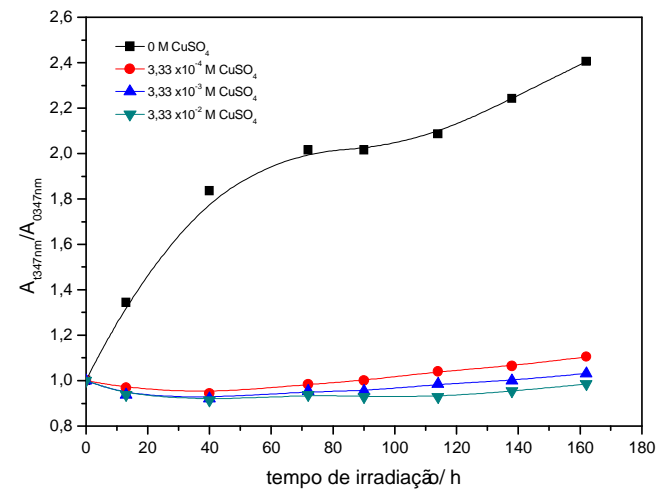

(B)

Figura 48. Mudança da absorção em 402 nm (A) e em 347 nm (B) durante a irradiação de PSS/QTX em presença de sulfato de cobre. 


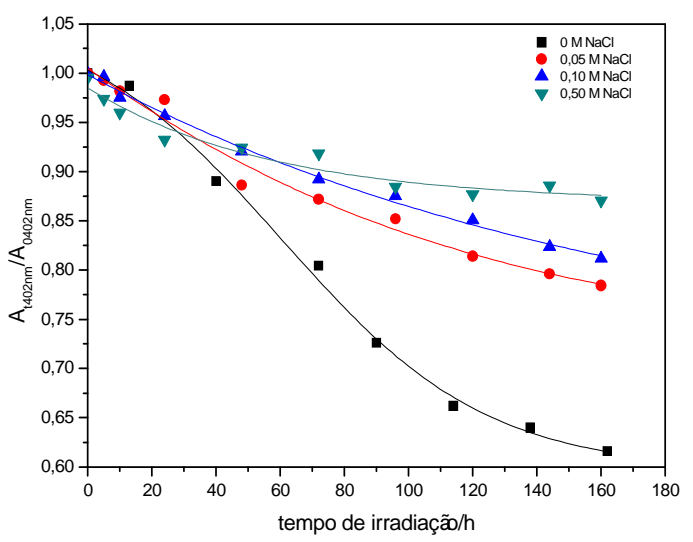

$\mathrm{NaCl}$

(A)

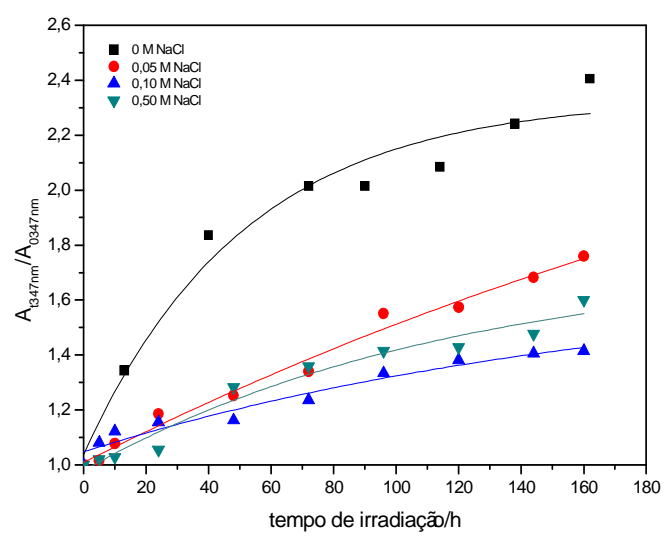

(B)

Figura 49. Mudança da absorção em 402 nm (A) e em 347 nm (B) durante a irradiação de PSS/QTX em presença de cloreto de sódio.

A adição de $\mathrm{Na}_{2} \mathrm{SO}_{4}$ no sistema PSS/QTX resultou em um comportamento análogo ao da solução de QTX em água na presença destes íons sulfato, ou seja, retardou o processo de fotodegradação.

Na Figura 48 é possível notar que na ausência de sulfato de cobre a degradação foi cerca de vinte vezes maior que na presença de deste sal. Este comportamento pode ser atribuído não apenas ao fato que o sulfato pode estar reagindo com radicais hidroxilas do sistema formando espécies menos reativas como mostrado na Equação $27,{ }^{36,37}$ mas também se pode considerar que íons de cobre são supressores do singlete da QTX, sugerindo que o processo de degradação de poliestirenossulfonato de sódio fotossensibilizado por este corante fica praticamente inibido.

A porcentagem de degradação da solução de QTX em solução aquosa na presença de poliestirenossulfonato de sódio em função da concentração de íons inorgânicos foi calculada pela Equação 22 é apresentada na Tabela 8, onde se vê 
que em todos os sistemas estudados a presença de íons inorgânicos desfavorece o processo de degradação. $^{32,33}$

Tabela 8- Porcentagem de degradação QTX em solução polimérica depois de $160 \mathrm{~h}$ de irradiação na presença de sais inorgânicos.

\section{Sistemas} [sal inorgânico]/M

\% de Degradação (160h)

\begin{tabular}{|c|c|c|}
\hline ausência & 0 & 38 \\
\hline \multirow[t]{3}{*}{$\mathrm{Na}_{2} \mathrm{SO}_{4}$} & 0,05 & 20 \\
\hline & 0,1 & 21 \\
\hline & 0,2 & 24 \\
\hline \multirow[t]{3}{*}{$\mathrm{CuSO}_{4}$} & $3 \times 10^{-4}$ & 6 \\
\hline & $3 \times 10^{-3}$ & 2 \\
\hline & $3 \times 10^{-2}$ & 2 \\
\hline \multirow[t]{3}{*}{$\mathrm{NaCl}$} & 0,05 & 22 \\
\hline & 0,1 & 19 \\
\hline & 0,5 & 13 \\
\hline
\end{tabular}

Estes resultados da degradação do sistema PSS/QTX na presença dos sais inorgânicos obtidos por espectroscopia de absorção no UV-Vis estão de acordo com aqueles obtidos para o mesmo sistema estudado por SEC em 4.3.1.5. 


\subsubsection{Efeito do sorbato de potássio}

Estudou-se o efeito de sorbato de potássio para investigar se a degradação é iniciada a partir do estado singlete ou triplete da QTX. As concentrações de sorbato foram definidas pelo estudo de supressão mostrado em 4.1.6.3. A metodologia foi exatamente igual à descrita em 4.3.1.6.

A relação das bandas em 402 nm e 347 nm dos espectros de absorção de QTX em solução polimérica na presença de diferentes concentrações de sorbato de potássio está apresentada nas Figuras 50A e 50B, respectivamente.

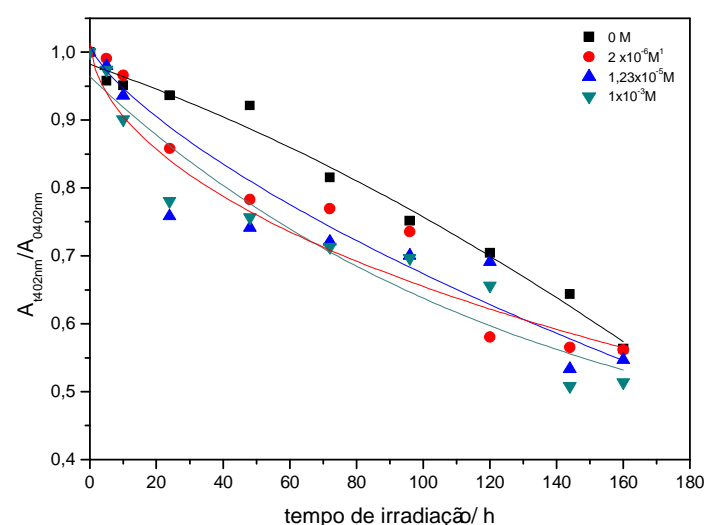

(A)

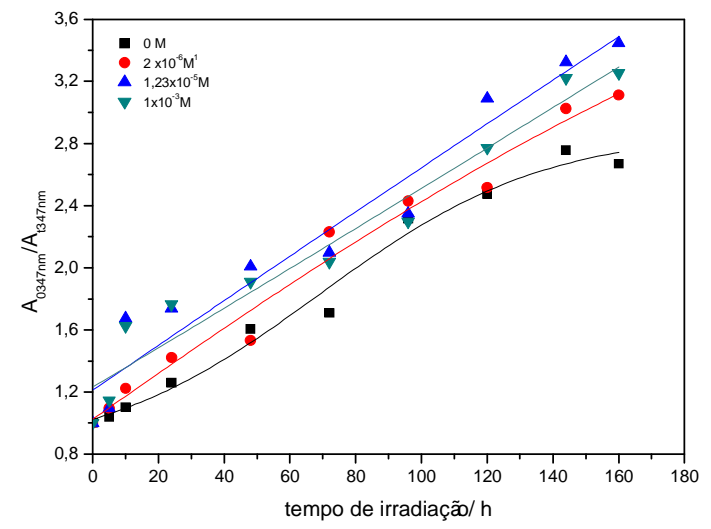

(B)

Figura 51. Mudança da absorção em 402 nm (A) e em 347 nm (B) durante a irradiação de PSS/QTX em presença de sorbato de potássio.

A presença de sorbato na solução de QTX/PSS acelerou o processo de degradação em todas as concentrações investigadas. Em resposta a esta degradação, a absorção na região de 347 nm aumentou durante a irradiação. Sabese que houve a redução da massa molar ponderal média como apresentado em 4.3.1.6. A porcentagem de degradação QTX/PSS na ausência de sorbato foi de 
$40 \%$. Na presença de $1 \times 10^{-3} \mathrm{M}$ de sorbato, esta porcentagem de degradação foi de 49\% após 160h de irradiação (Figura 51).

A rápida degradação de QTX em solução polimérica na presença deste dieno pode ser novamente um forte indício de que o processo de fotodegradação de PSS sensibilizado por QTX se inicia pela abstração de hidrogênio do polímero pelo estado singlete do corante e não pelo triplete como é comum em cetonas aromáticas. ${ }^{62}$

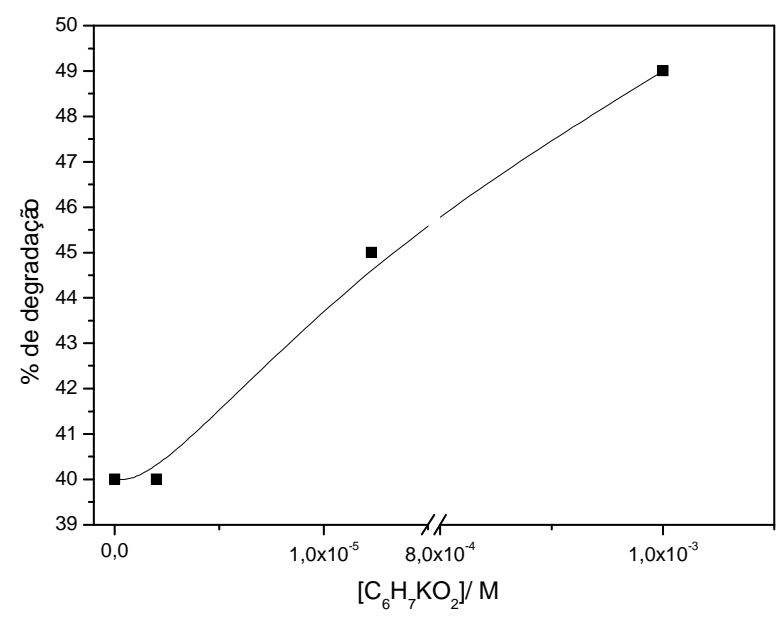

Figura 51. Porcentagem de degradação da solução de QTX contendo PSS $1,0 \mathrm{gL}^{-1}$ depois de $160 \mathrm{~h}$ de irradiação em função da concentração de sorbato de potássio.

\subsubsection{Terceira parte: Reações elementares}

\subsubsection{Estudo dos transientes da QTX em PSS}

Os espectros de transiente de QTX em água na presença de poliestirenossulafonato de sódio foram investigados em atmosfera de nitrogênio, em ar e em oxigênio. A concentração de QTX em água foi de $2,5 \times 10^{-4} \mathrm{M}$, que 
corresponde a uma absorção de 0,3 na região de excitação do laser (355nm). Os espectros de absorção de cada sistema são apresentados nas Figuras 52A até 54A. Todos os decaimentos do triplete foram monitorados em $600 \mathrm{~nm}$ (região de absorção T-T) e estão apresentados nas Figuras 52B a 54B.

$\mathbf{N}_{2}$

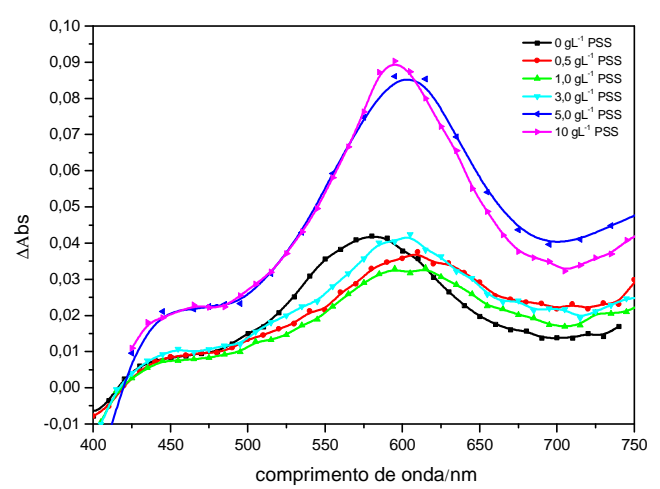

(A)

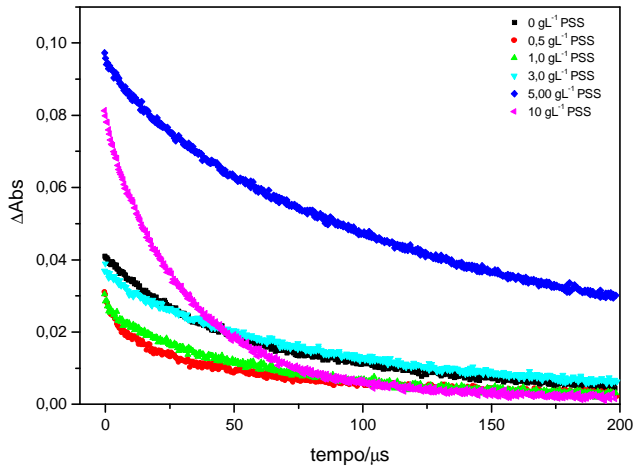

(B)

Figura 52. Espectro de absorção do transiente de QTX em água em atmosfera de $\mathrm{N}_{2}(\mathrm{~A})$. Decaimento de absorção do transiente de QTX em água, em $600 \mathrm{~nm}$ em atmosfera de $\mathrm{N}_{2}$ (B).

Ar

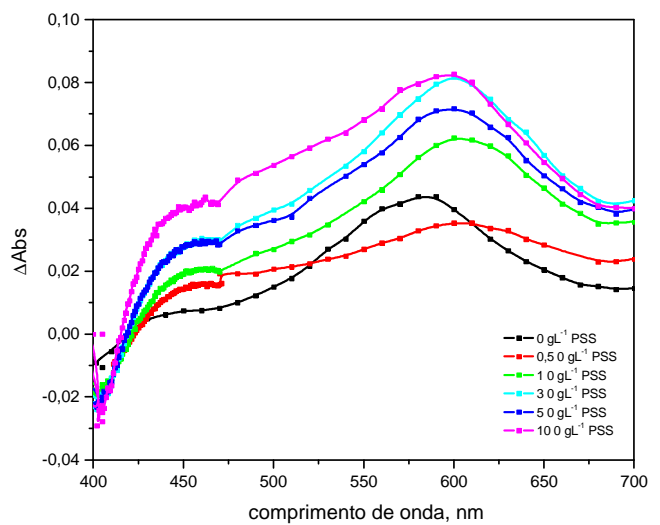

(A)

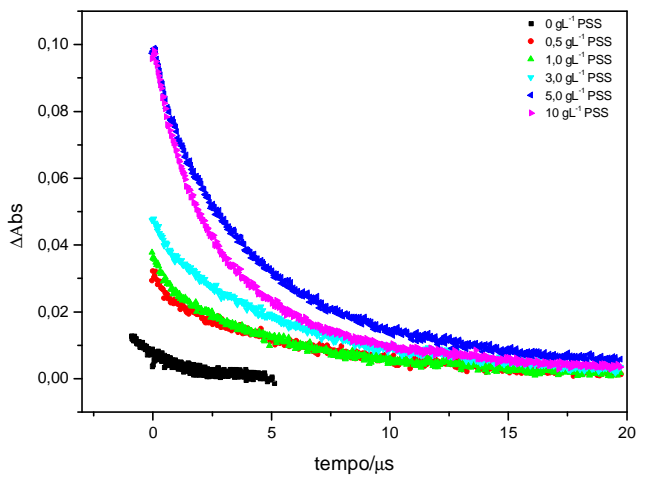

(B)

Figura 53. Espectro de absorção do transiente de QTX em água em ar (A). Decaimento de absorção do transiente de QTX em água, em $600 \mathrm{~nm}$ em ar (B). 
$\mathrm{O}_{2}$

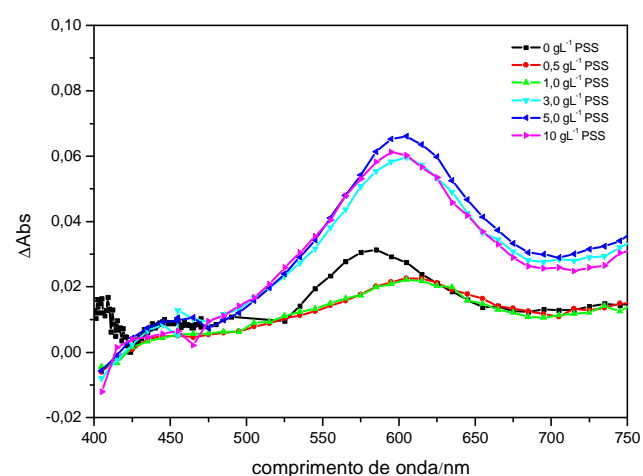

(A)

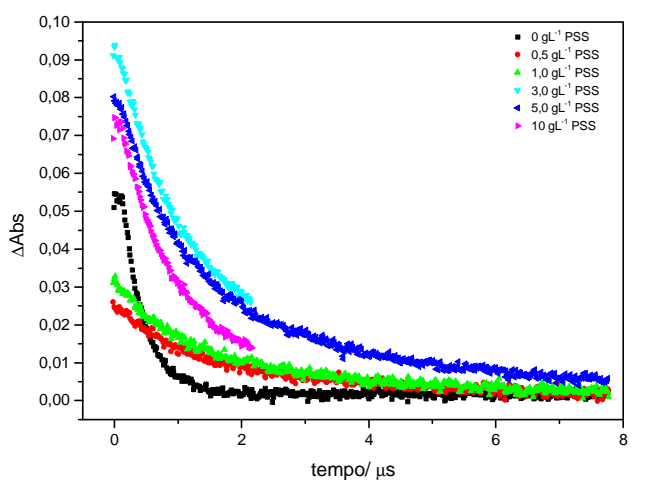

(B)

Figura 54. Espectro de absorção do transiente de QTX em água em atmosfera de $\mathrm{O}_{2}(\mathrm{~A})$. Decaimento de absorção do transiente de QTX em água, em $600 \mathrm{~nm}$ em atmosfera de $\mathrm{O}_{2}$ (B).

Os espectros de absorção de transiente de QTX em presença de PSS apresentam as mesmas bandas observadas em água. A banda em $600 \mathrm{~nm}$ é atribuída à absorção T-T. Assim como para a QTX em água, também não foi possível observar a banda em 400-450 nm referente ao radical cetila. Ocorre um deslocamento da banda de absorção T-T para a região do vermelho em função da concentração de PSS na solução de QTX. Esse deslocamento pode ser justificado considerando o efeito de polaridade no meio, ou seja, quando a concentração de polímero é aumentada a QTX fica mais próxima da região hidrofóbica do polímero devido a formação de microambientes e menos polar em relação à água. ${ }^{41}$

O decaimento do estado triplete da QTX em solução desoxigenada e na

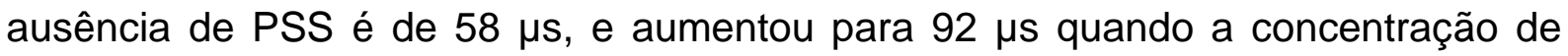
PSS foi de 5,0 $\mathrm{gL}^{-1}$. Em solução areada e na presença de PSS o tempo de vida aumenta de 1,6 $\mu$ s para em média 4,4 $\mu$ s. Em atmosfera de oxigênio segue este mesmo comportamento, ou seja, o tempo de vida aumenta de $0,5 \mu$ s para no mínimo o dobro na presença de polímero (Tabela 9). Este aumento no tempo de vida de 
triplete do corante com o aumento da concentração do PSS sugere a formação de microambientes. Como a QTX se incorpora nestes microambientes, dificulta a supressão por oxigênio. A mudança do ambiente pode afetar o tempo de vida de triplete. Resultados semelhantes foram encontrados para o corante safranina na presença de monômero estirenossulfonato de sódio e toluenossulfonato de sódio. ${ }^{70}$

Tabela 9- Tempo de vida de triplete de QTX na presença e na ausência de PSS em diferentes atmosferas.

\section{Atmosfera}

$\begin{array}{lll}\mathrm{N}_{2} & \text { ar } & \mathrm{O}_{2}\end{array}$

\begin{tabular}{ccccccc}
\hline [PSS] $/ \mathbf{g L}^{-1}$ & $\lambda_{\text {máx }} / \mathbf{n m}$ & $\tau / \boldsymbol{\mu s}$ & $\lambda_{\text {máx }} / \mathbf{n m}$ & $\tau / \mu \mathbf{s}$ & $\lambda_{\text {máx }} / \mathbf{n m}$ & $\tau / \mu \mathbf{s}$ \\
\hline 0 & 580 & 58 & 580 & 1,6 & 580 & 0,5 \\
0,5 & 609 & 52 & 604 & 5,4 & 608 & 1,7 \\
1,0 & 604 & 54 & 605 & 4,5 & 607 & 1,6 \\
3,0 & 600 & 75 & 600 & 5 & 604 & 1,4 \\
5,0 & 602 & 97 & 600 & 4 & 603 & 1,4 \\
10 & 596 & 32 & 592 & 3 & 599 & 1 \\
\hline
\end{tabular}

\subsubsection{Determinação das constantes de supressão de QTX em molécula modelo}

A fim de investigar a habilidade de QTX em abstrair o átomo de hidrogênio da cadeia polimérica do poliestirenossulfonato de sódio, escolheu-se uma molécula modelo. A molécula escolhida foi 0 n-butil benzeno sulfanato de sódio. A 
concentração de QTX foi $2,5 \times 10^{-4} \mathrm{M}$ em água. Os decaimentos foram monitorados a $600 \mathrm{~nm}$ (corresponde a região de absorção T-T). As soluções foram desoxigenadas por 30 min. O gráfico de Stern-Volmer está apresentado na Figura 55. O valor obtido de $\mathrm{k}_{\mathrm{q}}$ foi de $2,24 \times 10^{8} \mathrm{M}^{-1} \mathrm{~s}^{-1}$. O valor da constante obtido foi menor que o encontrado quando se utilizou hidroquinona ou sorbato de potássio, para os quais a ordem da constante de supressão foi de $10^{9}$.

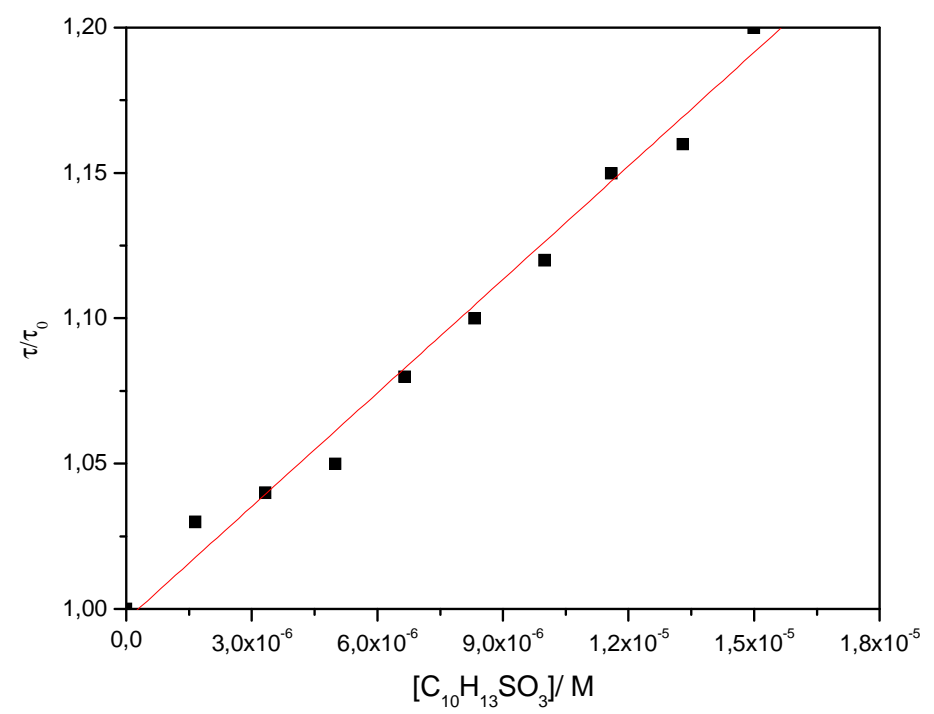

Figura 55. Gráfico de Stern-Volmer da supressão de QTX em água por diferentes concentrações de n-butil bezeno sulfonato de sódio.

\subsubsection{Mecanismo proposto para fotodegradação de PSS sensibilizado por QTX}

O mecanismo de degradação de PSS sensibilizado por QTX é proposto a partir dos resultados discutidos em 4.3 a 4.3.3.2.

O mecanismo é mostrado no Esquema 21 e suas etapas estão representadas por números romanos. O mecanismo de degradação consiste em várias etapas. $\mathrm{Na}$ 
Etapa I, o corante $\left(D_{0}\right)$ absorve luz, é promovido para o estado singlete $\left({ }^{1} D\right)$ e por cruzamento intersistema passa para o estado triplete $\left({ }^{3} \mathrm{D}\right)$, Etapa II.

No estado triplete, o corante pode reagir com o oxigênio $\left(\mathrm{O}_{2}\right)$, Etapa III, e formar uma espécie reativa como o oxigênio singlete ou outros radicais que são responsáveis pela formação de fotoprodutos, como mostrado no mecanismo de degradação de QTX em solução aquosa em 4.1.7. Na Etapa IV, o corante no estado triplete pode abstrair o hidrogênio do polímero, formando o radical cetila $\left(\mathrm{DH}^{\circ}\right)$ e o radical alquila $\left(\mathrm{P}^{\bullet}\right)$.

Nos experimentos de fotodegradação de PSS/QTX na presença do supressor de triplete, o sorbato de potássio, foi observado que a porcentagem de fotodegradação foi maior quando comparada ao PSS/QTX na ausência de supressor. Isto indica que o estado triplete do corante não seria a principal via para o mecanismo de degradação de PSS/QTX.

A QTX no estado singlete pode reagir com o oxigênio ou com outra molécula de corante, gerando radicais responsáveis pela formação de seus fotoprodutos (Etapa V). Detalhes da fotodegradação de QTX em água foram mostrados em 4.1.7. O corante pode formar o radical cetila devido à abstração de hidrogênio do polímero e formação do macrorradical alquila, Etapa VI.

A reação de abstração de hidrogênio leva a formação de dois tipos de radicais, um na posição $\alpha$, e outro menos provável, na posição $\beta$. Esses dois macrorradicais estão ilustrados no Esquema 22.

A partir desta etapa, o macrorradical $\left(\mathrm{P}^{\bullet}\right)$ pode reagir com oxigênio e formar o radical alquilperoxila $\left(\mathrm{PO}_{2}{ }^{\circ}\right)$, Etapa VII. Esse radical, $\mathrm{PO}_{2}{ }^{\circ}$, pode reagir tanto com $\mathrm{o}$ radical cetila da QTX, formando o $\mathrm{PO}_{2} \mathrm{H}$ (Etapa VIII), ou pode reagir com outra molécula de polímero (P-H) e formar um hidroperóxido, $\mathrm{POOH}$ (Etapa IX). 
Como a energia da ligação $\mathrm{O}-\mathrm{O}$ do hidroperóxido é baixa, esta pode sofrer quebra homolítica pelo efeito da luz, gerando dois radicais, uma alcoxila (PO*) e uma hidroxila $\left(\mathrm{HO}^{\circ}\right)$ (Etapa $\left.\mathrm{X}\right)$. $\mathrm{O}$ radical hidroxila pode atacar a cadeia polimérica e formar um novo macrorradical alquila e uma molécula de água (Etapa XI).

O radical alcoxila é responsável pelos processos de quebra na cadeia de PSS e formação de novos grupos, como a acetofenona, Etapa XII. A acetofenona absorve na mesma região que a luz incidente, podendo participar das reações do processo de degradação, que dificulta sua caracterização. A Etapa XIII mostra a formação de polieno.

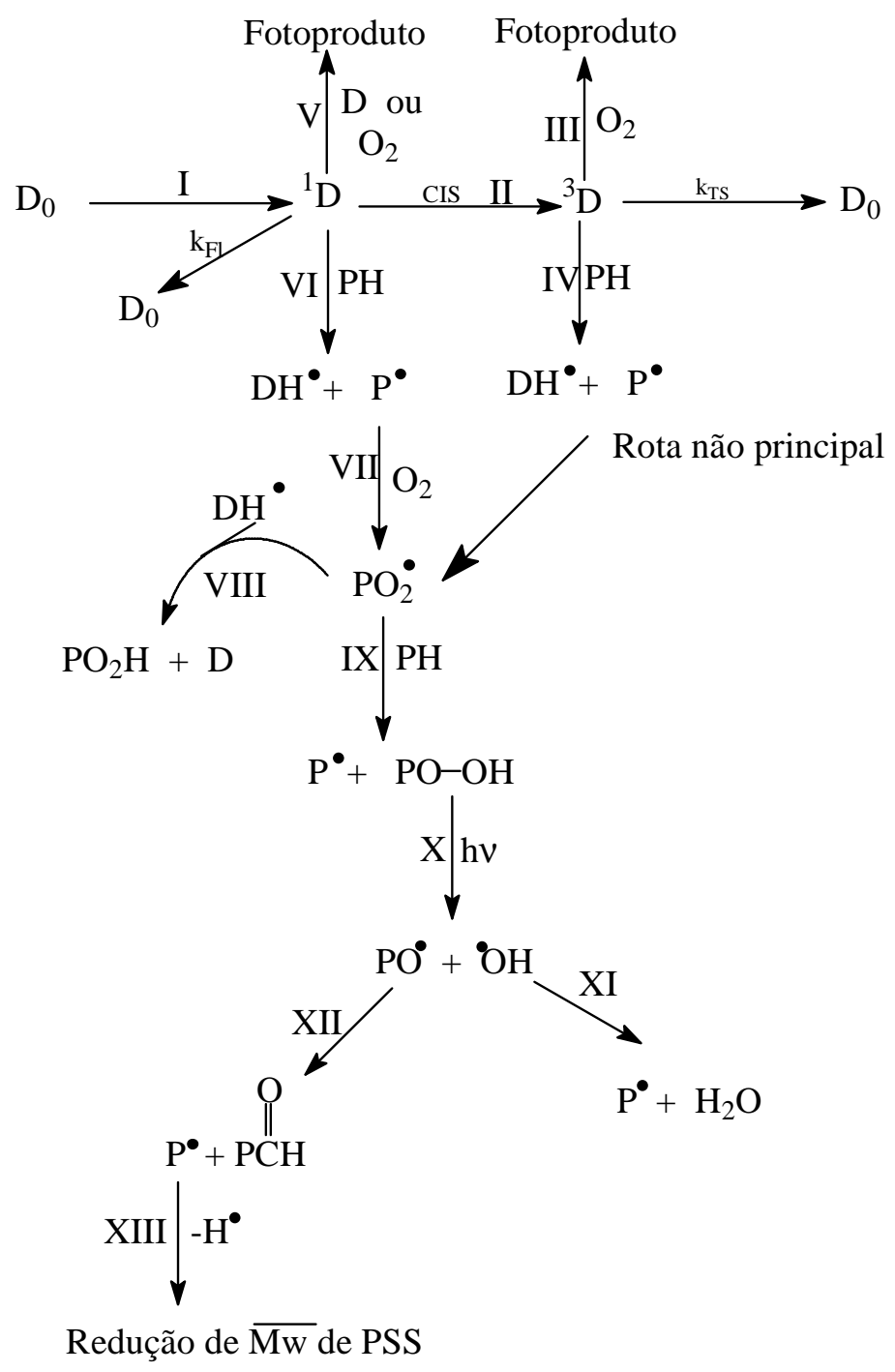

Esquema 21. Mecanismo de degradação de PSS sensibilizado por QTX. D representa o corante e P representa a cadeia polimérica. 
Para a melhor compreensão do mecanismo das quebras na cadeia de PSS e das reações com os radicais, as etapas do mecanismo de PSS/QTX através das estruturas do polímero estão mostradas no Esquema 22.

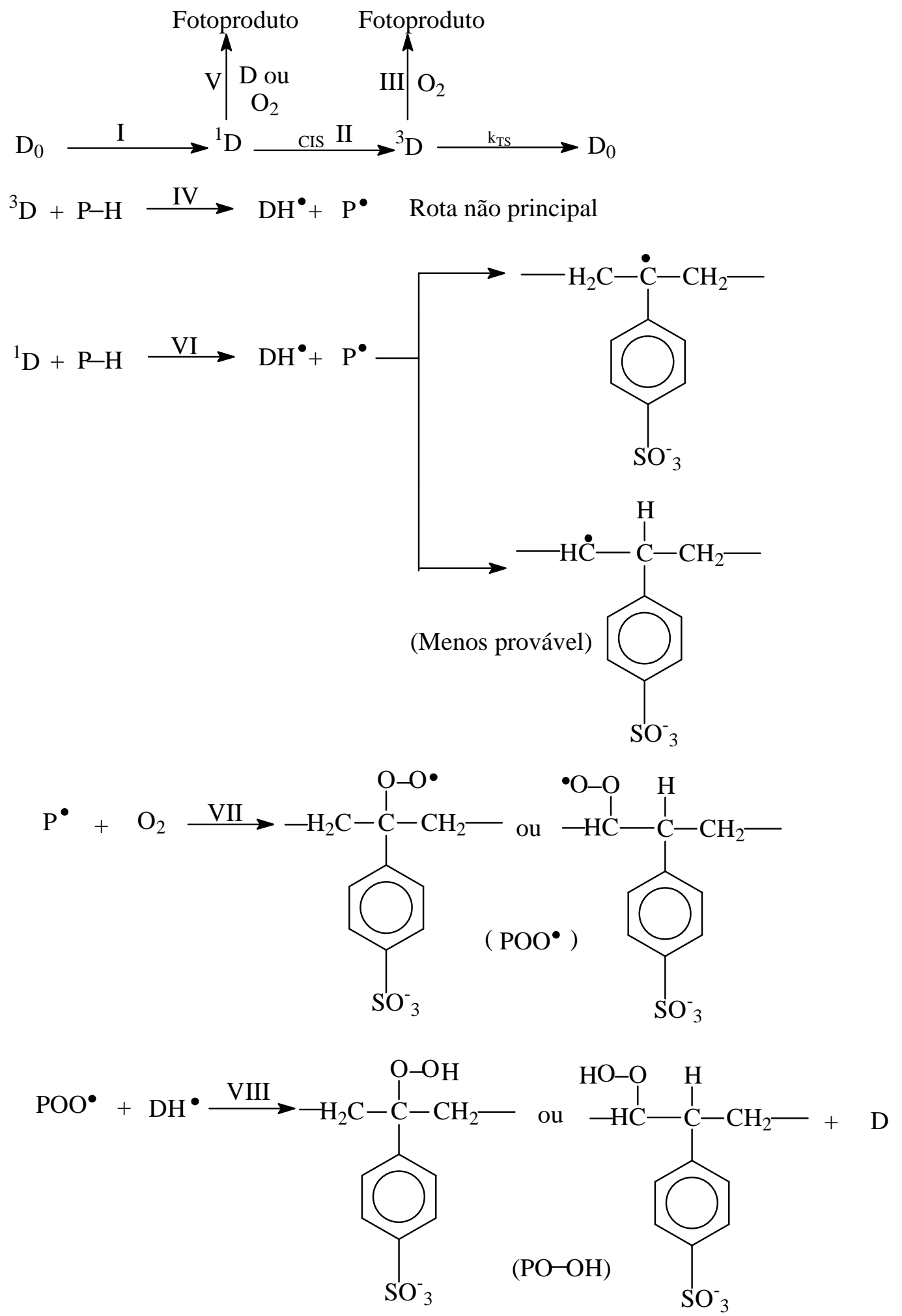




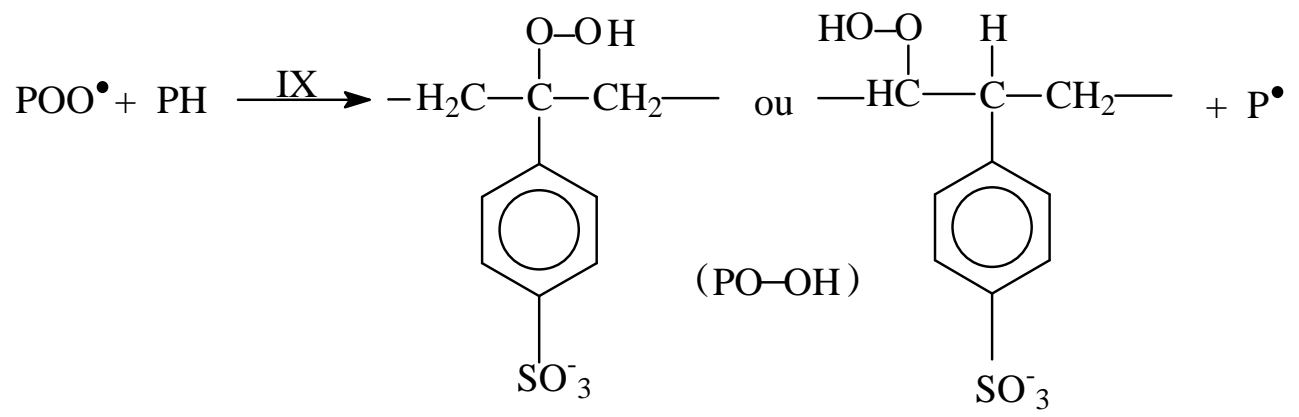

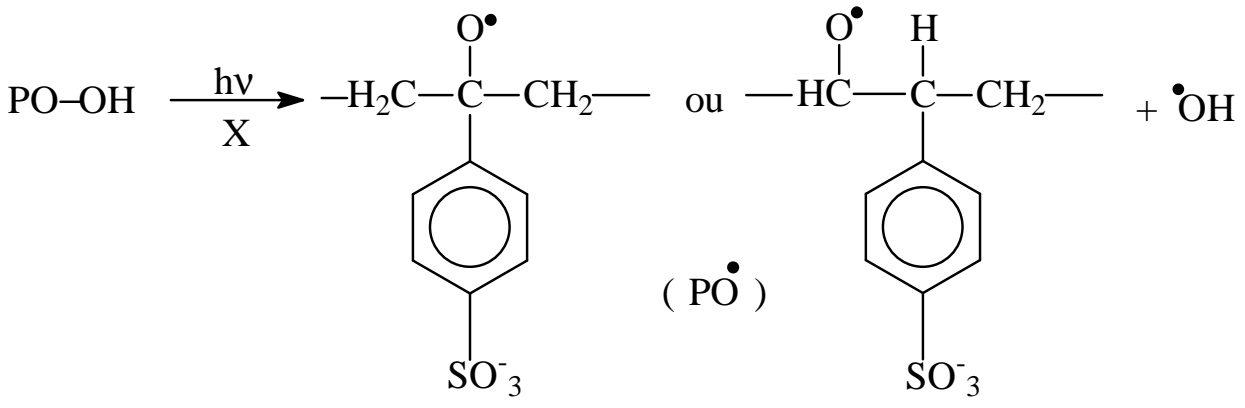

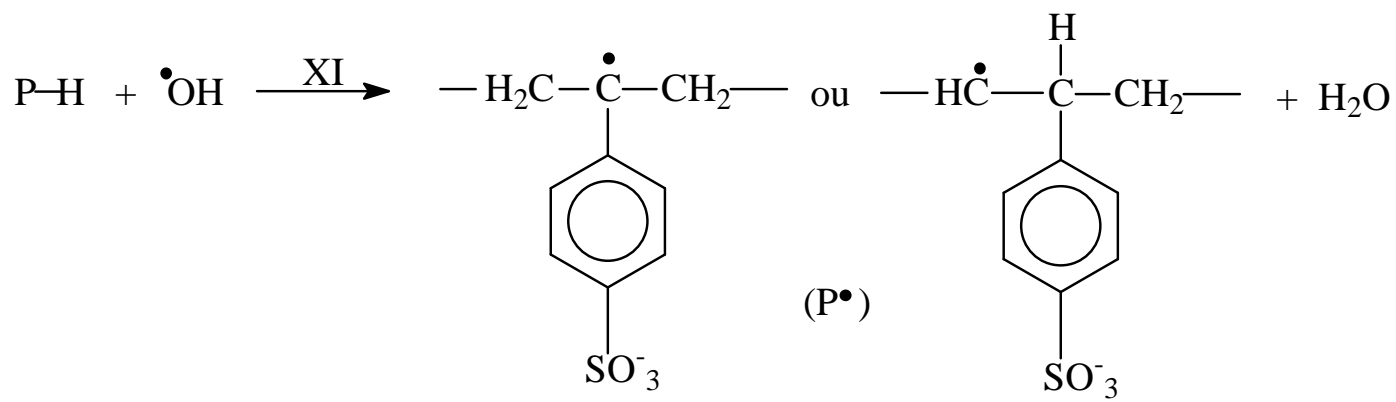

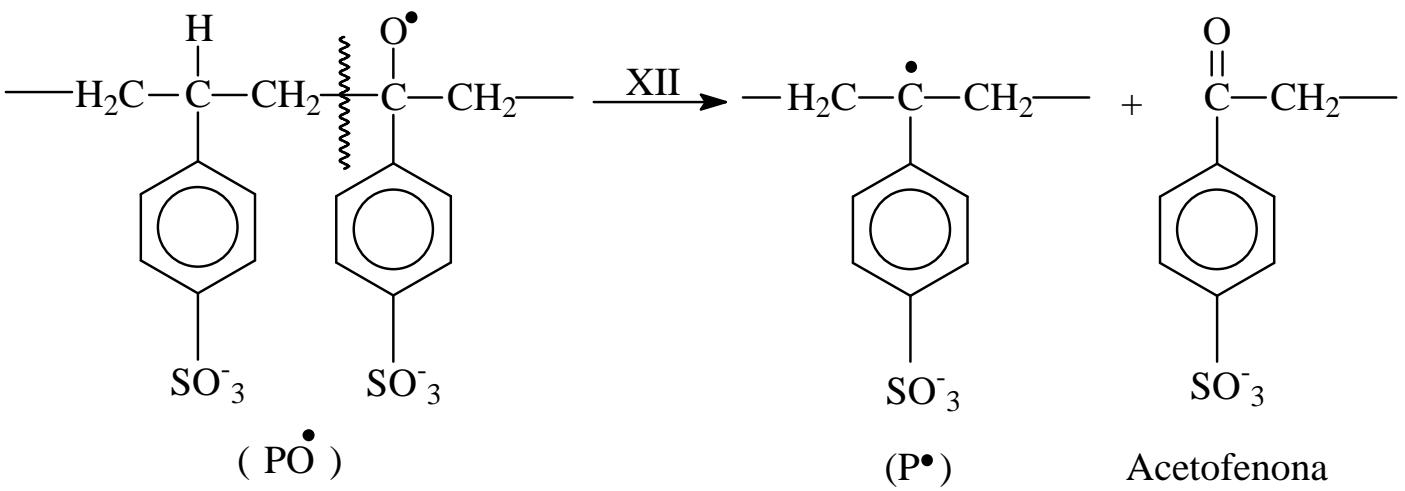

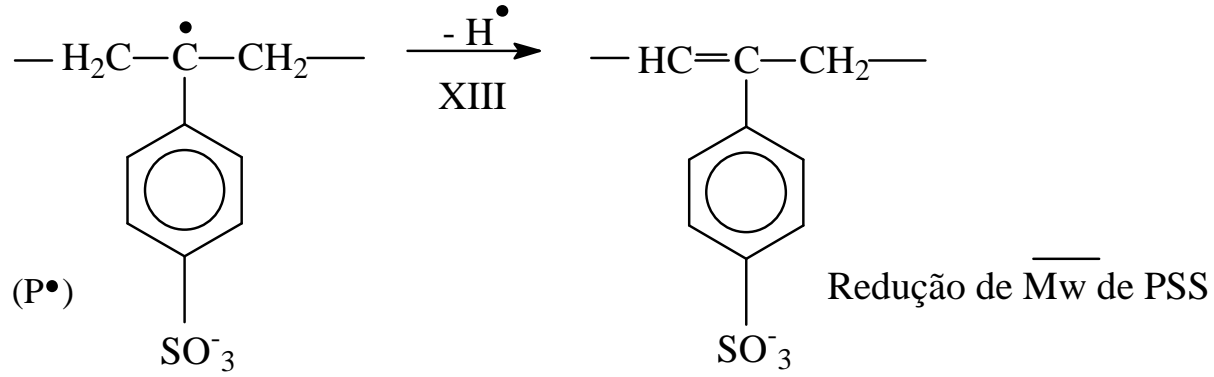

Esquema 22. Mecanismo de degradação de PSS sensibilizado por QTX. 


\section{CONCLUSÕES}

A fotodegradação da QTX em água foi investigada usando a espectroscopia UV-Vis. Durante a degradação de QTX em água ocorreu diminuição em 402 nm, região atribuída à degradação de corante, e simultaneamente ocorreu um aumento na absorção na região de $300-350$ nm, região de formação de fotoprodutos como sulfóxidos.

A maior porcentagem de degradação de QTX em água ocorreu na concentração de $1 \times 10^{-4} \mathrm{M}$. $\mathrm{O}$ efeito de $\mathrm{pH}$ mostrou que a porcentagem de fotodegradação em pH neutro ou básico é maior que em pH 3,5. A adição de íons sulfato na solução retarda o processo de degradação, devido à formação de um radical menos reativo. A presença de sorbato de potássio acelerou o processo de degradação de QTX em água.

A caracterização de fotoprodutos de QTX em água gerados pela fotólise foi realizada por CLAE-EM, e estes foram sulfonas e sulfóxidos.

Através da técnica de fotólise de pulso de laser foi possível verificar o comportamento espectral e os tempos de vida de triplete da QTX em água e em diferentes solventes. Os espectros de absorção do transiente de QTX em água e em outros solventes estudados (etanol, metanol, 1-propanol, 1-butanol, 2-propanol e acetonitrila) apresentaram uma intensa banda na região de 500 a $700 \mathrm{~nm}$, referente à absorção T-T. Observou-se um deslocamento para a região do azul com o aumento de polaridade do meio, assim como o aumento no tempo de vida de triplete de QTX. As constantes de supressão de triplete de QTX por hidroquinona e sorbato de potássio ficaram próximas à constante difusional. 
O mecanismo proposto para a fotodegradação de QTX em solução aquosa foi proposto considerando o estado singlete da QTX como a principal rota no processo de degradação, apesar de não ser muito comum para cetonas aromáticas.

A degradação de PSS em água e na presença de QTX foi monitorada por cromatografia de exclusão de tamanho (SEC) e viscosidade. A fotodegradação de PSS em água não foi observada.

Durante a degradação de PSS fotossensibilizada por QTX houve diminuição nos valores de $\overline{M w}$ implicando em quebra aleatória de cadeia analisadas por SEC. O número médio de quebra de cadeia $(\mathrm{S})$ foi determinado por viscosidade. A lineriadade de S em função do tempo de irradiação confirma a quebra de cadeia aleatória.

O maior coeficiente de degradação, $k$,ocorreu na concentração de $1 \times 10^{-4} \mathrm{M}$ de QTX. Em pH 9,0, $k$ foi de cerca de quatro vezes maior que em $\mathrm{pH}$ 3,5. O meio alcalino provoca a aceleração do processo de degradação devido ao corante abstrair um elétron do radical do íon hidróxido para produzir o radical hidroxila. A presença de oxigênio é essencial para o processo de fotodegradação. $O$ efeito de íons inorgânicos diminuiu o processo de quebra de cadeia no PSS. O coeficiente de velocidade de degradação aumentou com o aumento da adição de sorbato de potássio na solução PSS/QTX.

A fotodegradação da QTX na presença de PSS também foi investigada usando a espectroscopia UV-Vis. Quando a solução PSS/QTX é irradiada ocorreu diminuição da banda em 402 nm, região atribuída à degradação de corante, e simultaneamente ocorreu um aumento na absorção na região de 300-350 nm, região de formação de fotoprodutos. Estes fotoprodutos podem ser derivados do corante, como sulfóxidos, e derivados do polímero, como polienos e acetofenonas. 
Os resultados obtidos por UV-Vis para fotodegradação do PSS/QTX estão de acordo com os resultados obtidos por SEC, uma vez que oxigênio acelerou o processo e a presença de íons inorgânicos inibiu a fotodegradação.

A presença de um supressor de triplete, o sorbato de potássio, na degradação de PSS/QTX aumentou a porcentagem de degradação. Estes resultados sugerem um mecanismo de degradação do PSS fotossensibilizado por QTX que apresenta como rota principal a abstração de hidrogênio do polímero pelo estado singlete de QTX, posteriormente ocorrem as reações com o oxigênio para a formação de radicais (hidroperóxidos, radicais alquilperoxila e alcoxila) que contribuem para o processo de degradação. Como fotoproduto desta irradiação seria a quebra de cadeia polimérica, com redução da massa molar de PSS e a formação de acetofenona. Como a acetofenona absorve na região de luz incidente, esta pode ser excitada e participar durante o processo, dificultando assim sua caracterização.

Os espectros de transientes e tempo de vida de triplete de QTX em água e na presença de PSS foram monitorados por fotólise por pulso de laser. Observou-se um aumento no tempo de vida de triplete de QTX em função da concentração de PSS. Isso pode ser justificado considerando a formação de microambientes, que protegeria a supressão de QTX por oxigênio. 


\title{
6.REFERÊNCIAS
}

\footnotetext{
${ }^{1}$ SUPPAN, P. Chemistry and Light. Cambridge: The Royal Society of Chemistry, 1994. 295 p.

${ }^{2}$ DAUTZEMBERG, H.; JAEGER, W.; KOTZ, J.; PHILIPP, B.; SEIDEL, C. H.; STSCHERBINA, C. Polyelectrolytes: formation, characterization and application. New York: Hanser Publishers, 1994. $343 \mathrm{p}$.

${ }^{3}$ HARA, M. Polyelectrolytes- science and technology. New York: Marcel Dekker, 1992. 399 p.

${ }^{4}$ BEHAR, D.; RABANI, J. Pulse radiolysis of poly(styrenesulfonate) in aqueous solutions. Journal Physical Chemistry, 92, p. 5288-5292, 1988.
}

${ }^{5}$ BHARDWAJ, Y.K.; MOHAN, H.; SABHARWAL, S.; MUKHERJEE, T. Radiation effect on poly(psodium styrene sulphonate) of different degrees of polymerization in aqueous solution: pulse radiolysis and state state study. Radiation Physics and Chemistry, 62, p. 229-242, 2001.

${ }^{6}$ JIANG, D. D.; YAO, Q.; MCKINNEY, M. A.; WILKIE, C. A. TGA/FTIR studies on the thermal degradation of some polymeric sulfonic and phosphonic acids and their sodium salts. Polymer Degradation and Stability, 63, p. 423-434, 1999.

\begin{abstract}
${ }^{7}$ YAO, Q.; WILKIE, C. A. Thermal degradation of blends of polystyrene and poly(sodium 4styrenesulfonate) and copopolymer, poly(styrene-co-sodium 4-styrenesulfonate). Polymer Degradation and Stability, 66, p. 379-384, 1999.
\end{abstract}

${ }^{8}$ RABEK, J. F. Mechanisms of photophysical process and photochemical reactions in polymer: theory and applications. New York: John Wiley \& Sons, 1987. 756 p.

${ }^{9}$ WAYNE, R. P. Principles and applications of photochemistry. New York: Oxford University Press, 1988. 268 p.

${ }^{10}$ ALLEN, N. S.; MCKELLER, J. F. Photochemistry of dye and pigmented polymers. London: Applied Science Publishers, 1980. 284 p.

${ }^{11}$ KLESSINGER, M.; MICHL, J. Excited states and photochemistry of organic molecules. Weinheim: VHC, 1995. 537 p.

${ }^{12}$ RABELO, M. Ativação de polímeros. São Paulo: Artliber Editora, 2000. 242 p.

${ }^{13}$ CANEVAROLO JUNIOR, S. V. Ciências dos polímeros - um texto básico para tecnólogos e engenheiros. São Paulo: Artliber Editora, 2006. 280 p.

${ }^{14}$ REICH, L.; STIVALA, S. S. Elements of polymer degradation. New York: McGraw-Hill, 1971. 361 p. 
${ }^{15}$ GRASSIE, N.; SCOTT, G. Polymer degradation and stabilization. Cambridge: Cambridge University Press, 1985. 222 p.

${ }^{16}$ DE PAOLI, M. A. Degradação e estabilização de polímeros. São Paulo: Artliber Editora, 2009. $286 \mathrm{p}$.

${ }^{17}$ ALLEN, N. S.; EDGE, M. Fundamentals of polymer degradation and stabilization. London: Elsevier Applied Science,1992. 175 p.

${ }^{18}$ RABEK, J. F. Photodegradation of polymers - physical chracteristics and applications. Berlin: Springer, 1996. 212 p.

${ }^{19}$ FELISBERTI, M. I; SARON, C. Ação de colorantes na degradação e estabilização de polímeros. Química Nova, 29, p. 124-128, 2006.

${ }^{20}$ GRIFFITHS, J. Developments in the chemistry and technology of organic dyes. London: Blackwell Scientific, 1984. 132 p.

${ }^{21}$ ALLEN, N. S. Photofading and light stability of dyed and pigmented polymers. Polymer Degradation and Stability, 44, p. 357-374,1994.

${ }^{22}$ COWAN, D. O.; DRISKO, R. L. Elements of organic photochemistry. New York: Plenum Press, 1978. $586 \mathrm{p}$.

${ }^{23}$ CERMINARO, P. J. Polimerização de metil metacrilato fotoiniciada por pironina Y. 2005.109 p. Dissertação (Mestrado em Ciências) - Instituto de Química de São Carlos, Universidade de São Paulo.

${ }^{24}$ GRASSIE, N. Developments in polymer degradation- I. London: Applied Science Publishers, 1977. $284 \mathrm{p}$.

${ }^{25}$ LEY, C.; MORLET-SAVARY, F.; FOUASSIER, J. P.; JACQUES, P. The spectral shape dependence of xanthone triplet-triplet absorption on solvent polarity. Journal of Photochemistry and

Photobiology A: Chemistry, 137, p.87-92, 2000.

${ }^{26}$ NEUMANN, M. G.; GEHLEN, M. H.; ALLEN, N. S.; CORRALES, T.; PEINADO, C.; CATALINA, F. Photophysics and photoreactivity of substituted thioxanthones. Journal of Chemistry Society, Faraday Transactions, 93, p. 1517-1521, 1997.

${ }^{27}$ ENCINAS, M. V.; RUFS, A. M.; CORRALES, T.; CATALINA, F; PEINADO, C.; SCHMITH, C.; NEUMANN, M. G.; ALLEN, N. S. The influence of the photophysics of 2-substituted thioxanthones on their activity as photoinitiators. Polymer, 43, p. 3909-3913, 2002.

${ }^{28}$ LUCAS, E. F.; SOARES, B. G.; MONTEIRO, E. Caracterização de exclusão de tamanho. In: Determinação de peso molecular e análises térmicas. Rio de Janeiro: Editora Interciência, 2000. $366 \mathrm{p}$. 
${ }^{29}$ SKOOG, D. A. Principles of Instrumental analysis. Orlando: Saunders College Publication, 1998. $836 \mathrm{p}$.

${ }^{30}$ KINART, W. J.; SKOWRONSKI, R.; TURALA, L.; DAWID, W.; OMAKOWSKA, J; KINART, C. M. Electrochemistry studies of 2-hydroxy-3-(3,4-dimethyl-9-oxo-9H-thioxanthen-2-yloxy) N,N,N,-trimethyl1-propanium chloride. Journal of Electroanalytical Chemistry, 294, p. 293-297, 1990.

${ }^{31}$ ONU, A.; PALAMARU, M.; TUTIVAN, E.; CIOBANU, C. Photodegradation of polyamidehydroxyurethane type polymer in aqueous solution. The role of some dyes in the degradation. Polymer Degradation and Stability, 60, p. 465-470, 1998.

${ }^{32}$ ABDULLAH, F. H.; RAUF, M. A.; ASHRAF, S. S. Photolytic oxidation of Safranin-O with $\mathrm{H}_{2} \mathrm{O}_{2}$. Dyes and Pigments, 72, p. 349-352, 2007.

${ }^{33}$ RAUF, M. A.; ASHRAF, S. S. Radiation induced degradation of dyes - An overview. Journal of Hazardous Materials, 166, p. 6-16, 2009.

${ }^{34}$ DONG, Y.; CHEN, J.; CHUNHUI, L.; ZHU, H. Decoloration of three azo dyes in water by photocatalysis of $\mathrm{Fe}(\mathrm{III})$ - oxalate complexes $/ \mathrm{H}_{2} \mathrm{O}_{2}$ in the presence of inorganic salts. Dyes and Pigments, 73, p. 261-268, 2007.

${ }^{35}$ MURUGANANDHAM, M.; SWAMINATHAN, M. Photochemical oxidation of reative azo dye with UV$\mathrm{H}_{2} \mathrm{O}_{2}$ process. Dyes and Pigments, 62, p. 269-275, 2004.

${ }^{36}$ ALHAMEDI, F. H.; RAUF, M. A.; ASHRAF, S. S. Degradation studies of Rhodamine B in the presence of $U V / \mathrm{H}_{2} \mathrm{O}_{2}$. Desalination, 239, p.159-166, 2009.

${ }^{37}$ MURUGANANDHAM, M.; SWAMINATHAN, M. Photocatalytic decolourisation and degradation of Reactive Orange 4 by $\mathrm{TiO}_{2}$-UV process. Dyes and Pigments, 68, p. 133-142, 2006.

${ }^{38}$ BARRA, M.; BOHNE, C.; SCAIANO, J. C. Effect of cyclodextrin complexation on the photochemistry of xanthone. Absolute measurement of the kinetics for triplet-state exit. Journal of the American Chemical Society, 112, p. 8075-8079, 1990.

${ }^{39}$ MORRISON, R. T. Química orgânica. Lisboa: Fundacão Calouste Gulbenkian, 1983. 1510 p.

${ }^{40}$ KISSINGER, P. T.; HOLT, P. T.; REILLEY, C. N. Electrochemical studies of thioxanthene, thioxanthone, and relatated species in nonaqueous media. Journal of Electroanalytical Chemistry, 33, p. 1-12, 1971.

${ }^{41}$ FERREIRA G. C.;SCHMITT, C. C.; NEUMANN, M. G. Depedence of the thioxanthone triplet-triplet absorption spectrum with solvent polarity and aromatic ring substitution. Journal of the Brazilian Chemical Society, 17, p.905-909, 2006. 
${ }^{42}$ ALLEN, N. S.; SALLEH, N. G.; EDGE, M.; SHAH, M.; LEY, C.; MOLERT-SAVARY, F.; FOUASSIER, J. P.; CATALINA, F.; GREEN, A.; NAVARATNAM, S.; PARSONS, B. J. Photophysical properties and photoinduced polymerization activity of novel 1-chloro -4oxy/acyloxythioxanthone initiators. Polymer, 40, p. 4181-4193, 1999.

${ }^{43}$ MORLET-SAVARY, F.; LEY, C.; JAQUES, P.; WIEDER, F.; FOUASSIER, J. P. Time dependent solvent effects on the $T_{1}-T_{n}$ absorption spectra of thioxanthone: a picoseconds investigation. Journal of Photochemistry and Photobiology A: Chemistry, 126, p. 7-14, 1999.

${ }^{44}$ MONTALTI, M.; PRODI, L.; CREDI, A.; GANDOLFI, M. T. Handbook of photochemistry. New York: CRC Taylor \& Francis, 2006. 650 p.

${ }^{45}$ DAVILA, J.; HARRIMAN, A.; RICHOUX, M-C. Photogeneration of hydrogen sensitized by water 9oxothioxanthone. Journal of Chemistry Society, Faraday Transactions, 84, p. 287-297, 1988.

${ }^{46}$ MILAN, M. D.; LOCKIN, J.; FULGHUM, T.; BABA, A.; ADVINCULA, R. C. Polymer thin films photodegradation and photochemical crosslinking: FT-IR imaging, evanescent waveguide spectroscopy, and QCM investigation. Polymer, 46, p. 5556-5568. 2005.

${ }^{47}$ TANIELIAN, C.; MECHIN, R.; SHAKIRULLAH, M. Origin of blue bleaching and polymer degradation in the methylene blue-sensitized photo-oxygenation of polybutadiene. Journal of Photochemistry and Photobiology A: Chemistry, 64, p.191-199, 1992.

${ }^{48}$ BRANDRUP, J.; IMMERGUT, E. H. Polymer handbook. New York: Jhon Willey\& Sons, 1975.

${ }^{49}$ CANEVAROLO JUNIOR, S. V. Técnicas de caracterização de polímeros. In: cromatografia por exclusão de tamanho. São Paulo: Editora Artliber, 2003. 448 p.

${ }^{50}$ MOREIRA, J. C.; SILVA, I. F.; WANG, S. H.; BALOGH, D. T. Determinação das constantes K e $\alpha$ da Equação de Mark-Houwink de poli(p-acetóxiestireno). Polímeros: ciência e tecnologia, 14, p.8082, 2004.

${ }^{51} \mathrm{SHYICHUK}$, A. V. How to measure the degradation index by viscosimetry. Journal of Applied Polymer Science, 62, p. 1735-1738, 1996.

${ }^{52}$ COLLINS, C. H.; BRAGA, G. L.; BONATO, P. S. Introdução a métodos cromatográficos. Campinas: Editora Unicamp, p.185-222, 1997. 279 p.

${ }^{53}$ DAVID, C.; BAEYENS-VOLANT, D.; DELAUNOIS, G.; LU VINH, Q.; PIRET, W; GEUSKENS, G. Photo-oxidation of polymers- III: Molecular weight changes in the photolysis and photo-oxidation of polystyrene. European Polymer Journal, 14, 501-507, 1978.

${ }^{54}$ VINU, R.; MADRAS, G. Photocatalytic degradation of methyl methacrylate copolymers. Polymer Degradation and Stability, 93, 1140-1449, 2008. 
${ }^{55}$ TORIKAI, A.; SHIBATA, H. Photodegradation of polystyrene: Effect of polymer structure on the formation of degradation products. The Arabian Journal of Science and Engineering, 27, p.11-24, 2002.

${ }^{56}$ KARMORE, V.; MADRAS, G. Thermal degradation of polystyrene by Lewis acid in solution. Industrial \& Engineering Chemical, 41, p. 657-660, 2002.

${ }^{57}$ BOtTINO, F. A.; CINQUEGRANI, A. R.; PASQUALE, G. D.; LEONARDI, L.; POLLICINO, A. Chemical modifications, mechanical properties and surface photo-oxidation of films of polystyrene(PS). Polymer Testing, 23, p. 405-411, 2004.

${ }^{58}$ RANBY, B.; RABEK, J. F. Photodegradation, photo-oxidation and photostabilization of polymers. London: Jhon Willey\& Sons, $1975.560 \mathrm{p}$.

${ }^{59}$ HULT, A.; RANBY, B. Photo-cured organic coatings: part I- secundary reactions in thioxanthone/ amine photo-cured organic coatings. Polymer Degradation and Stabilility, 8, p. 75-84, 1984.

${ }^{60}$ SHI, W.; ZANG, J.; Shi XU-M.; JIANG, GUO-D. Different photodegradation process of PVC with different average degrees of polymerization. Journal of Applied Polymer Science, 117, p. 528-540, 2008.

${ }^{61}$ WEIR, N. A.; KUTOK, P.; WHITING, K. Some aspects of the long- wave photo-oxidation of polystyrene. Polymer Degradation and Stability, 24, p. 247-256, 1989.

${ }^{62}$ BLAKE, J.; LUKEMAN, M.; SCAIANO, J. C. Photolabile protecting groups based on the singlet state photodecarboxylation of xanthone acetic acid. Journal of the American Chemical Society, 131, p. 4127-4135, 2009.

${ }^{63}$ ZAMOTAYEV, P. V.; GRANCHAK, V. M. Crosslinking of polyethylene photoiniciated with thioxanthone. Polymer Science, 31, p. 2350-2355, 1989.

${ }^{64}$ SASTRE, R.; GONZALEZ, F. Photodegradation of polystyrene sensitised by polyhalogenated compounds. Polymer Photochemistry, 1, p. 153-163, 1981.

${ }^{65}$ LUCKI, J.; RABEK, J. F.; RANBY, B.; JIANG, Y. C. Spectral differences in photodegraded polystyrene in various solvents. Polymer, 27, p. 1193-1200, 1986.

${ }^{66}$ KUBICA, J.; WALIGÓRIA, B. The effect of carbonyl compounds on photo-oxidation in polystyrene films. European Polymer Journal, 13, p. 325-329, 1977.

${ }^{67}$ THANKI, P. N.; SINGH, R. P. Photostabilization of nylon 66 in the presence of acid blue dyes. Polymer Degradation and Stability, 75, p. 423-430, 2002.

${ }^{68}$ HULT, A.; RANBY, B. Photo-cured organic coatings:part: II- yellowing and photo-oxidation of thioxantone/amine photo-cured organic coatings. Polymer Degradation and Stability, 8, p.89-105, 1984. 
${ }^{69}$ GEUSKENS, G.; BAEYENS-VOLANT, D.; DELAUNOIS, G.; LU-VINH, Q.; PIREY, W.; DAVID, C. Photo-oxidation of polymers-I: a quantitative study of chemical reactions resulting from irradiation of polystyrene at $253.7 \mathrm{~nm}$. In the presence of oxygen. European Polymer Journal,14, p. 291-297, 1977.

${ }^{70}$ NEUMANN, M. G.; SCHMITT, C. C.; MACIEL, H. M. The effect of monomer aggregation in the photopolymerization of styrenesulfonate. Journal of Physical Chemistry B, 105, p. 2939-2944, 2001. 